\title{
The Suzuki-Miyaura reaction after the Nobel prize
}

Irina P. Beletskaya, ${ }^{\mathrm{a}, *}$ Francisco Alonso $^{\mathrm{b}, *}$ and Vladimir Tyurin ${ }^{\mathrm{c}}$

a Department of Chemistry, Moscow State University, Leninskie Gory, GSP-1, Moscow 119991, Russia; Email: beletska@org.chem.msu.ru

b Instituto de Síntesis Orgánica (ISO) and Departamento de Química Orgánica, Facultad de Ciencias, Universidad de Alicante, Apdo.99,03080Alicante, Spain; E-mail: falonso@ua.es

${ }^{c}$ A. N. Frumkin Institute of Physical Chemistry and Electrochemistry, Russian Academy of Sciences, 31 Leninsky Prospect, GSP-1, Moscow 119071, Russia

Dedicated to Professor Armando J.L. Pombeiro for his outstanding achievements in Coordination Chemistry and Catalysis

\begin{abstract}
Synthetic organic chemistry experienced a significant advance in the last quarter of the $20^{\text {th }}$ century with the advent of the transition-metal catalyzed cross-coupling reactions. The utility of these reactions was universally acknowledged and expressed in the Chemistry Nobel prize awarded to professors Heck, Suzuki and Negishi in 2010. In this scenario, the discovery of the Suzuki-Miyaura reaction was a landmark that occupies a privileged position because of its versatility, compatibility and pivotal contribution to diverse disciplines, including materials science and drug discovery. Despite the substantial progress attained for this reaction until 2010, there is still room for improvement, particularly, if we are concerned about the health of the Earth and aware of the paramount importance to produce substances under the guidelines of sustainable and Green Chemistry. In the present review, we summarize the efforts devoted by a wide and specialized scientific community to upgrade the Suzuki-Miyaura reaction during the post-Nobel prize period. An overview covering new catalytic systems, methods and conditions is provided, together with some applications and updated mechanistic viewpoints.
\end{abstract}

\section{Contents}

1. Introduction

2. Palladium complexes

2.1. Phosphine ligands

2.2. NHC ligands

2.3. Palladacycles and other ligands

2.4. Heterogeneous palladium complexes

3. Palladium nanoparticles

3.1. Unsupported nanoparticles

3.2. Supported nanoparticles

4. Alternative metals, substrates and methods

4.1. Other metal catalysts

4.2. Unconventional substrates

4.3. Non-traditional reaction conditions

5. Stereoselective reactions

6. Some synthetic applications

7. Mechanistic aspects

8. Summary and outlook 


\section{Introduction}

The Suzuki-Miyaura reaction is a highly implemented and demanded cross-coupling reaction in synthetic organic chemistry that does not tarnish the usefulness of similar reactions involving other organometallic/organoelement compounds. The use of organoboron compounds and the particularly stable and quite affordable arylboronic acids, compatible with almost any functional group, together with the possibility of using varied solvents under relatively mild reaction conditions, has determined its extensive use in organic synthesis for carbon-carbon bond formation and, especially, in biaryl synthesis [1], to obtain useful compounds such as pharmaceuticals [2] and natural products [3]. Indeed, the Suzuki-Miyaura reaction is the second most frequently used reaction in drug discovery and development [2b].

By the time A. Suzuki was awarded the Nobel prize in Chemistry in 2010, the main obstacles of the Suzuki-Miyaura reaction concerning challenging substrates had been solved; the research was somewhat reoriented to upgrade the efficiency of the catalytic systems ever since. For instance, new procedures emerged with the aim to work at ultra-low catalyst loading [4], avoiding the usage of toxic phosphine ligands or in the absence of ligands [5], in aqueous solutions as reaction media or in neat water [6], among others. Another important direction of the research was the application of heterogeneous catalysis in order to allow easier catalyst recovery and reuse. In this context, palladium nanoparticles (PdNPs) play an important role; their participation in the Suzuki-Miyaura reaction was originally detected when using a catalyst/pre-catalyst, which, in fact, was a nanoparticle precursor in many cases where it was previously thought that a zero-valent palladium complex was operating. In practice, this type of complexes can collapse with the release of atomic palladium that, immediately, aggregates into nanoparticles. This event usually happens when ligands weekly holding non-valent palladium are present, i.e., the most frequently used phosphine ligand triphenylphosphine, but also in cyclopalladates [7] and even in carbene complexes of palladium [8]. This type of catalysis (i.e., nanocatalysis), together with the leaching issue, has blurred the boundary between heterogeneous and homogeneous catalysis, causing a lively discussion about its real nature and its repercussions on the reaction mechanism.

Due to our ongoing interest in cross-coupling reactions [9], in 2008, we reviewed the SuzukiMiyaura reaction under non-conventional conditions [10]. Herein, we want to report the major advances attained in the post-Nobel prize era for this reaction, trying to cover not only the diversity of the catalytic systems but other aspects ranging from alternative methods and substrates to some useful applications in organic synthesis. We will lay particular emphasis on the reaction mechanism through some revealing recent contributions.

\section{Palladium complexes}

It is well known the key role played by phosphine ligands in palladium-catalyzed cross-coupling reactions. The strong dependence of the success of the reaction on the nature of the ligand led to the development of a plethora of structurally different phosphine ligands in the past decades. In parallel, the Suzuki-Miyaura reaction itself, along with the Heck reaction, served as model reactions to test the activity of palladium complexes with new ligands [11].

\subsection{Phosphine ligands}

The cross-coupling of arylboronic acids and aryl halides catalyzed by palladium phosphine complexes can be considered a classic example of the Suzuki-Miyaura reaction. The introduction of phosphine ligands such as $\mathrm{P}(t-\mathrm{Bu})_{3}, \mathrm{PCy}_{3}$ (by Littke and $\mathrm{Fu}$ ) [12], and Buchwald's biphenyl ligand XPhos [13] paved the way to the use of aryl chlorides in the Suzuki-Miyaura reaction under fairly 
mild conditions. These sterically hindered phosphines form mono-ligated complexes with enhanced reactivity [14]. Nixantphos showed an excellent performance among the chelating diphosphine ligands [15] (Chart 1).
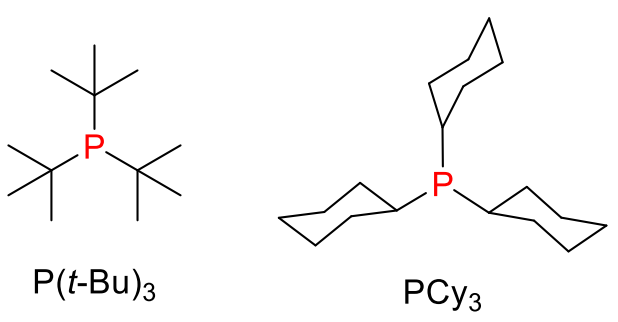<smiles>CCCc1cc(C(C)C)c(-c2ccccc2P(=O)(O)c2ccccc2)c(C(C)C)c1</smiles><smiles>O=[PH](O)c1cccc2c1Oc1c(P)cccc1N2</smiles>

Chart 1. Examples of mono-ligated phosphine ligands.

Lipshutz et al. reported the new ligand HandaPhos, which allowed the coupling of both, aryl iodides and bromides with arylboronic acids using $1000 \mathrm{ppm}$ of catalyst in water at room temperature, in the presence of the surfactant Nok (for $24 \mathrm{~h}$ ) (Scheme 1) [16]. This type of micellar catalysis facilitated the product separation by simple filtration without employing organic solvents. The filtrate containing the catalyst was reused in subsequent cycles leading to a stable yield of $90 \%$ in five cycles.

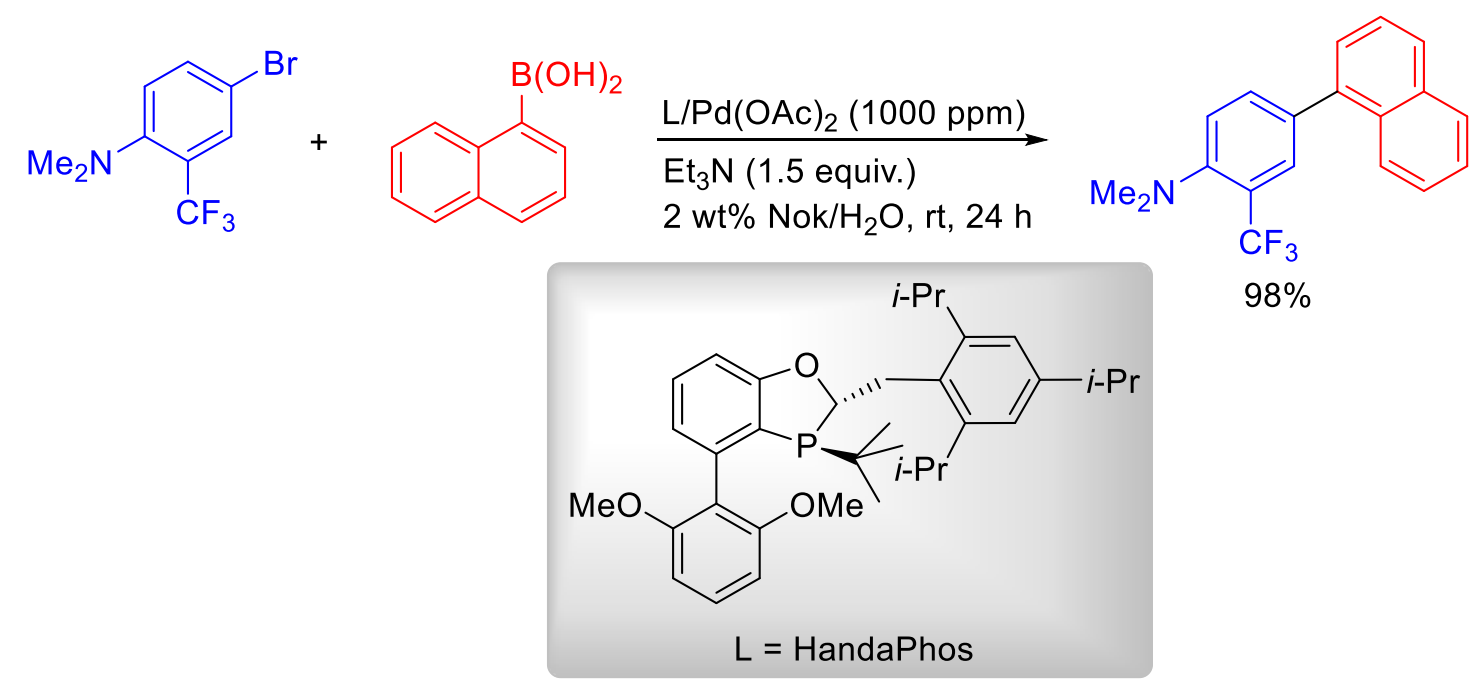

Scheme 1. Suzuki-Miyaura reaction catalyzed by $\mathrm{Pd}(\mathrm{OAc})_{2}$-HandaPhos.

It is known that palladium complexes with alkylphosphines, especially sterically hindered ones, are highly active in cross-coupling reactions. In this regard, phosphines containing the adamantyl group are especially interesting because of their high stability as ligands. Tri(1-adamantyl)phosphine $\left(\mathrm{PAd}_{3}\right)$ was first synthesized by Carrow and Chen [11d] which, when combined with an acetanilido palladacycle resulted in a new pre-catalyst with exceptional activity: the reactions of aryl chlorides and arylboronic acids proceeded at room temperature with low catalyst loading. Moreover, good yields were obtained with challenging substrates, including those sterically hindered and heterocyclic, as well as with aryl chlorides with electron-donor substituents and alkylboronic acids (Scheme 2). 


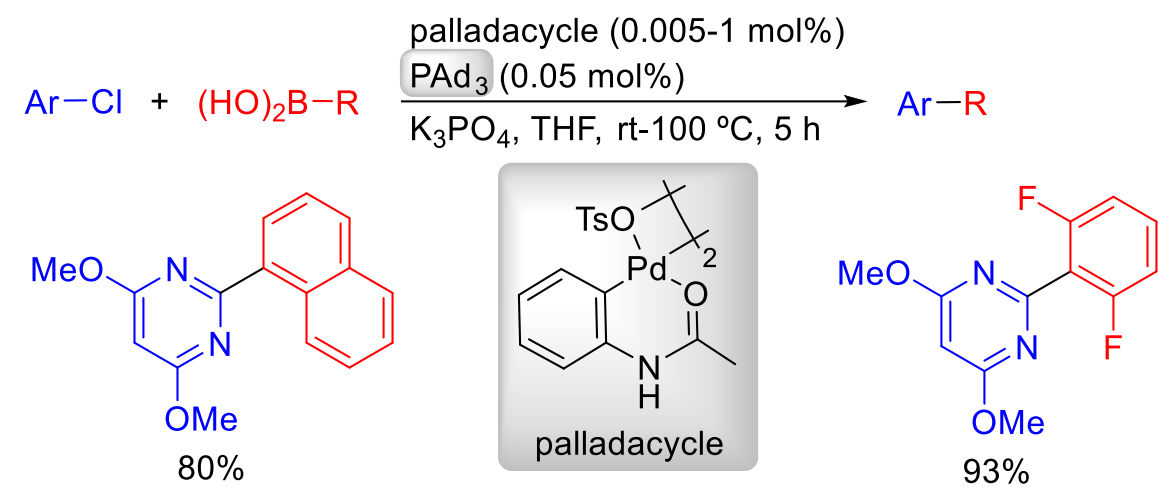<smiles></smiles>

$96 \%$<smiles>Cc1cccc(C)c1-c1cccc2ccccc12</smiles>

$80 \%$<smiles>Cc1noc(C)c1-c1ccccc1C#N</smiles>

$79 \%$<smiles>Cc1cccc(C)c1C</smiles>

$70 \%$

Scheme 2. Suzuki-Miyaura reaction catalyzed by a palladacycle-PAd $\mathrm{Ad}_{3}$

Using a sterically hindered phosphine oxide-oxaphosphacyclic ligand, Tang et al. effected the crosscoupling of aryl bromides [17a] and aryl/cycloalkenyl triflates [17b] with secondary alkylboronic acids (Scheme 3). Previous attempts to perform similar reactions led to isomerization products and low yields.

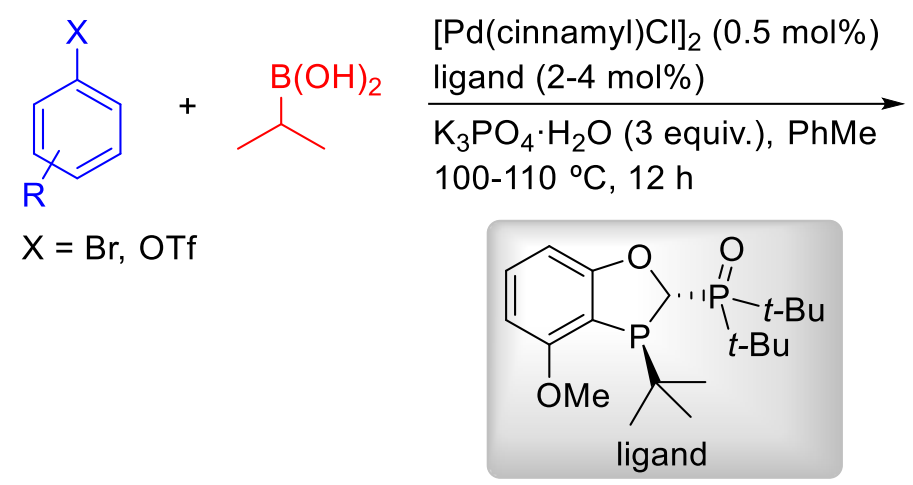<smiles>[R]c1ccc(C(C)C)cc1</smiles>

$45-97 \%$

Scheme 3. Cross-coupling of aryl bromides and triflates with secondary alkylboronic acids.

In a very interesting article, Tang et al. reported the Suzuki-Miyaura coupling of sterically encumbered di-ortho-substituted aryl bromides and secondary alkylboronic acids with the intervention of a Pd-AntPhos catalyst [18]. A broad range of products was obtained in good-toexcellent yields (Scheme 4). The method was applied to the synthesis of hexaalkylbenzenes as "molecular gears". 


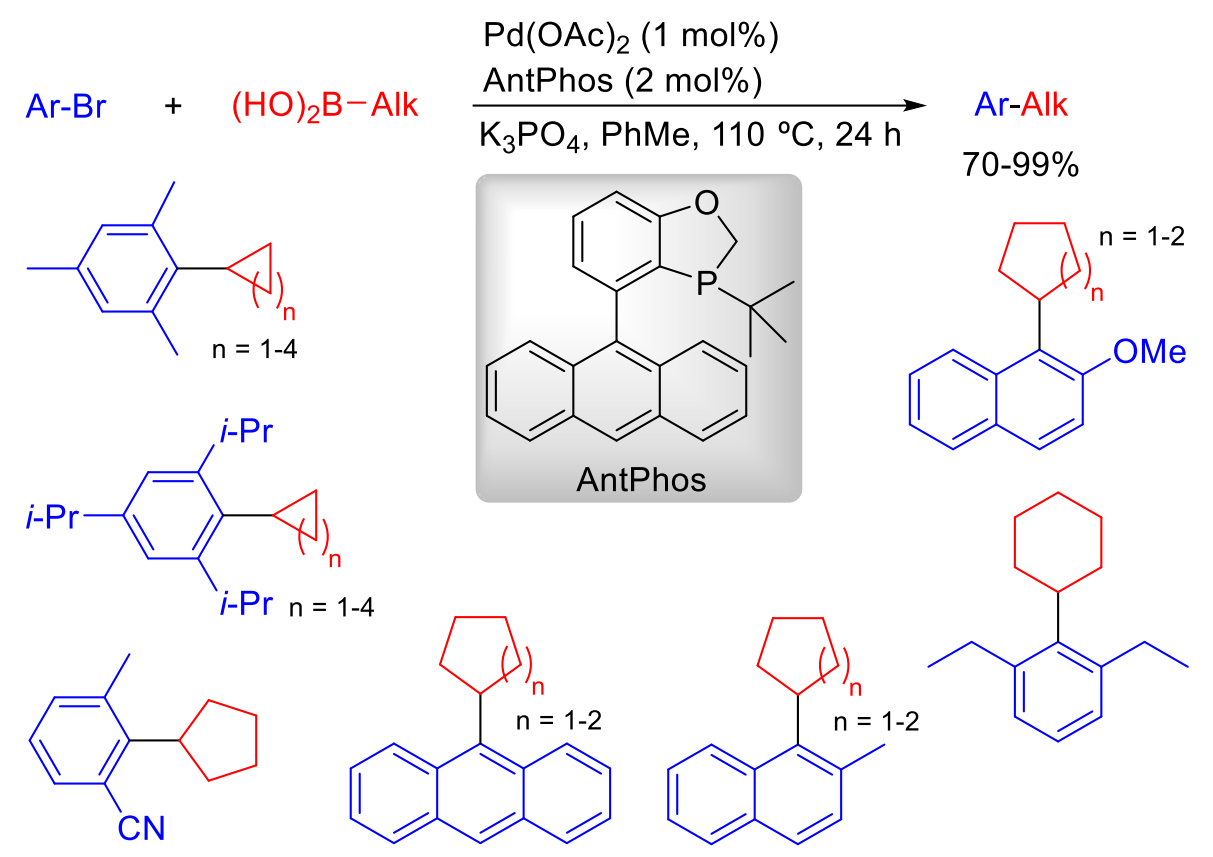

Scheme 4. Suzuki-Miyaura coupling of di-ortho-substituted aryl bromides and secondary alkylboronic acids.

The design of enzyme-like catalysts based on ligands with a cavity being capable to accommodate the substrate was successful achieved by Sémeril and Matt et al. [11a] (Chart 2). This group synthesized a variety of calix[4]arenes with a $\mathrm{PPh}_{2}$ group anchored to its upper rim. The monophosphine ligand bearing a $p$-methoxybenzyl group in the lower rim, in combination with $\mathrm{Pd}(\mathrm{OAc})_{2}$, led to high catalytic activity $\left(\mathrm{TOF}=321,000 \mathrm{~h}^{-1}\right)$ in the arylation of 4-bromotoluene with phenylboronic acid. The calixarene ligands were also efficient in the cross-coupling of the less reactive 4-chlorotoluene and 4-chloroanisole using $1 \mathrm{~mol} \% \mathrm{Pd}$, though longer reaction time was required for full conversion.

Cost cutting is an inherent requirement in industrial production, that is why efforts of researchers were aimed at reducing the content of expensive palladium catalysts to "homeopathic" amounts [19]. In this sense, a record was achieved by Sollogoub et al. using a tetraphosphine derivative of $\alpha$ cyclodextrin as a ligand ( $\alpha$-Cytep) [11c] (Chart 2). The catalyst loading, down to $10^{-10} \mathrm{~mol} \%$, allowed staggering numbers of TON $=340,000,000,000$ and TOF $=1,000,000,000 \mathrm{~h}^{-1}$ in the reaction of phenylboronic acid with 4-bromoacetophenone in xylene at $120^{\circ} \mathrm{C}$. Uozumi and Roy [4] have recently published a review on the latest developments in the field of homeopathic catalysis in cross-coupling reactions.
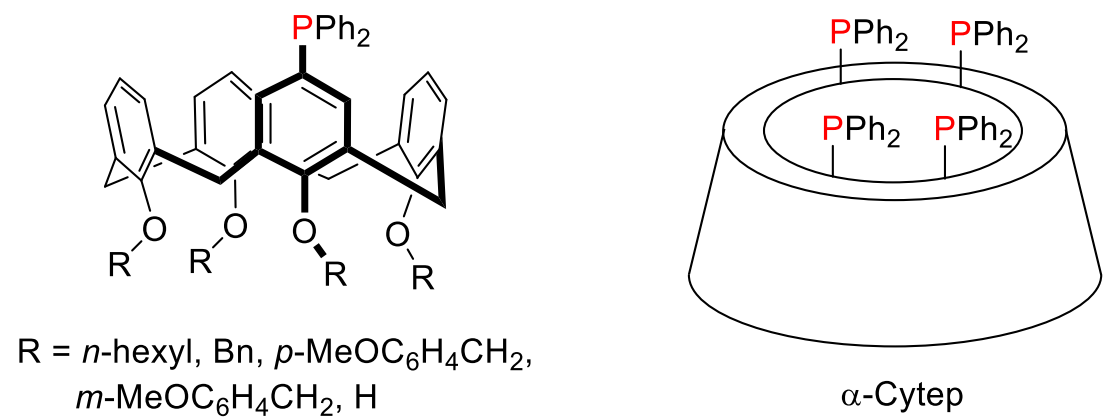

Chart 2. Diphenylphosphino-substituted calix[4]arenes and $\alpha$-cyclodextrin. 
Interesting results were recently reported by Chinese authors [20], who studied the catalysis of the Suzuki-Miyaura reaction with a palladium cation cluster; the latter was obtained from palladium(II) chloride and triphenylphosphine during the reduction by sodium borohydride, with subsequent replacement of the chloride anion with antimony hexafluoride (Scheme 5). The cluster was found to be stable at high temperatures (up to $170{ }^{\circ} \mathrm{C}$ ). The Suzuki-Miyaura reaction between aryl bromides bearing various substituents and phenylboronic acid took place in aqueous isopropanol, at room temperature, with low catalyst loading $(0.08 \mathrm{~mol} \%)$ and high TOFs $\left(1,000-5,000 \mathrm{~h}^{-1}\right)$.

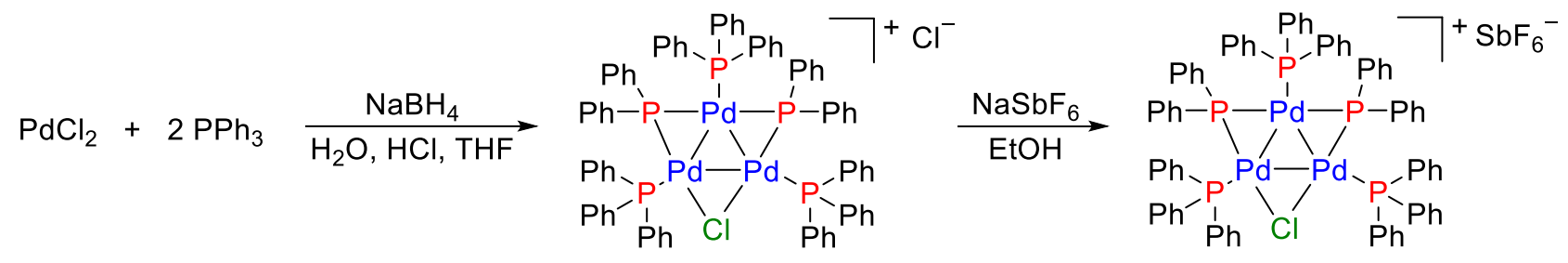

Scheme 5. Synthesis of a palladium-cation cluster.

\subsection{Carbene ligands $(\mathrm{NHC})$}

The emergence of N-heterocyclic carbene (NHC) complexes of palladium exhibiting high catalytic activity, firstly used in the Heck reaction by Herrmann et al. [21], opened a new era in palladium catalysis. The success in this field was primarily due to the work by Nolan et al. [22], who used a $N, N^{\prime}$-bisarylimidazole palladium complex to catalyze the Suzuki-Miyaura reaction with aryl halides and aryl triflates [23]. It is worthy of note that, in some cases, these complexes generate PdNPs under the reaction conditions applied, which were also stabilized by the carbene ligands.

Especially effective and convenient was the family of precatalysts proposed by Organ [24], PEPPSI (pyridine-enhanced precatalyst preparation stabilization and initiation), which are complexes of $\mathrm{N}, \mathrm{N}$-disubstituted imidazole carbene ligands with palladium dichloride and the fourth coordinating place of palladium is occupied by 3-chloropyridine [25] (Chart 3). The pyridine unit easily dissociates promoting the interaction of the carbene complex with the substrate. Recently, Liu et al. proposed a new PEPPSI variation, PEPPSI-IPent ${ }^{\mathrm{An}}$, that combines an acenaphthylene fragment in the heterocyclic skeleton with 3-pentyl groups at the $\mathrm{N}$-aryl substituents [26]. The palladium complex with this ligand allows to perform the reaction of sterically hindered aryl halides and hetero(aryl) boronic acids in high yields under fairly mild conditions (Scheme 6).

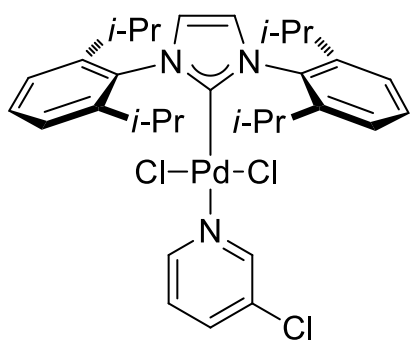

Pd-PEPPSI

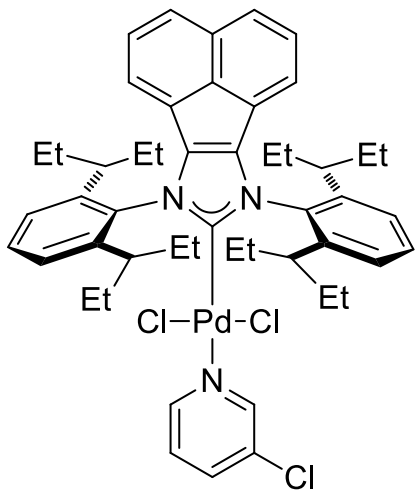

Pd-PEPPSI-IPent ${ }^{A n}$

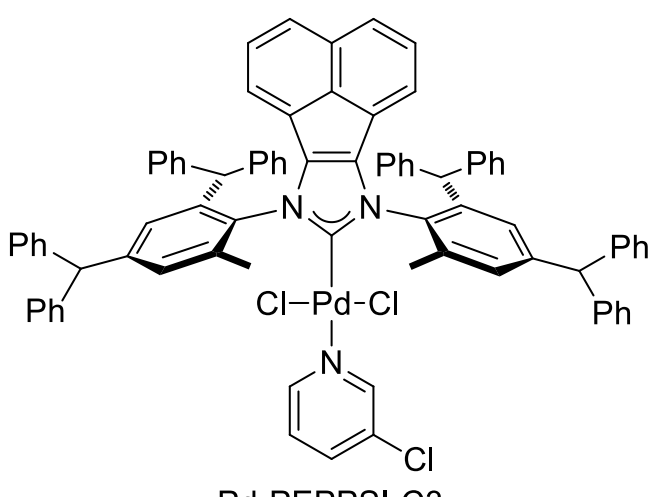

Pd-PEPPSI-C3

Chart 3. PEPPSI-type precatalysts. 
<smiles>[R][R]1ccc([R])c([CH])c1[R]</smiles>

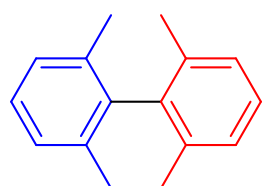

$93 \%$

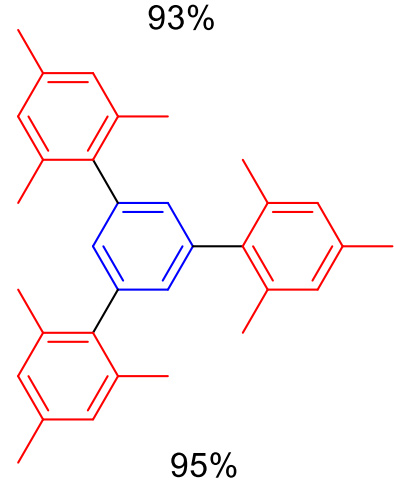

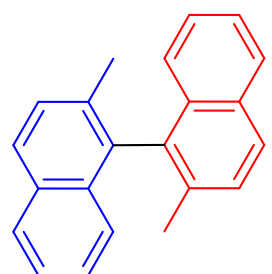

$81 \%$

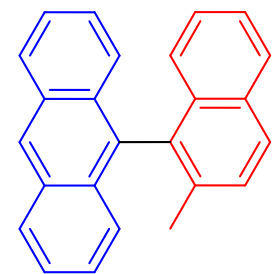

$72 \%$

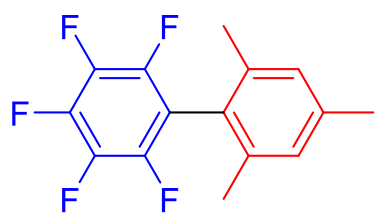

$88 \%$

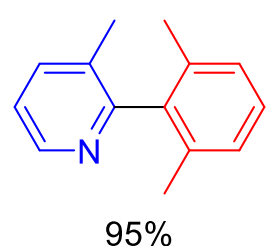

$95 \%$

Scheme 6. Cross-coupling of sterically hindered aryl halides and aryl boronic acids.

The PEPPSI-C3 ligand (Chart 3) was obtained by varying the substituents at the $\mathrm{N}$-aryl groups. Its improved properties made possible to replace the strong base $\mathrm{K}-t-\mathrm{BuO}$ with the much weaker $\mathrm{K}_{2} \mathrm{CO}_{3}$, compatible with a wider range of substrates [27]. The high activity of this catalyst was demonstrated in successful reactions of heterocyclic substrates using a low palladium loading (0.05-0.5 mol\%) (Scheme 7).

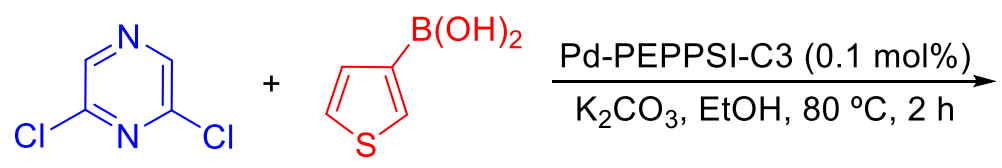<smiles>O=S(=O)(O)c1ccsc1-c1cncc(-c2ccsc2)n1</smiles>

Scheme 7. Suzuki-Miyaura reaction catalyzed by Pd-PEPPSI-C3.

In the quest for more efficient precatalysts based on the NHC palladium complexes, Ying et al. designed a NHC-ligated O-palladated acetanilide complex which succeeded in the Suzuki-Miyaura coupling of challenging substrates, including deactivated aryl and alkyl substrates, and the extremely sterically hindered 1-chloro-2,6-diisopropylbenzene [28] (Scheme 8); many reactions proceeded even at room temperature. 

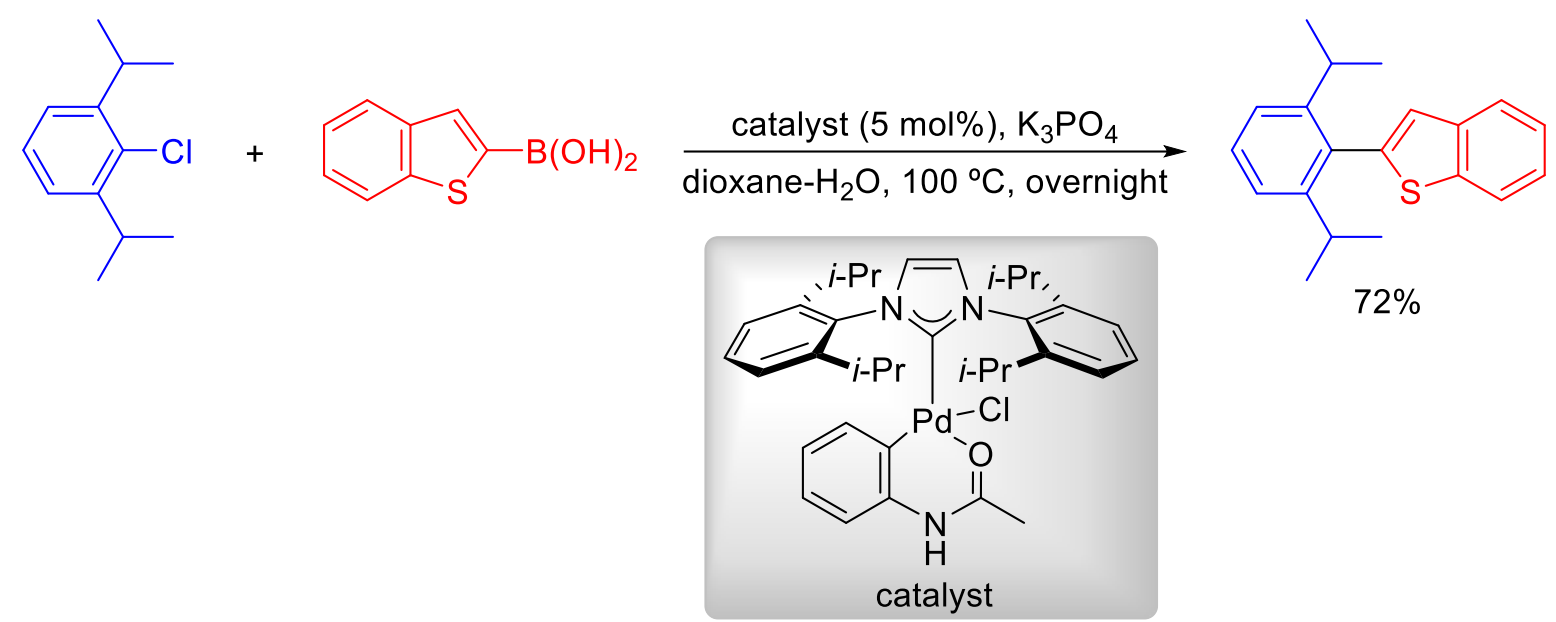

Scheme 8. Suzuki-Miyaura reaction catalyzed by a NHC-ligated O-palladated acetanilide complex.

Chen and Kao compared some precatalysts based on NHC palladium complexes, bearing nitrogen ligands susceptible of ortho-palladation, and found out that the acyclic ligated complexes showed considerably greater activity than the palladacyclic counterparts. This behavior was attributed to the cleavage of the palladacycles as being a necessary preactivation step [29]. The cross-coupling of sterically hindered deactivated aryl chlorides with sterically hindered arylboronic acids was high yielding at room temperature in air (Scheme 9).
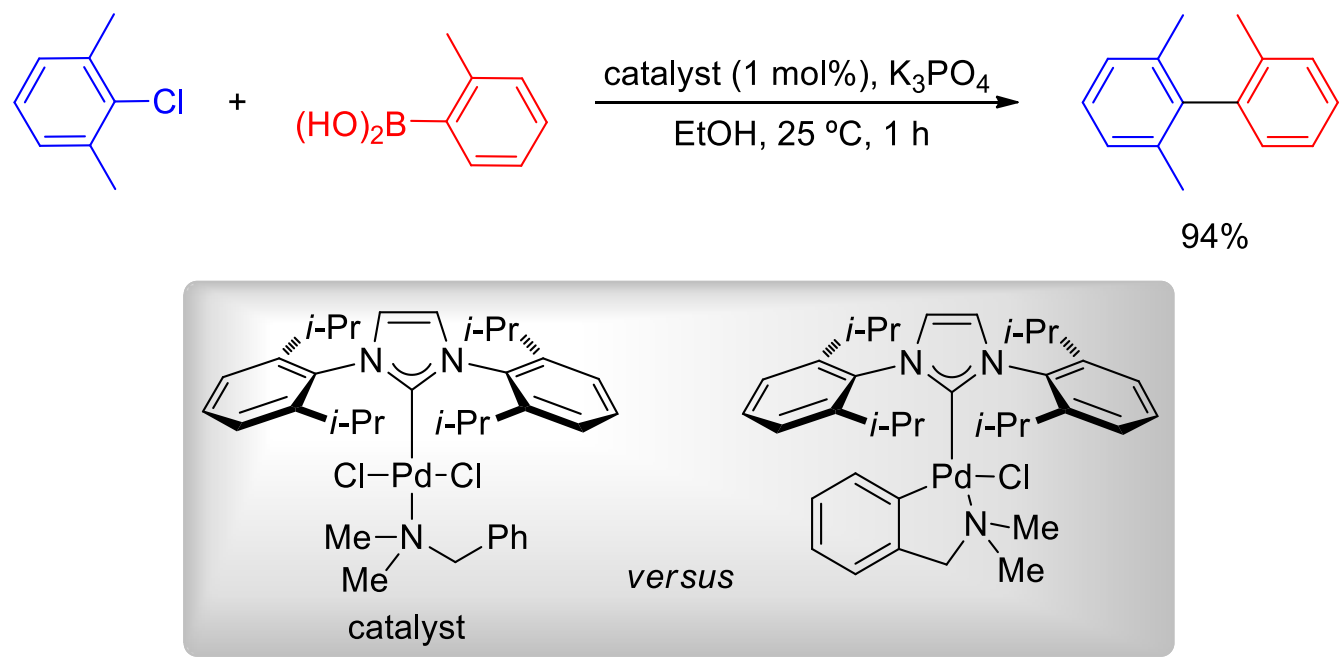

Scheme 9. Suzuki-Miyaura reaction catalyzed by NHC palladium complexes bearing nitrogen ligands.

Polarz et al. designed a hybrid surfactant, with a N-heterocyclic carbene pincer ligand as a polar head, for reactions involving hydrophilic and hydrophobic reagents or those with a different solubility [30]. The palladium complex of this surfactant proved to be highly effective in the reaction of 4-bromoacetophenone and phenylboronic acid in water and much more active than a similar pincer ligand without the hydrophobic tail (Scheme 10). 

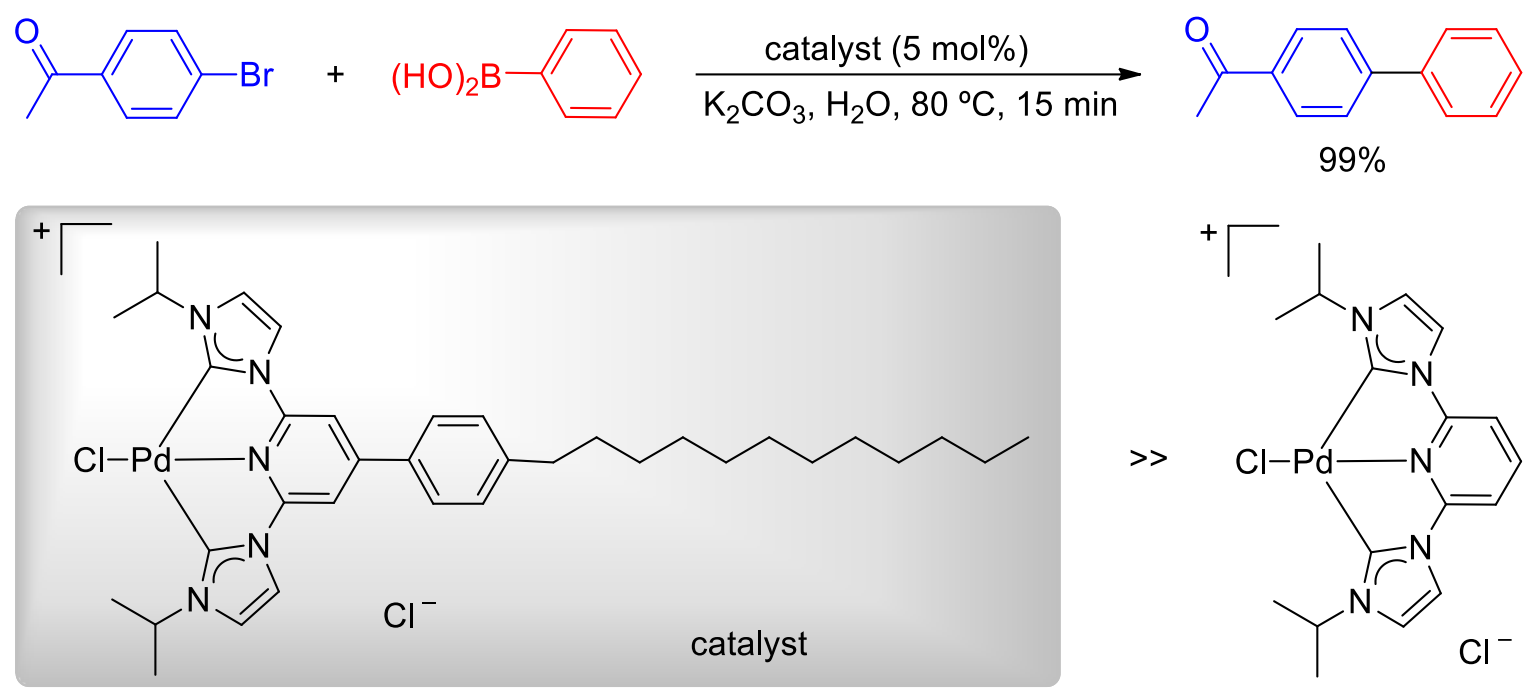

Scheme 10. Suzuki-Miyaura reaction catalyzed by a Pd-NHC pincer ligand.

As an alternative to NHC ligands, Kukushkin et al. [31] suggested the use of acyclic diaminocarbenes (ADC). Palladium complexes of these ligands demonstrated an efficacy comparable to that of the NHC-Pd counterparts. Water-soluble diaminocarbene palladium complexes catalyzed some Suzuki-Miyaura reactions in water with high TONs $\left[4.7 \times 10^{4}\right.$ (aryl bromides), $9.2 \times 10^{3}$ (activated aryl chlorides] (Scheme 11) [31b].

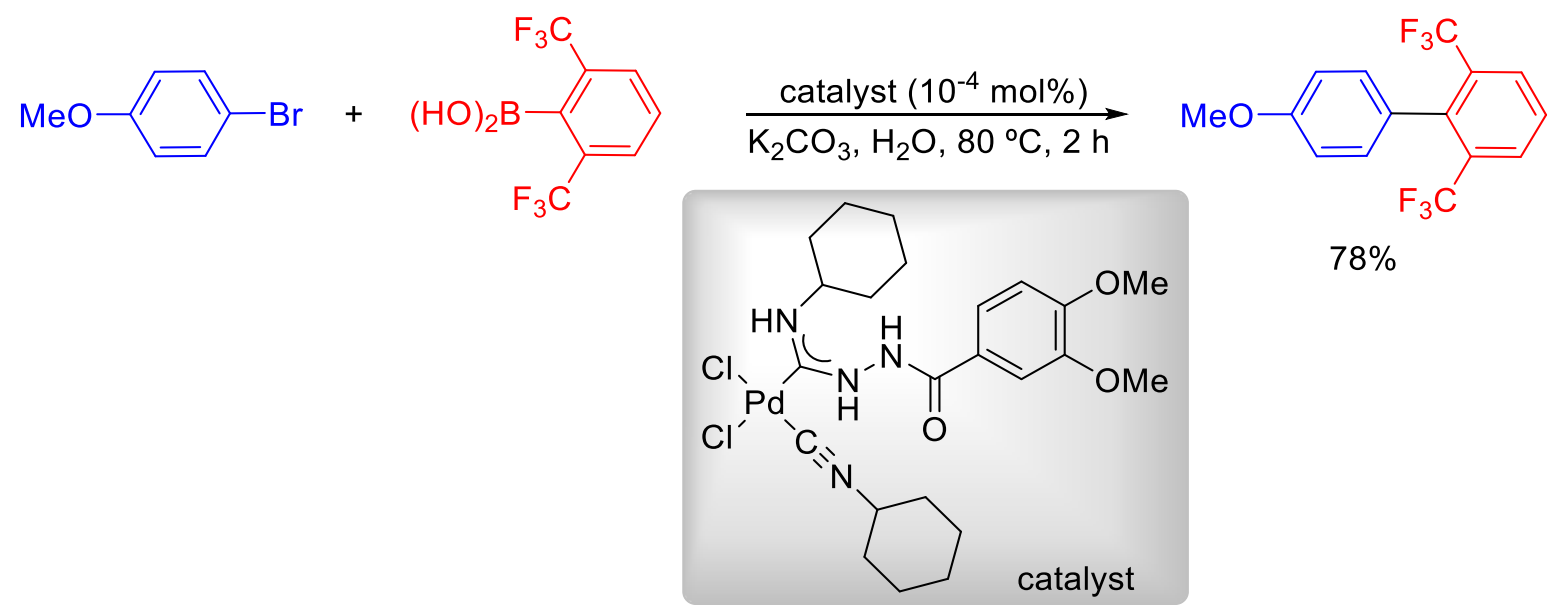

Scheme 11. Suzuki-Miyaura reaction catalyzed by a Pd-acyclic diaminocarbene.

\subsection{Palladacycles and other ligands}

There has been an ongoing interest in developing diverse palladacycles and pincer complexes with different coordinating atoms $(\mathrm{P}, \mathrm{N}, \mathrm{S}, \mathrm{Se}$ and their combinations). Their history, evolution and current trends have been concisely described in a recent review [32]. The application of palladacycles and pincer complexes as catalysts (in fact, pre-catalysts) begun with the work of Herrmann and Beller et al. [33], which raised the great interest of researchers in the field of palladium catalysis. Notably, it was possible to perform Suzuki-Miyaura reactions with a small amount of palladium complex, even with low-active substrates, reaching high TONs and even TOFs (usually, at the initial reaction stage). The assumption that the couple $\mathrm{Pd}(\mathrm{II}) \leftrightarrow \operatorname{Pd}(\mathrm{IV})$ participated in the catalytic cycle under the action of the aryl halide was considered dubious [11d, 34]. Indeed, it turned out that palladacycles acted as reservoirs for PdNPs in the Heck and Suzuki reactions [7b]. Apparently, PdNPs aggregation was prevented when slowly generated, what guaranteed the feasibility of the reaction either via homogeneous (in the case of leaching) or heterogeneous 
catalysis [7b]. However, the fact that pincer complexes with strong-donor phosphine or carbene ligands can stabilize $\operatorname{Pd}(0)$ favors the participation of various types of catalysts in the process [35].

Palladacycles, including the palladium-coordinated phosphine ligands developed by Buchwald et al., have been conveniently used as precatalysts, the reduction of which leads to the formation of the corresponding monoligated $\operatorname{Pd}(0)$ phosphine complexes (Chart 4) [36]. The same group reported palladacycles with a mesylate substituent as a leaving group which, in the presence a weak base, could be applied to the coupling of aryl chlorides with unstable boronic acids under mild conditions (Scheme 12) [36b]. The high activity of the in-situ formed palladium-monoligated phosphine complexes was also demonstrated for sterically hindered and unstable substrates, in particular, perfluoroarylboronic acids. The latter are rather unstable in basic medium and, under ordinary reaction conditions, the products cannot be obtained in satisfactory yields. With these monoligated complexes, the Suzuki-Miyaura reaction proceeds faster than the protodeboration and biaryls were formed in high yields [35a, 35b]. Nájera et al. studied the application of oxime-derived palladacycles as catalysts and published the corresponding review [37].<smiles>C[Te][Te](Cl)(Cl)c1ccccc1CCN</smiles><smiles>Cl[Te]1(Cl)Nc2ccccc2-c2ccccc21</smiles><smiles>CO[P+]1([Tl])Nc2ccccc2-c2ccccc21</smiles>

$\mathrm{L}=$ phosphine ligand

Chart 4. Palladacycle-based catalysts reported by the group of Buchwald.

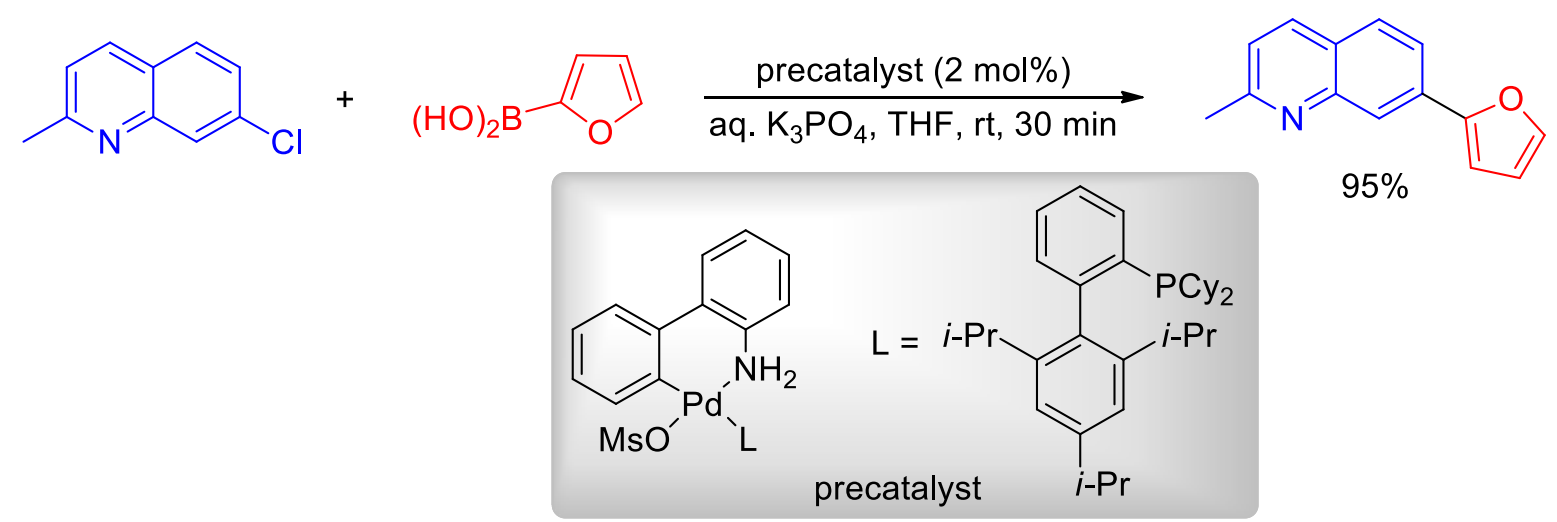

Scheme 12. Suzuki-Miyaura reaction catalyzed by a mesylate-substituted palladacycle.

Palladacycles with a covalent $\mathrm{C}_{\mathrm{sp} 3}-\mathrm{Pd}$ bond, where palladium is coordinated to $\mathrm{S}$ and $\mathrm{N}$ atoms, and pincer complexes with Se-Pd-Se coordination bonds were proven to be catalytically active in the Suzuki-Miyaura reaction [38]; both types of complexes were reported to form PdNPs. The activity of the pre-catalyst with the $\mathrm{C}_{\mathrm{sp} 3}$-Pd bond was shown to be slightly higher, affording the usage of small quantities of palladium in some reactions (Scheme 13). 

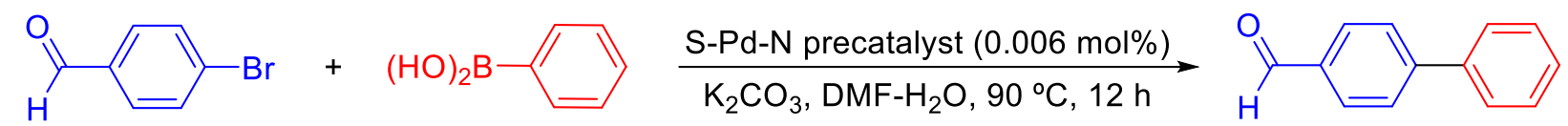

$100 \%$

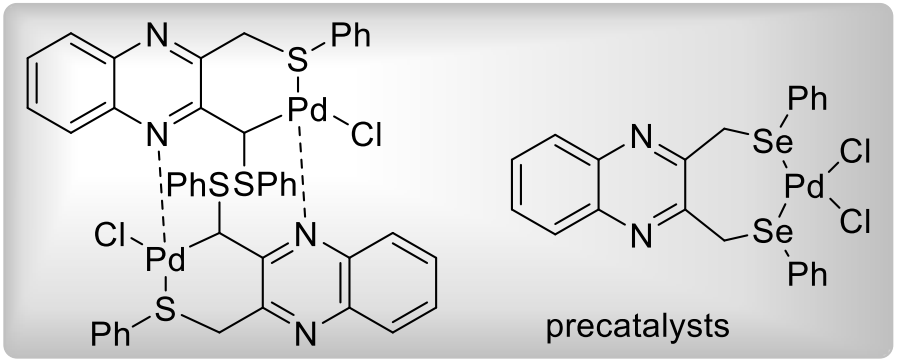

Scheme 13. Suzuki-Miyaura reaction catalyzed by $S$ and Se palladacycles.

The intention to replace toxic phosphine ligands with nitrogen- or oxygen-containing ligands was proven to be quite successful, especially, because they can be often combined with the use of water and aqueous solvents. For instance, it was shown that $\mathrm{Pd}(\mathrm{II})$ complexes with water-soluble salen ligands catalyzed the Suzuki-Miyaura reaction of aryl bromides in water at $100{ }^{\circ} \mathrm{C}$ [39]. Furthermore, the method could be extended to a multi-gram scale (Scheme 14) and the catalyst could be reused in four runs with a good performance.

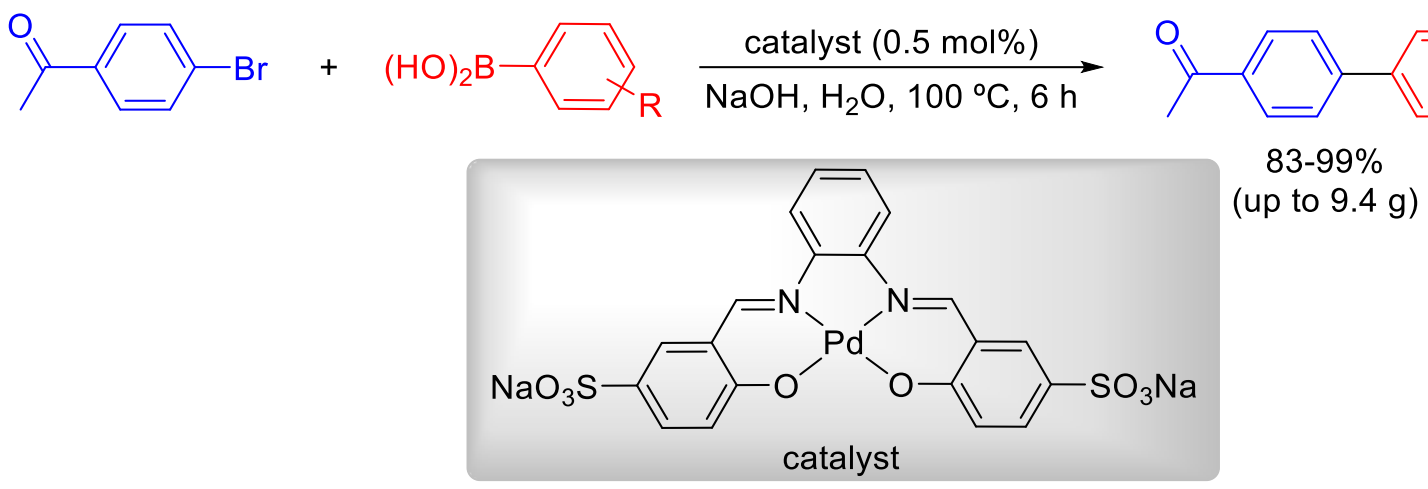

Scheme 14. Multi-gram scale Suzuki-Miyaura reaction catalyzed by a Pd-salen complex.

Liu and Huo et al. introduced a series of benzocyclohexane-ketoamines ligands for palladium in the Suzuki-Miyaura reaction [40]. The $N$-fluorenyl-substituted derivative was effective in the coupling of both electron-rich and electron-poor aryl bromides with various arylboronic acids, leading to the corresponding biaryls in good-to-excellent yields (91-96\% in most cases). The sterically demanding 2,4,6-trimethylbromobenzene was successfully coupled, whereas deactivated aryl chlorides where more reluctant to react (Scheme 15). 


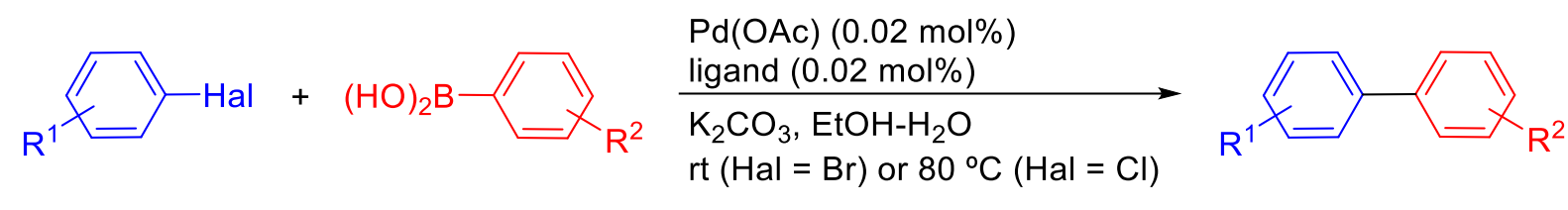

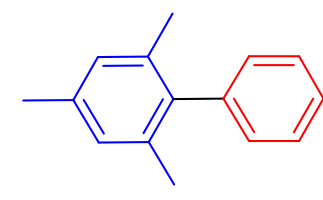

6 h, $77 \%$

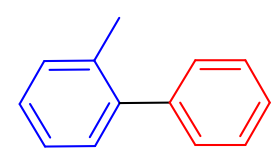

$6 \mathrm{~h}, 68 \%$

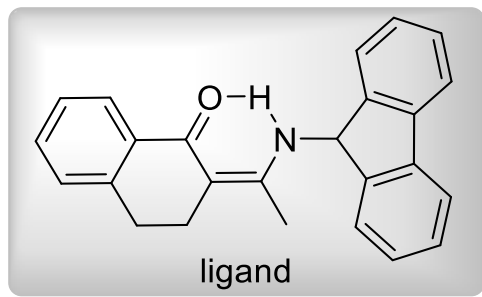

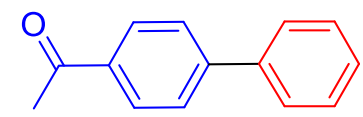

2 h, $99 \%$

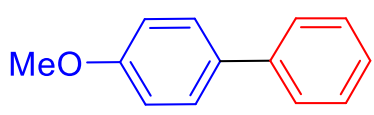

$2 \mathrm{~h}, 97 \%$

$H a l=B r$

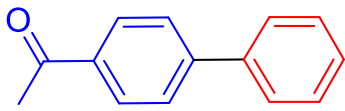

12 h, $63 \%$

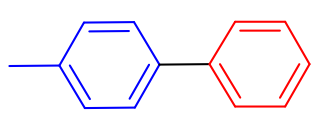

12 h, 31\%

$H a I=C l$

Scheme 15. Suzuki-Miyaura reaction catalyzed by a Pd-benzocyclohexane-ketoamine complex.

The same research group reported palladium complexes derived from three bisacetylacetonate ligands (Chart 5) [41]. The best ligand was that with an anthracene unit which, under equal conditions as those depicted in Scheme 16, but using $0.01 \mathrm{~mol} \%$ catalyst and ligand, gave nearly the same outcome as for the aforementioned $N$-fluorenyl benzocyclohexane-ketoamine ligand.<smiles>CC(=O)C(C(C)=O)C(C(C)=O)C(C)=O</smiles>

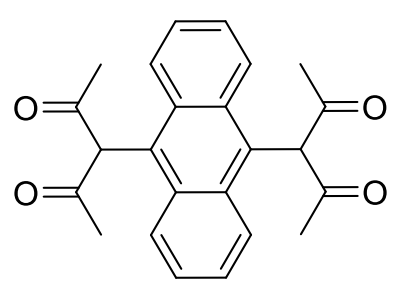

Chart 5. Bisacetylacetonate ligands.

Stefankiewicz et al. have recently discovered an interesting effect of $\mathrm{pH}$ on the Suzuki reaction when using a $\mathrm{Pd}(\mathrm{II})$ complex with a pyridyl-substituted $\beta$-diketone [42]. A cationic palladium complex with a pyridyl ligand was formed in an acidic environment, whereas a neutral complex $\beta$ diketonate was obtained in basic medium (Scheme 16). Interestingly, the change in $\mathrm{pH}$ allowed to control Suzuki-Miyaura reactions catalyzed by the complex: the reaction takes place under basic conditions but it is stopped in acidic medium and can be resumed by increasing the $\mathrm{pH}$. Unfortunately, the authors did not investigate what happened to the complexes as a result of palladium being reduced to $\operatorname{Pd}(0)$, something that always occurred during the reaction. 


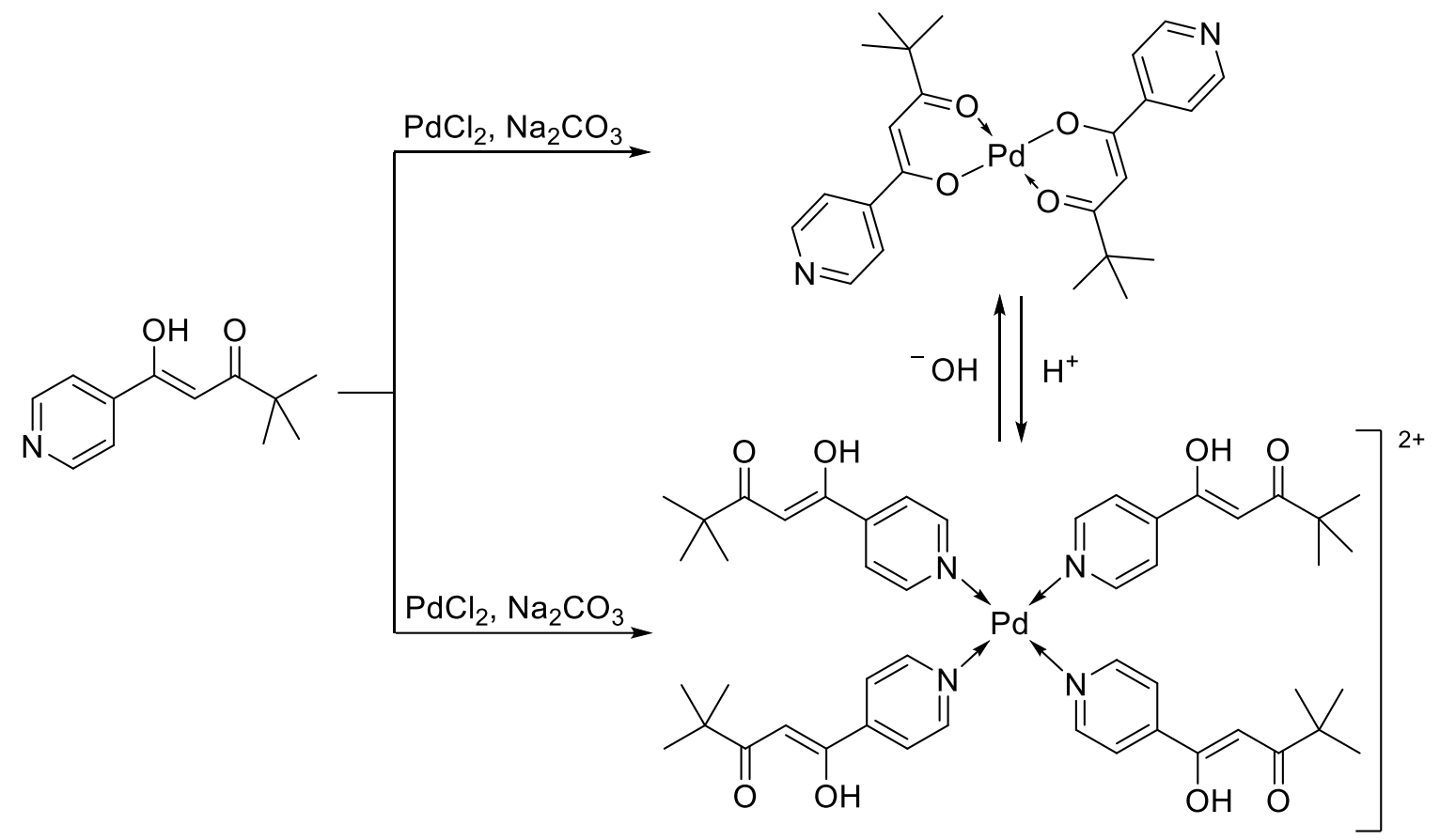

Scheme 16. Effect of the $\mathrm{pH}$ on a Pd-pyridyl-substituted $\beta$-diketone complex.

Hanhan et al. described a new water-soluble sulfonated N,N,N-tridentate ligand derived from 2,5bis(imidazol-2-yl)pyridine [43]. Its palladium complex catalyzed Suzuki-Miyaura reactions with sterically hindered aryl chlorides and arylboronic acids in water under microwave irradiation (Scheme 17). The yields could be improved to $>90 \%$ by changing the potassium ion into TBAB and Bmim ions. The different tests practiced pointed to a catalysis of homogeneous nature.
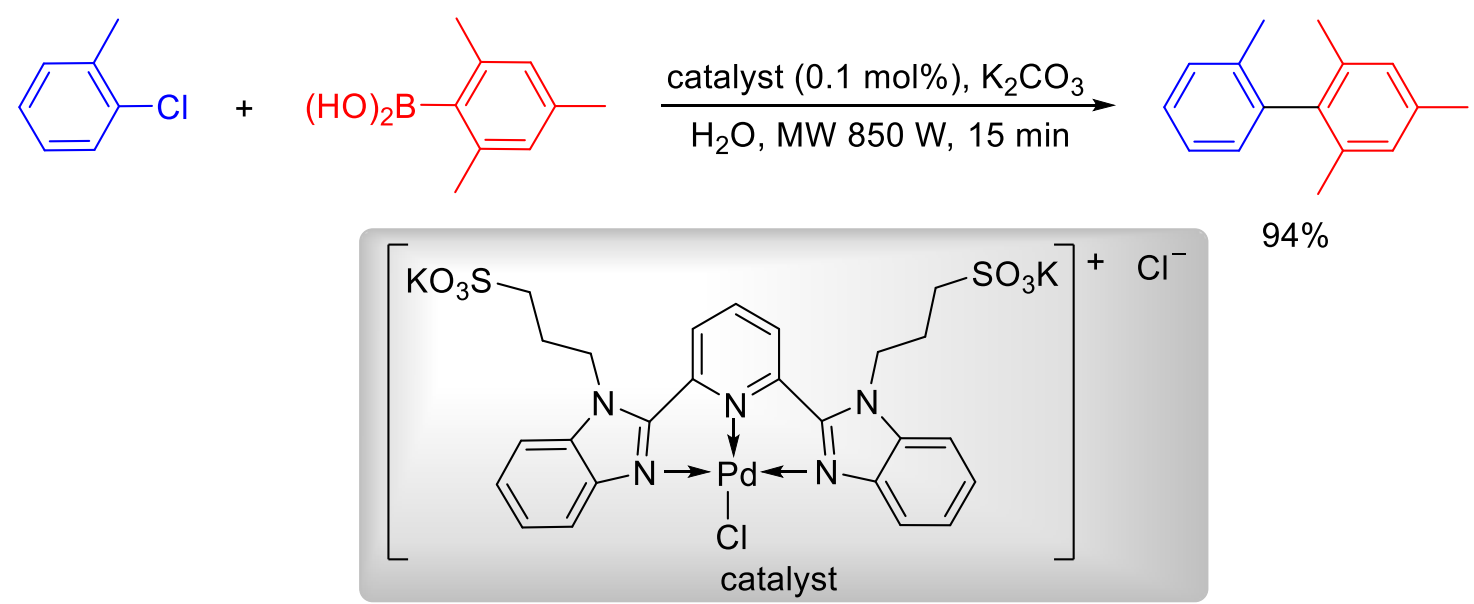

$94 \%$

Scheme 17. Suzuki-Miyaura reaction catalyzed by a Pd sulfonated N,N,N-tridentate complex.

\subsection{Heterogenized palladium complexes}

In search for greener and more sustainable catalytic protocols, efforts have been devoted to replace organic solvents with water, as well as the traditional pre-catalysts of palladium phosphine complexes with palladium salts [e.g., $\mathrm{Pd}(\mathrm{OAc})_{2}, \mathrm{PdCl}_{2}$ ]. Notwithstanding these endeavors, the separation of palladium from the product is still and often troublesome, with the consequent contamination of the latter. The immobilization of palladium complexes can overcome this drawback. For instance, Bora et al. immobilized a NHC palladium complex on silica (Figure 1), which catalyzed reactions of arylboronic acids with (hetero)aryl bromides at $50{ }^{\circ} \mathrm{C}$ and aryl 
chlorides at $80{ }^{\circ} \mathrm{C}$ in a mixture of isopropanol-water [44]. The catalyst activity noticeably decreased during recycling; consequently, the reaction time had to be increased with each cycle.

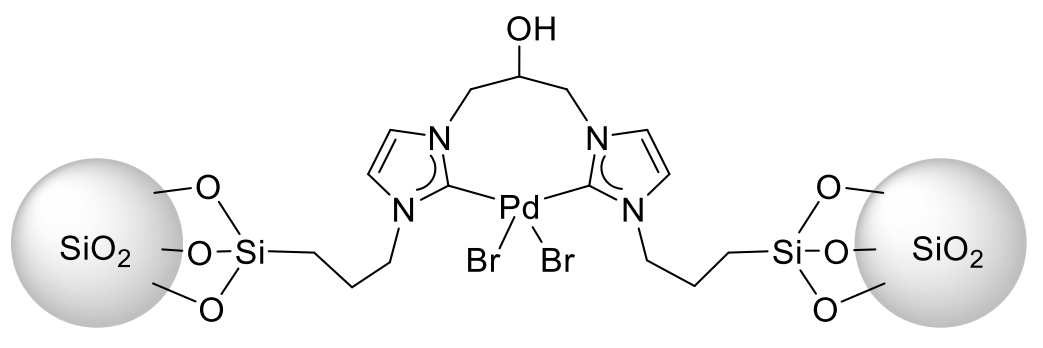

Figure 1. NHC palladium complex on silica.

Historically, the simplest and most common polymeric support has been the Merrifield resin. In 1976, for the first time, Pittman et al. published an article on a polymer-immobilized palladium catalyst based on diphenylphosphine-substituted Merrifield resin [45]. The insertion of phosphino groups into the Merrifield resin and the subsequent treatment with a palladium salt or complex led to the immobilized phosphine-palladium complex (Scheme 18). Jang pioneered the use of this catalyst in the Suzuki-Miyaura reaction of organoboron compounds and vinyl halides, aryl iodides and aryl triflates [46]. The cross-coupling products were obtained in high yields and the catalyst was successfully recycled five times without any loss of activity.

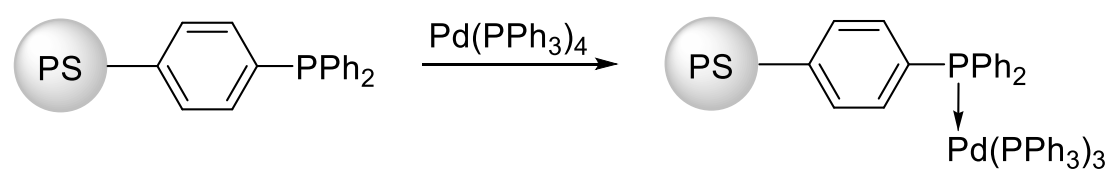

Scheme 18. Immobilized phosphine-palladium complex.

Over the past two decades, numerous articles described the immobilization of palladium complexes on a range of polymer supports. It is obvious that immobilization of a homogeneous metal complex on a solid support facilitates the separation of the catalyst from the reaction mixture and increases its stability. On the other hand, the structure of such a complex, fixed on the surface of a solid support, differs from that of the homogeneous counterpart and, often, shows lower activity [47]. Tada et al. immobilized a phosphine-polymeric palladium complex on the surface of silica [48]. With this catalyst, the cross-coupling reaction of several arylboronic acids and aryl iodides was achieved in high yields (up to 100\%) and relatively short reaction times (2-3 h). In addition, size and shape could be added to the catalyst. For this purpose, a silica gel matrix was made around the immobilized complex, in which a molecular imprint of the 2,2'-biphenol template ligand was left (Scheme 19). After ligand removal, a reaction space was obtained in the form of a template-ligand molecule imprint. A significant dependence of the yield on the steric volume and shape of the substrates was noticed for this complex in a matrix with a molecular imprint. 


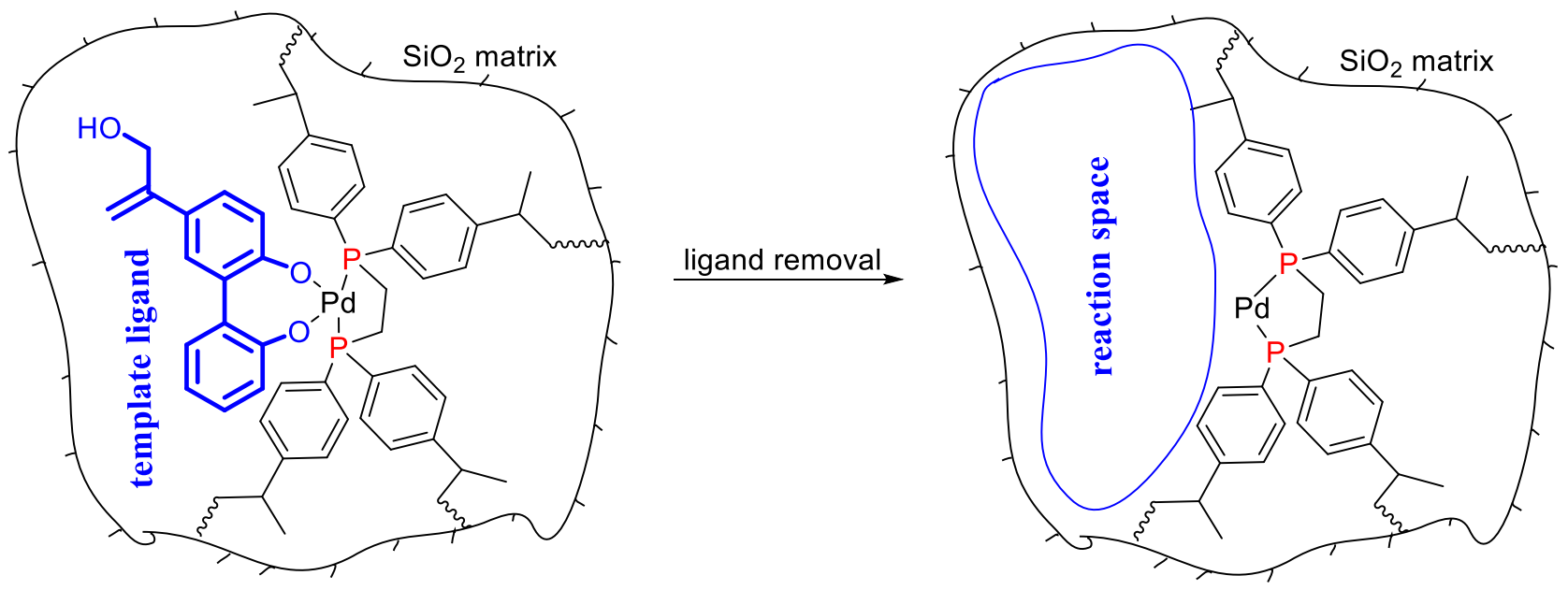

Scheme 19. Phosphine-polymeric palladium complex immobilized on the surface of silica.

Trzeciak et al. prepared two immobilized palladium catalysts on polysiloxane supports bonded to imidazole [49a] and 1,2,3-triazole [49b] heterocycles (Chart 6). Both catalysts gave quantitative yields in the reaction of $o$-bromotoluene with phenylboronic acid for $3 \mathrm{~h}$ and $1 \mathrm{~h}$, respectively, at 60 ${ }^{\circ} \mathrm{C}$ in aqueous isopropanol. Although both catalysts were reusable, the triazole-based one showed larger recycling capability (nine vs. six cycles). The yields were high for aryl bromides with electron-donating substituents (e.g., 4-Me, 2-OMe) but poor for those with the electronwithdrawing groups (e.g., 2-CHO, 2-Ac). The mercury and hot filtration tests pointed to a homogeneous pathway through palladium leaching.

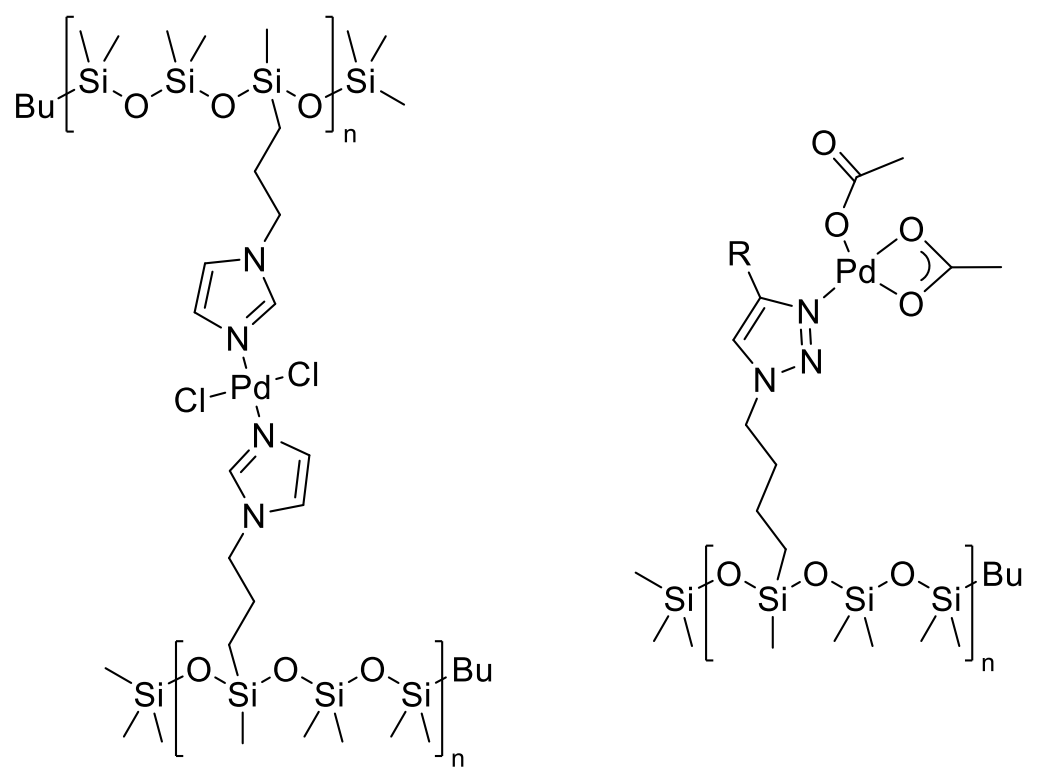

Chart 6. Palladium catalysts immobilized on polysiloxane supports.

Karimi et al. obtained NHC-based organometallic polymers with the palladium cation being located in the main polymeric chain [50]. This kind of self-supported catalyst was able to catalyze the cross-coupling of aryl chlorides and arylboronic acids in water at low palladium concentration (Scheme 20). The high activity of the catalyst was partly explained in terms of the hydrophobic substrates being concentrated in the lipophilic areas of the polymer in the aqueous medium. The catalyst was reused in seven cycles with a slight progressive decrease in activity. 


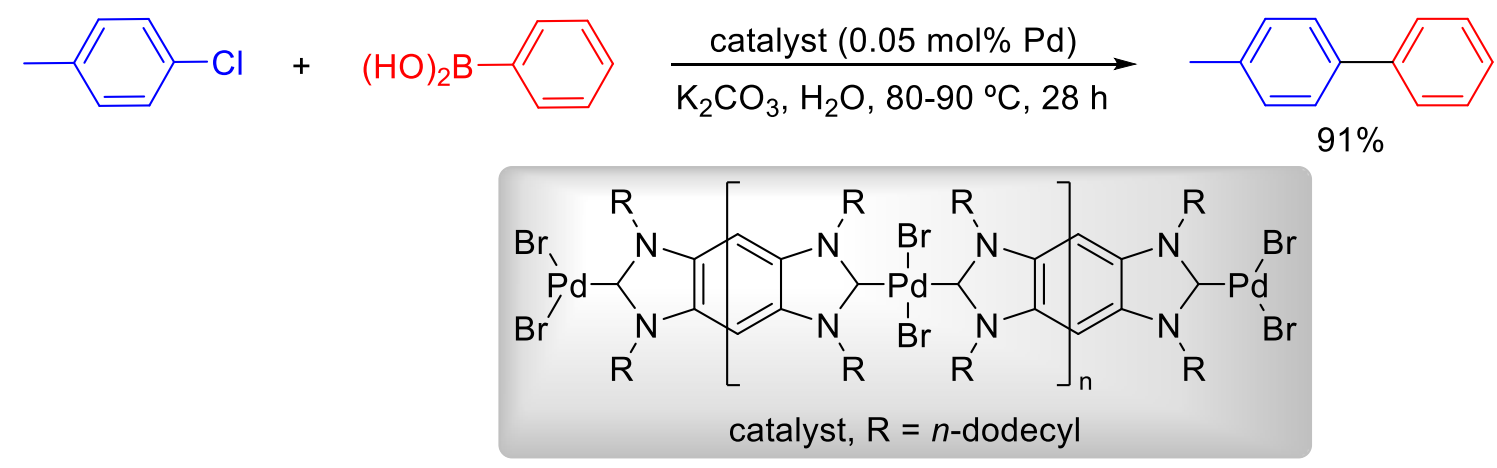

Scheme 20. Suzuki-Miyaura reaction catalyzed by a NHC-based organometallic polymer.

In recent years, covalent organic frameworks (COFs) have emerged as novel alternative supports to insoluble cross-linked polymers. These macromolecular substances are porous crystals consisting of ordered two- or three-dimensional polymer networks, thus representing organic analogues of zeolites. Such materials are usually synthesized by polycondensation of polyfunctionalized molecules; for instance, COF-LZU1, possessing a graphite-like layered hexagonal structure, was obtained by the interaction of 1,3,5-triformylbenzene with 1,4-phenylenediamine (Scheme 21) [51]. In this framework, the linking imino groups can coordinate metal cations, and that is why the treatment of the material with palladium acetate led to the adsorption of palladium inside the pores. With the resulting catalyst, the reaction of phenylboronic acid with aryl iodides and bromides was successfully performed in $p$-xylene, but at a relatively high temperature $150{ }^{\circ} \mathrm{C}$. The yield in the reaction of phenylboronic acid with $p$-nitrobromobenzene remained constant at $97 \%$ in four consecutive cycles (Scheme 21). 


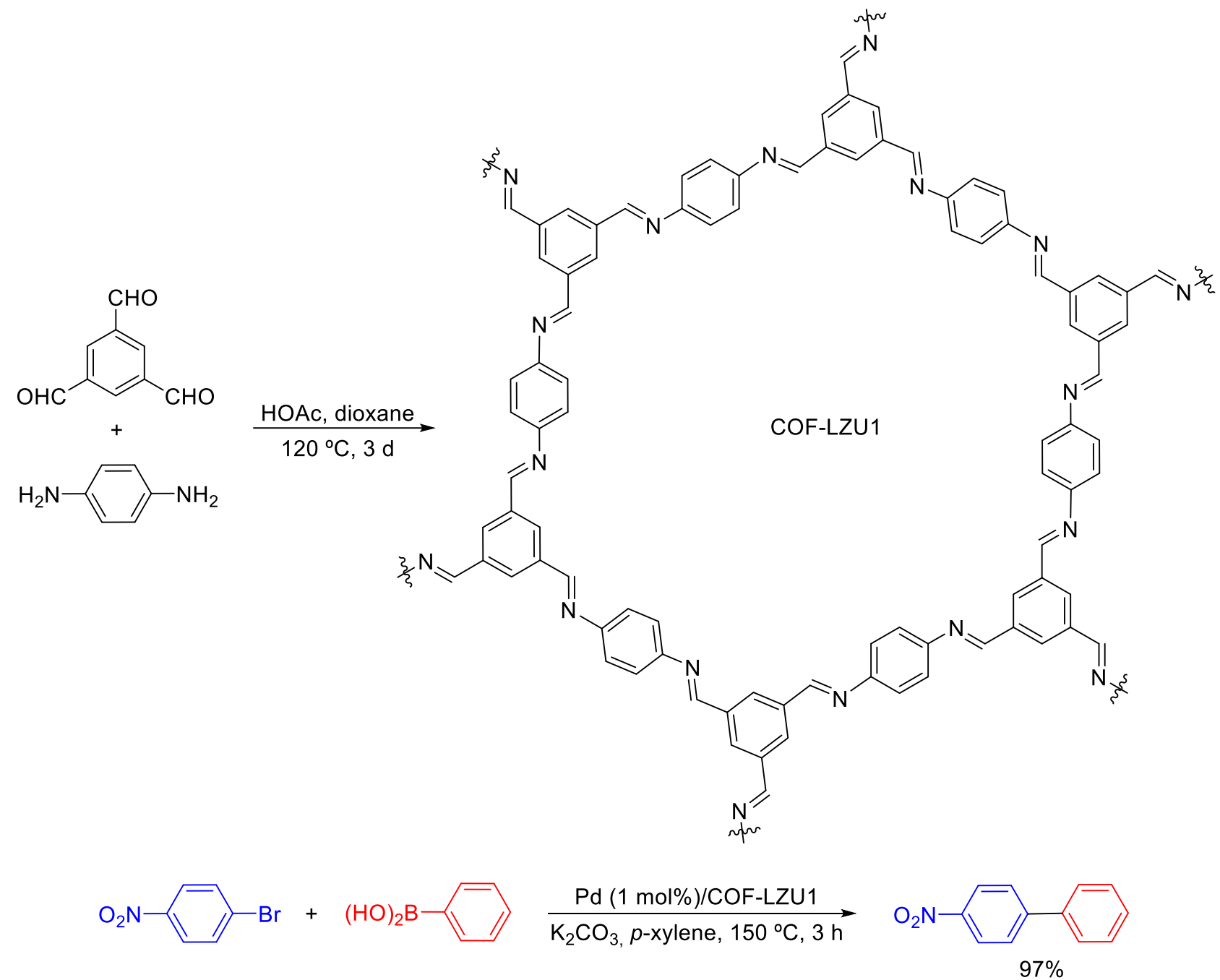

Scheme 21. Suzuki-Miyaura reaction catalyzed by COF-LZU1.

The tetrahedral structure of the node tetra(4-aminophenyl)methane, when condensed with terephthalic aldehyde, led to a diamond-like structure of the COF-300 framework (Scheme 22) [52]. During palladium(II) acetate adsorption in COF-300, palladium cations are coordinated by the imino groups. The resulting material catalyzed the reaction of various boronic acids with aryl bromides and iodides in aqueous methanol at $70{ }^{\circ} \mathrm{C}$ (Scheme 23). The catalyst was much more active than COF-LZU1, with TOF $=3,000 \mathrm{~h}^{-1}$. The TEM analysis of the catalyst after the reaction revealed the presence of PdNPs of $5 \mathrm{~nm}$ size. The catalyst activity in the reaction of phenylboronic acid and bromobenzene remained constant in five cycles. The hot filtration test was negative with a palladium concentration in the product of $85 \mathrm{ppb}$. The authors believe that palladium was effectively coordinated inside the pores, what prevented its leaching into the solution. 


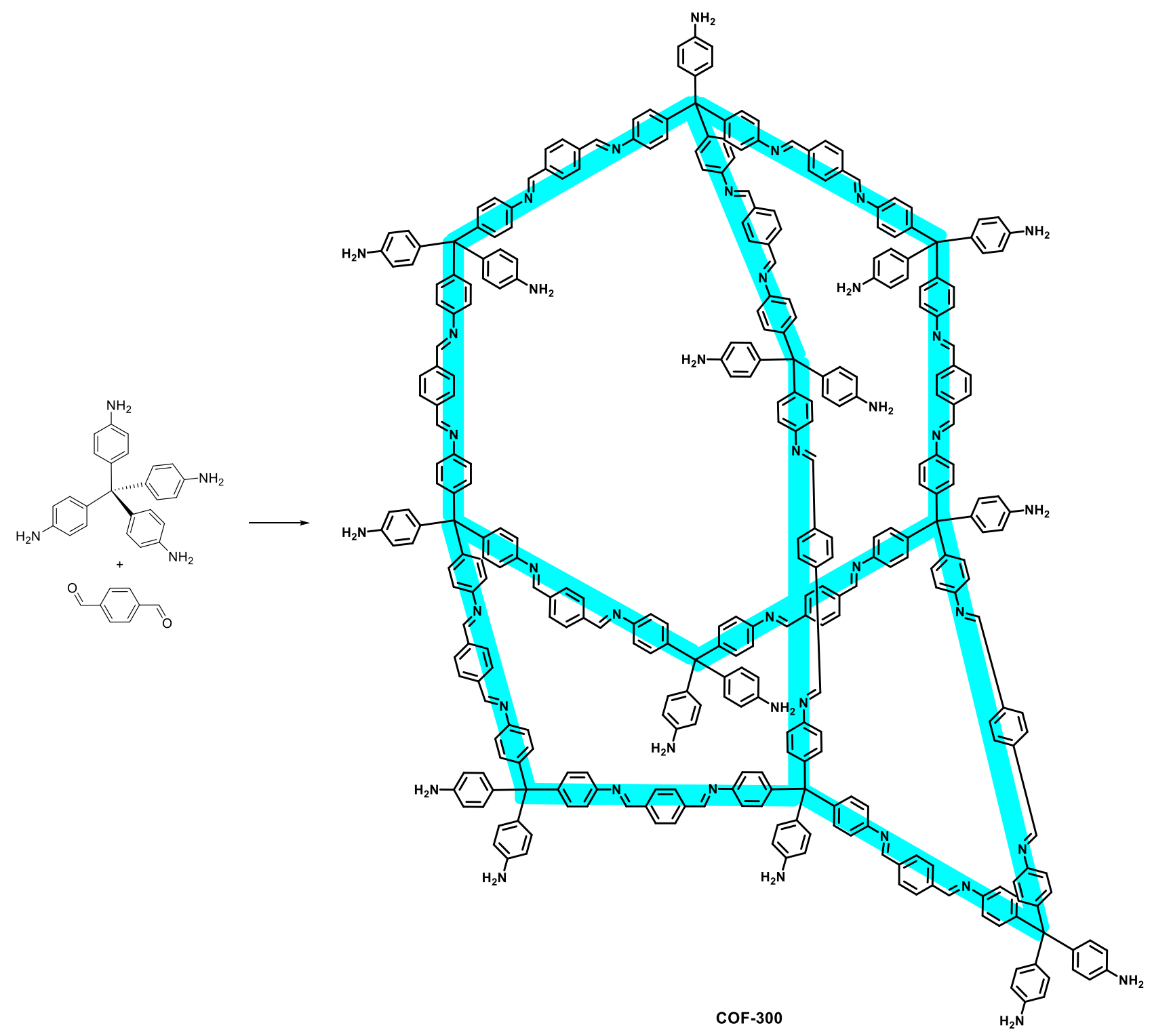

Scheme 22. Synthesis of COF-300.
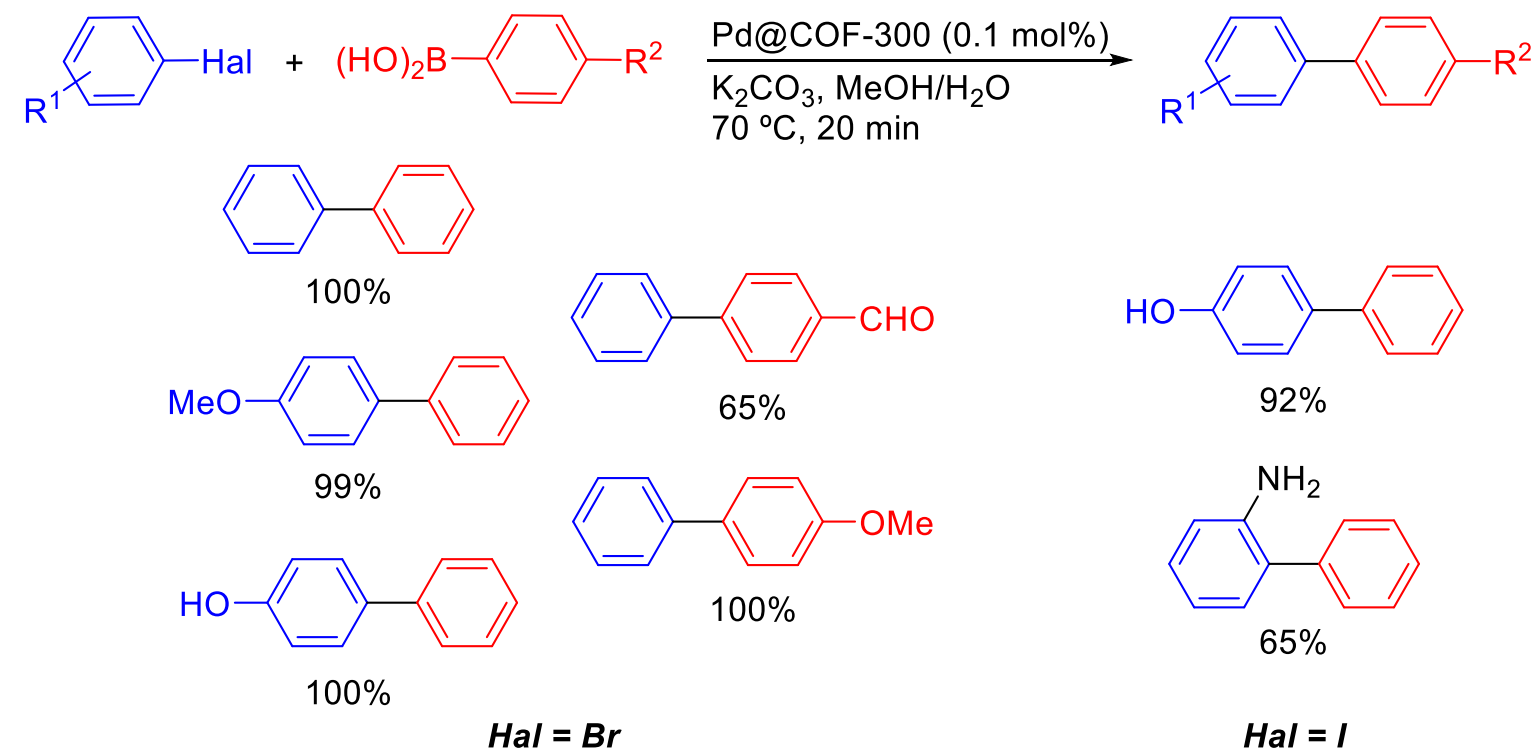

$\mathrm{Hal}=\mathrm{Br}$

$H a I=I$

Scheme 23. Suzuki-Miyaura reaction catalyzed by Pd@COF-300. 
The heterobimetallic framework $\mathrm{Pd} / \mathrm{Y}-\mathrm{MOF}$, obtained from $\mathrm{K}_{2} \mathrm{PdCl}_{4}$, 2,2'-bipyridyl-5,5'dicarboxylic acid and $\mathrm{Y}\left(\mathrm{NO}_{3}\right)_{3} \cdot 6 \mathrm{H}_{2} \mathrm{O}$, was active in the Suzuki-Miyaura reaction in water at $80{ }^{\circ} \mathrm{C}$. Unfortunately, a sharp decrease in the yield was recorded when going from iodobenzene, through bromobenzene to chlorobenzene (Scheme 24) [53]. In the case of iodobenzene, the authors demonstrated the possibility of catalyst recycling in five runs with little decrease in the yield (96$82 \%)$. XPS analysis of the catalyst before and after the reaction revealed the presence of only $\mathrm{Pd}(\mathrm{II})$. The authors suggested that the air oxygen oxidized the $\mathrm{Pd}(0)$ produced during the reaction back to $\mathrm{Pd}(\mathrm{II})$, with the coordination to the bipyridyl groups preventing palladium leaching and, hence, the formation of PdNPs. The hot filtration test, the solid-phase poisoning test with poly(4vinylpyridine) to scavenge dissolved palladium and three-phase test with immobilized 4iodoacetophenone, confirmed the heterogeneous nature of the catalysis.
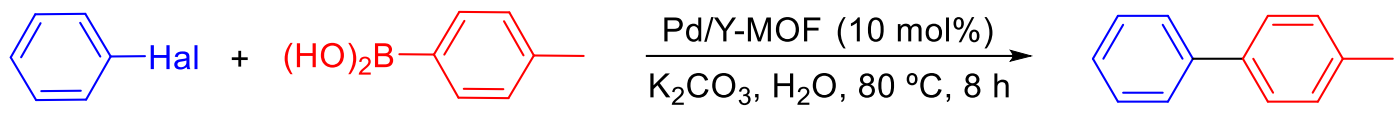

$$
\begin{array}{ll}
\mathrm{Hal}=\mathrm{I} & 96 \% \\
\mathrm{Hal}=\mathrm{Br} & 59 \% \\
\mathrm{Hal}=\mathrm{Cl} & 22 \%(\text { TBAB, } 12 \mathrm{~h})
\end{array}
$$

Scheme 24. Suzuki-Miyaura reaction catalyzed by Pd/Y-MOF.

$\mathrm{Li}$ et al. immobilized the palladium complex $\mathrm{Pd}\left(\mathrm{H}_{2}\right.$ bpydc $) \mathrm{Cl}_{2}\left(\mathrm{H}_{2}\right.$ bpydc $=2,2^{\prime}$-bipyridine-5,5'dicarboxylic acid) on the porous metal-organic framework UiO-67, $\mathrm{Zr}_{6} \mathrm{O}_{4}(\mathrm{OH})_{4}(\mathrm{bpdc})_{6}(\mathrm{bpdc}=$ para-biphenyldicarboxylate) [54]. The resulting material was an efficient catalyst for the SuzukiMiyaura reaction with aryl chlorides, being capable to catalyze the reaction of even deactivated 2methoxychlorobenzene at $120{ }^{\circ} \mathrm{C}$ (Scheme 25). Furthermore, the catalyst could be recovered and reused in five cycles with no apparent loss of activity.
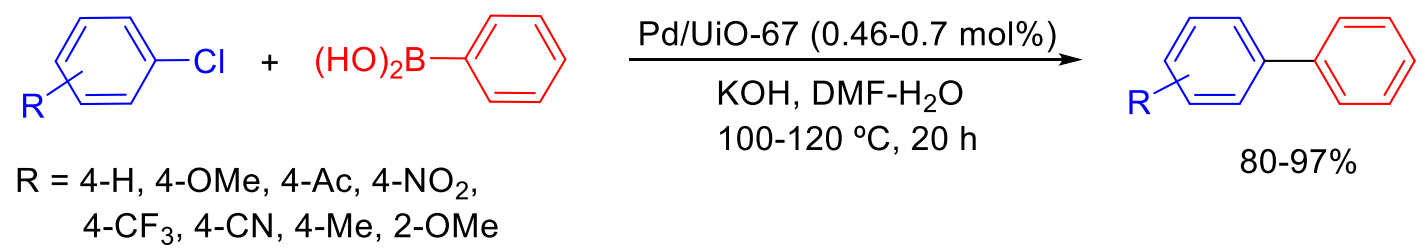

Scheme 25. Suzuki-Miyaura reaction catalyzed by Pd/UiO-67.

Nagai and Goto introduced a $\mathrm{Pd}(\mathrm{II})$ complex with melamine cyanurate (Pd/M-CA) as a catalyst for the Suzuki-Miyaura reaction [55]. At the optimized conditions $\left(\mathrm{EtOH}-\mathrm{H}_{2} \mathrm{O}, \mathrm{K}_{2} \mathrm{CO}_{3}\right)$, the reaction of aryl iodides with arylboronic acids proceeded at room temperature in high yields; the reaction of aryl bromides needed warming at $80{ }^{\circ} \mathrm{C}$, as well as the reaction of aryl iodides with $p$ (trifluoromethyl)phenylboronic acid (Scheme 26). The catalyst was reused in six cycles with a slight decrease in the yield. The preliminary reduction of $\mathrm{Pd}(\mathrm{II})$ to $\mathrm{Pd}(0)$ resulted in increased activity, allowing to diminish the catalyst loading to reach significantly higher TONs $=17,600$ and TOFs $=880 \mathrm{~h}^{-1}$.

$$
\begin{aligned}
& \mathrm{R}^{1}-(\mathrm{HO})_{2} \mathrm{~B} \\
& \mathrm{Hal}=\mathrm{I}, \mathrm{Br} \\
& \mathrm{R}^{1}=\mathrm{H}, \mathrm{Me}, \mathrm{OMe}, \mathrm{NO}_{2} \\
& \mathrm{R}^{2}=\mathrm{H}, 2-\mathrm{Me}, 4-\mathrm{Me}, 4-\mathrm{CF}_{3}
\end{aligned}
$$

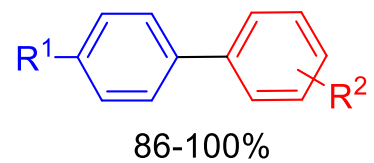

Scheme 26. Suzuki-Miyaura reaction catalyzed by melamine-cyanurate Pd complex. 


\section{Palladium nanoparticles}

Catalysis involving nanoparticles is, undoubtedly, a remarkable phenomenon because PdNPs allow to carry out reactions meeting the requirements of "Green Chemistry" (i.e., under mild conditions, without ligands and with the possibility of catalyst recycling) [56a, 56b] at the same time that a high product yield can be attained. However, the mechanism of these reactions is a matter of hot and continuous discussion because of the often dilemma to assign the heterogeneous or homogeneous nature of the process [56c]. Typically, catalysts that can be recycled several times with a constant yield are said to be "truly" heterogeneous, in spite of the fact that, very frequently, the progressive longer reaction time required in consecutive cycles is not indicated. Particle size and morphology comparative data before and after the reaction are also seldom presented. In some other cases, it is assumed that nanoparticles act as a reservoir for the formation of homogeneous species that leach into the solution. There is abundant literature supporting the leaching effect when the SuzukiMiyaura reaction is implemented using immobilized PdNPs [57]. Anyhow, this fact does not exclude the possibility of "partial" heterogeneous catalysis, though it can be very difficult to prove this option unambiguously. Therefore, let the matter rest and follow the proposal by El-Sayed et al.: "As long as we do not want to determine the exact mechanism(s), we can enjoy their high degree of freedom in catalysis" [58].

Given the large number of articles and reviews published on this subject, it is obvious that a universal catalyst has not been found and that there is no single mechanism for PdNPs-catalyzed cross-coupling reactions. In this context, it is worthwhile mentioning briefly some pioneering contributions from our group. In the application of PdNPs, we were primarily interested in reactions catalyzed by ligandless palladium [59], under mild conditions, in water [59a, 60], at low (homeopathic) palladium concentrations [19], with low-active aryl chloride-type substrates [61] and, most importantly, with the possibility of easy separation and reuse without any noticeable loss of the catalytic activity in several cycles [62].

Under homogeneous catalysis, as well as with immobilized palladium complexes, the complexes can dissociate to form atomic palladium, which, in turn, can aggregate in PdNPs. This event happens rapid in cases where the ligands do not strongly retain zero-valent palladium. Ligandless catalysis was investigated with simple palladium salts in order to avoid the use of expensive and toxic phosphine ligands; these salts led to PdNPs during the reduction, carried out in advance by reductants or in situ by the organoboron compound during the reaction. In this way, PdNPs have become an alternative to traditional palladium phosphine complexes, widely used in the last decade. Some PdNPs have been prepared with such a high activity that is comparable to that of the best phosphine palladium complexes, capable to catalyze the cross-coupling of deactivated electron-rich aryl chlorides (e.g., chloroanisole) with arylboronic acids.

The stabilization of the PdNPs can be accomplished by compounds with the ability to be adsorbed on the surface of the nanoparticles, thereby forming a protective layer that prevents their aggregation: surfactants, quaternary ammonium and phosphonium salts, and various ligands have been used as stabilizers. In 1994, Reetz et al. reported a simple way to obtain PdNPs of the desired size, stabilized by tetraoctylammonium bromide [63a]. Later on, in 1996, the possibility of using such PdNPs as catalysts for the Suzuki-Miyaura and Heck reactions was demonstrated for the first time [63b]. PdNPs can be also stabilized on different supports, either inorganic or organic, with this representing a growing research area in heterogeneous catalysis [64]. A range of parameters have been varied for the preparation of PdNPs in the search for stable and active catalysts; among them, the proper choice of the support is of paramount importance. Supports can be generally classified in organic, e.g., polymers [65], dendrimers [66], biomolecules [67]; inorganic, e.g., metal oxides [68], 
carbon materials [69]; and hybrid organic-inorganic materials, including metal organic frameworks [70], coordination polymers [71] and organic ligands attached to inorganic matrices [72].

\subsection{Unsupported nanoparticles}

Ganapathy and Sekar reported the biradical binaphthyl as an unusual stabilizer. This biradical formed a covalent bond with the palladium-atom surface in PdNPs (Scheme 27). These PdNPs catalyzed the reaction of aryl iodides and some aryl bromides with phenylboronic acid at room temperature, using $1 \mathrm{~mol} \%$ catalyst and $\mathrm{KF}$ in toluene-water (12-48 h, 65-97\% yield) [73]. The PdNPs were recovered by centrifugation and reused in three cycles with a yield that was consistent with the percentage of catalyst recovered (95-91\%).

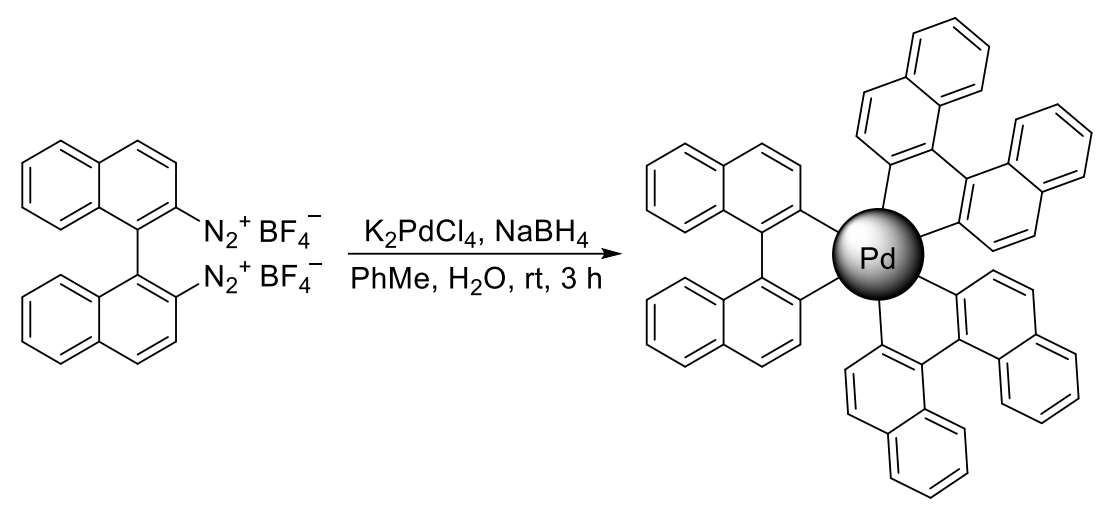

Scheme 27. Biradical binaphthyl-stabilized PdNPs.

Saikia et al. [74a] demonstrated that simple sucrose could be used as a PdNPs stabilizer. The Suzuki reaction of a wide range of substituted aryl and heteroaryl bromides with various arylboronic acids was effected in water at room temperature. After product separation by ether extraction, the aqueous phase containing the catalyst was reused in five cycles in the reaction of 4-bromoanisole and phenylboronic acid (Scheme 28). These authors also suggested the usage of urea as PdNPs stabilizer [74b]. In this way, diverse substituted aryl bromides rapidly reacted with arylboronic acids in isopropanol-water at room temperature (10-30 $\mathrm{min})$. The reaction of the sterically hindered $o$-dimethylbromobenzene and $o$-methylphenylboronic acid led to $90 \%$ product under these conditions (Scheme 29). Moreover, even aryl chlorides reacted when the temperature was raised to $100{ }^{\circ} \mathrm{C}$.

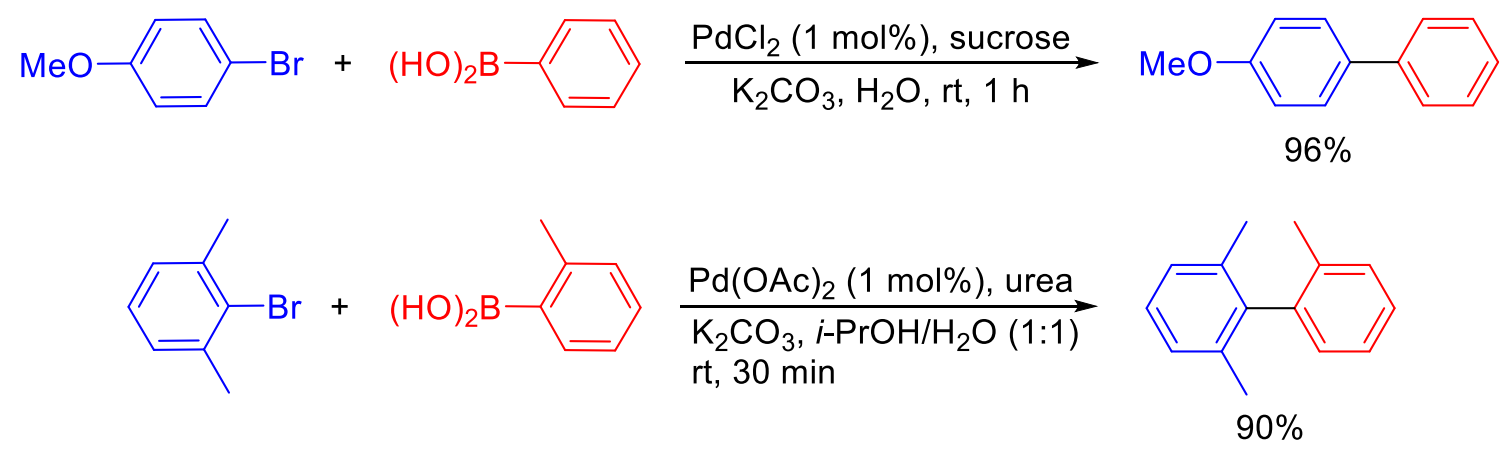

Scheme 28. Suzuki-Miyaura reactions catalyzed by sucrose-stabilized PdNPs.

Reduction of $\mathrm{Na}_{2} \mathrm{PdCl}_{4}$ with ascorbic acid in the presence of the surfactant hexadecylpyridinium chloride, in water, led to the production of a porous nanostructured palladium powder with perpendicular pore channels and ultrathin branches. This nanosized palladium catalyzed the reaction of iodobenzene and phenylboronic acid at $60{ }^{\circ} \mathrm{C}$ in aqueous ethanol with TOF $\sim 140 \mathrm{~h}^{-1}$ [75]. This catalyst outperformed the activity of Pd black and showed good recyclability in six cycles. 
Didicosyl selenide, $\mathrm{Se}\left(\mathrm{C}_{22} \mathrm{H}_{45}\right)_{2}$, was the first selenium ligand deployed to stabilize PdNPs (3-5 $\mathrm{nm}$ ). The catalyst was proven to be efficient and recyclable (five cycles) in the cross-coupling of arylboronic acids with aryl chlorides and aryl bromides (Scheme 29); the former were reluctant to react whereas the latter reacted in relatively short reaction times $(20-90 \mathrm{~min})$ in the first cycle [76].

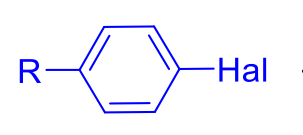

$\mathrm{Hal}=\mathrm{Br}, \mathrm{Cl}$

$\mathrm{R}=\mathrm{Me}, \mathrm{OMe}, \mathrm{CHO}$

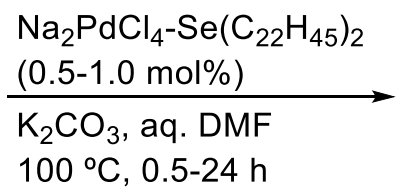

$100^{\circ} \mathrm{C}, 0.5-24 \mathrm{~h}$

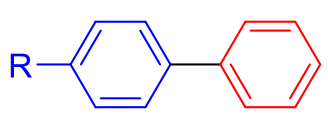

$32-100 \%$

conversion

Scheme 29. Suzuki-Miyaura reaction catalyzed by selenium-ligand stabilized PdNPs.

In continuation of the study on reactions catalyzed by ligandless palladium in aqueous media, Liu et al. published an article demonstrating the significant effect of oxygen and water in such reactions [77]. The effect of oxygen was negative in non-aqueous media, whereas the addition of a small amount of water to the pure organic solvent switched the oxygen-inhibited process to the oxygenpromoted one. The reaction of $p$-bromoanisole and phenylboronic acid catalyzed by $\mathrm{PdCl}_{2}$ in $50 \%$ aqueous ethanol was compared in different atmospheres (Scheme 30). The corresponding biaryl was produced in $100 \%$ yield in the open vessel while the yield dropped in oxygen-free atmospheres $\left(\mathrm{N}_{2}, \mathrm{H}_{2}, \mathrm{CO}_{2}\right.$ and $\left.\mathrm{CO}\right)$. Even a stronger effect of oxygen was noticed with pre-synthesized PdNPs $(10 \mathrm{~nm})$, which were practically inactive in an inert medium (Scheme 30) [78]. Apparently, the presence of oxygen promoted the activation of the aggregated catalyst by dissolving large palladium particles through the oxidation of $\operatorname{Pd}(0)$ to $\operatorname{Pd}(\mathrm{II})$.

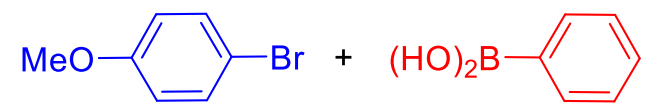

$\underset{50 \% \mathrm{EtOH}, 25^{\circ} \mathrm{C}, 30 \mathrm{~min}}{\stackrel{\mathrm{PdCl}_{2}(0.5 \mathrm{~mol} \%), \mathrm{K}_{2} \mathrm{CO}_{3}}{\longrightarrow}}$

$$
50 \% \mathrm{EtOH}, 25^{\circ} \mathrm{C}, 30 \mathrm{~min}
$$

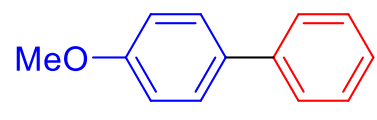

open air $100 \%$

$\mathrm{N}_{2} \quad 72 \%$

$\mathrm{H}_{2} \quad 49 \%$

$\mathrm{CO}_{2} \quad 12 \%$

$\mathrm{CO} \quad 0 \%$

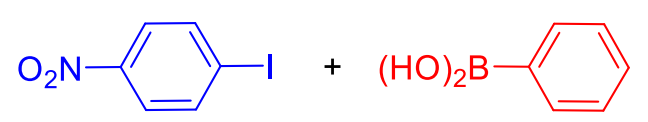

$\underset{\text { PdNPs }(0.3 \mathrm{~mol} \%), \mathrm{K}_{3} \mathrm{PO}_{4}}{\longrightarrow}$

i-PrOH $\left(50^{\circ} \mathrm{C}\right) 5 \mathrm{~h}$

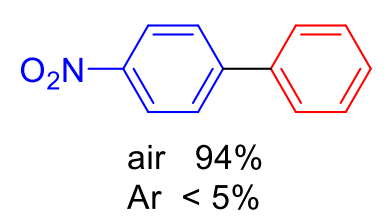

Scheme 30. Atmosphere effect in Suzuki-Miyaura reactions catalyzed by PdNPs.

The influence of the size and shape of PdNPs on the catalytic activity, stability and recyclability has been widely discussed in the literature [79]. Considerable attention has also been paid to the mechanism of these reactions [79d, 80], though it is difficult to compare different studies due to the variety of experimental conditions [7, 78, 81]. Catalysis by PdNPs has caused a lively discussion about its heterogeneous or homogeneous nature, because of the palladium leaching occurring during the oxidative addition to form "ArPdX" species. Proponents of the heterogeneous mechanism substantiated it on experiments where the catalyst recycling did not lead to a loss of the reaction product yield over the same time, with both the structure and size of the PdNPs remaining unchanged after the reaction. However, many researchers in the Suzuki-Miyaura and Heck reactions reported that the product yield fell as the number of cycles increased, the reaction time was longer and the size of the obtained PdNPs changed after the reaction. 
Amatore et al. shed some light on the nature of the PdNPs-catalyzed Suzuki-Miyaura reaction, in water at room temperature, using Au-Pd core-shell nanoparticles ( $\mathrm{Au} @ \mathrm{Pd}$ ) [82]. The presence of the gold nucleus allowed to carry out a precise study of the palladium surface through highly sensitive Raman spectroscopy and cyclic voltamperometry. The study was conducted for the coupling of $p-\mathrm{MeOC}_{6} \mathrm{H}_{4} \mathrm{Br}$ and $\mathrm{PhB}(\mathrm{OH})_{2}$ (Scheme 31). Both methods proved the existence of palladium leaching that was attributed to the synergistic action of $\mathrm{K}_{2} \mathrm{CO}_{3}$ and $\mathrm{PhB}(\mathrm{OH})_{2}$, instead of to the oxidative addition by the aryl halide. Equally surprising was the fact that the authors found no direct relationship between the half-reaction time and the quantity of dissolved palladium, indicating that not all the leached palladium was involved in the catalytic process.

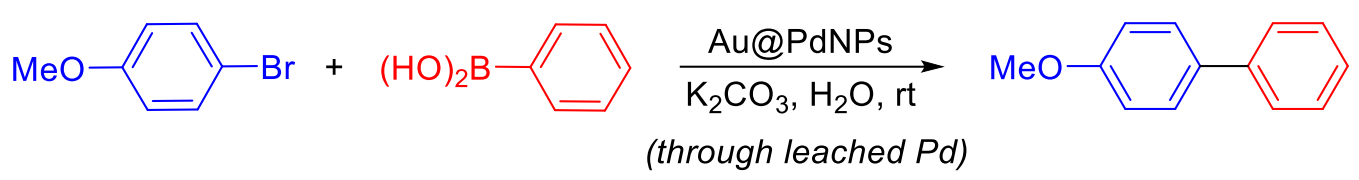

Scheme 31. Suzuki-Miyaura reaction catalyzed by Au-Pd core-shell NPs.

Corma et al. investigated the activity of palladium clusters, formed from several precursors under heating in $N$-methylpyrrolidin-2-one (NMP), in the Suzuki-Miyaura and other cross-coupling reactions [83]. $\mathrm{Pd}_{3}$ and $\mathrm{Pd}_{4}$ clusters were found to be the most active ones, as demonstrated by the high TOFs achieved at the outset of the reaction of $p$-bromoacetophenone and phenylboronic acid (Scheme 32).
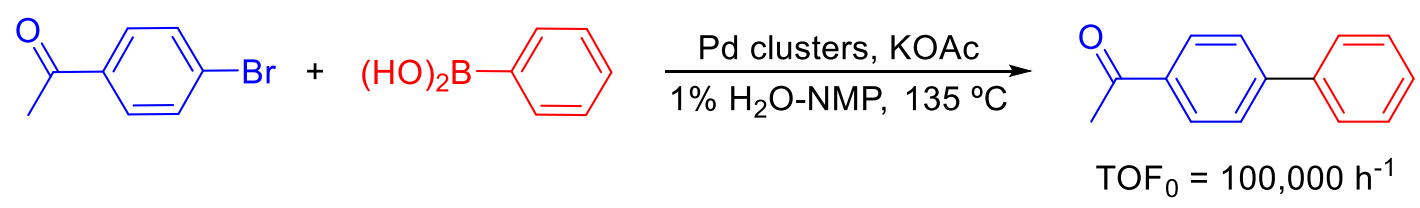

Scheme 32. Suzuki-Miyaura reaction catalyzed by Pd clusters.

\subsection{Supported nanoparticles}

\subsubsection{Polymers}

Polymers without functional groups, such as polystyrene (PS), are weakly coordinating supports for metal nanoparticles. Ohtaka and Nomura et al. prepared 2-3 nm PdNPs immobilized on polystyrene by heating an aqueous solution of palladium(II) acetate in the presence of $\mathrm{K}_{2} \mathrm{CO}_{3}$ [84]. This material catalyzed the reaction of $p$-tolylboronic and $p$-acetylboronic acids with arylbromides, in water at 80 ${ }^{\circ} \mathrm{C}$ for $1 \mathrm{~h}$ (89-99\% yield); high yield was also recorded for $p$-chloroacetophenone, though required longer heating $(12 \mathrm{~h})$ (Scheme 33). The catalyst retained its high activity in ten cycles in the reaction with bromobenzene and $p$-tolylboronic.
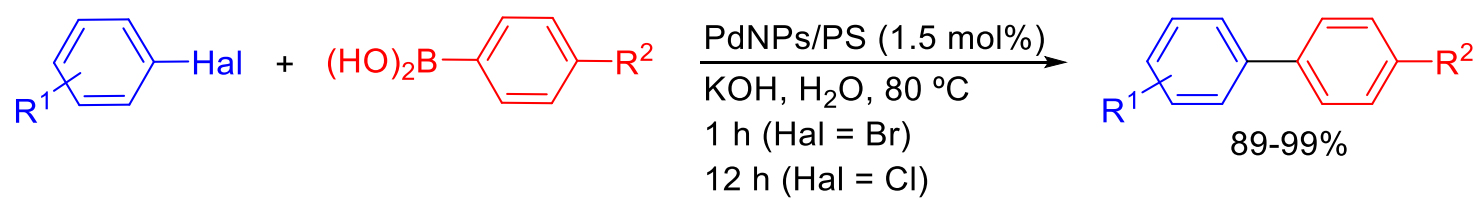

$$
\begin{aligned}
& \mathrm{Hal}=\mathrm{Br} ; \mathrm{R}^{1}=\mathrm{H}, 4-\mathrm{Ac}, 4-\mathrm{CF}_{3}, 4-\mathrm{Me}, 4-\mathrm{OMe}, 2-\mathrm{Me} ; \mathrm{R}^{2}=\mathrm{Me}, \mathrm{Ac} \\
& \mathrm{Hal}=\mathrm{Cl} ; \mathrm{R}^{1}=4-\mathrm{Ac} ; \mathrm{R}^{2}=\mathrm{Me}
\end{aligned}
$$

Scheme 33. Suzuki-Miyaura reaction catalyzed by polystyrene-immobilized PdNPs.

Ye et al. effectively encapsulated $\mathrm{Pd}$ in the cavities of partially cross-linked poly(1,3diethynylbenzene) (PDEB) obtained by palladium-catalyzed polymerization of 1,3-ethynylbenzene (Scheme 34) [85]. The authors suggested that the remaining free acetylene groups could interact 
with palladium. This Pd@PDEB system reached among the highest TONs $\left(0.8-100 \times 10^{4}\right)$ and TOFs $\left(0.02-10 \times 10^{4} \mathrm{~h}^{-1}\right)$ recorded for heterogeneously catalyzed Suzuki-Miyaura reactions, including deactivated aryl chlorides. The catalyst was reused in eleven cycles with a slight decrease in the conversion (99-85\%). The formation of $\mathrm{Pd}(0) \mathrm{NPs}$ was observed upon catalyst reuse, with a possible $\mathrm{Pd}$ dissolution/re-deposition process operating in these reactions.
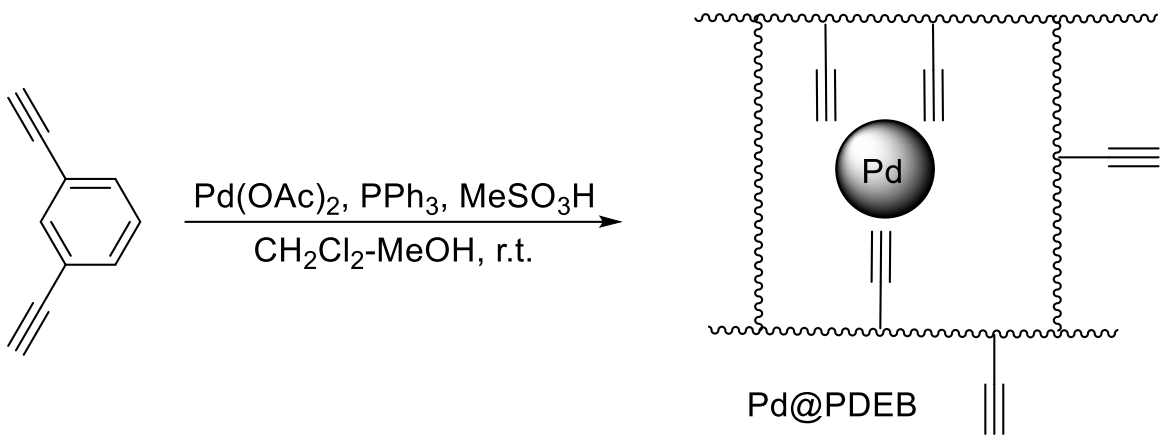

Scheme 34. Synthesis of PdNPs encapsulated in cross-linked poly(1,3-diethynylbenzene).

High activity was observed for catalysts supported on conductive polymers, which expanded conjugated electronic system can significantly affect the energy levels of palladium atoms in PdNPs. In a leading study, palladium immobilized on polyaniline (Pd/PANI) revealed excellent catalytic properties in the Suzuki-Miyaura reaction of aryl bromides, aryl chlorides and even aryl fluorides [86]. Taking also into account the constant activity during recycling, this catalytic system can be considered one of the most successful ones among polymer-immobilized palladium catalysts. Magdesieva et al. prepared a similar palladium composite with another conductive polymer, polypyrrole (PPy), composed of PdNPs and PPyNPs with average sizes in the ranges of 1.25-1.45 and 27-62 nm, respectively [87]. This material catalyzed the coupling of arylboronic acids and tetraarylboronates with a variety of aryl halides in NMP, though boronic acids were coupled only with bromobenzene (Scheme 35). Unfortunately, catalyst recycling was not effective.

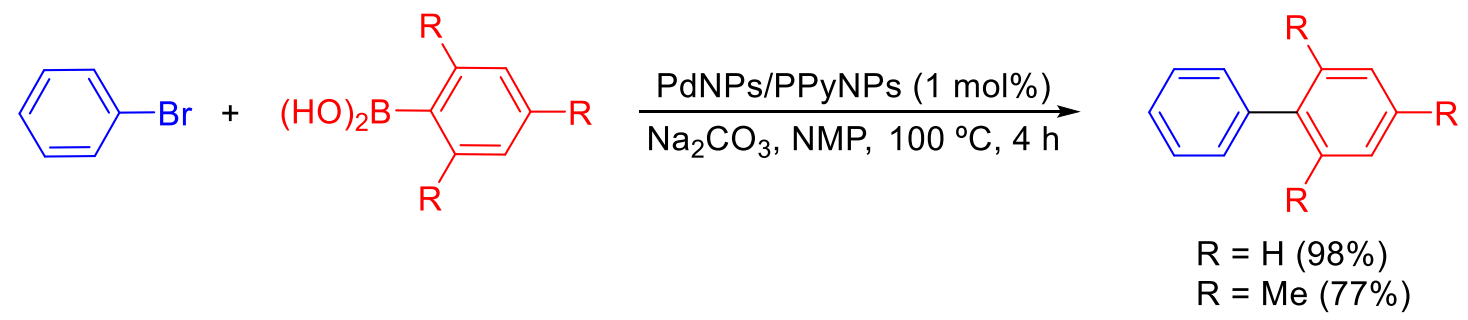

Scheme 35. Suzuki-Miyaura reaction catalyzed by PdNPs/PPyNPs.

Amphiphilic copolymers of hydrophilic $N$-vinylimidazole and hydrophobic amides, such as $N$ isopropylacrylamide and $N$-vinylcaprolactam, are so-called "smart" polymers because of their ability to change their physical and chemical properties depending on certain conditions [88]. These synthetic polymers are used to model properties of biopolymers and enzymes. A statistical copolymer containing 30\% $\mathrm{N}$-vinylimidazole and $70 \% \mathrm{~N}$-vinylcaprolactam (PVI-PVCL) was successfully utilized to immobilize PdNPs and showed excellent activity in the Suzuki-Miyaura reaction of aryl bromides bearing different types of substituents (electron-donating, electron-neutral and electron-acceptor ones) with phenylboronic acid, giving high diaryl yields (Scheme 36) [89]. Recycling of the catalyst in the reaction with $p$-bromoacetophenone gave a constant yield in eight cycles. Kinetic studies showed that more than half of the conversion was reached in the first few minutes, after which the reaction rate slowed down, taking about one hour to complete. This was explained by the fact that, under the reaction conditions, the arylboronic acid rapidly reduced $\mathrm{Pd}(\mathrm{II})$ 
to $\operatorname{Pd}(0)$ with the formation of highly active small-size PdNPs. Then, the latter gradually disappeared during the reaction, being dissolved and turning into larger and less active particles, something that was confirmed by TEM studies. The authors demonstrated that different basesolvent combinations, including $\mathrm{NaOH}-\mathrm{H}_{2} \mathrm{O}$ and $\mathrm{Et}_{3} \mathrm{~N}-\mathrm{DMF}$, led to high product yields. However, only a few of these combinations allowed catalyst recycling while maintaining the activity, with $\mathrm{K}_{2} \mathrm{CO}_{3}-\mathrm{EtOH}-\mathrm{H}_{2} \mathrm{O}$ being the best one. It must be pointed out that the reaction time had to be increased in order to get a constant yield upon recycling. This was demonstrated to be a consequence of the enlargement of the size of the PdNPs, with the concomitant decrease in activity.

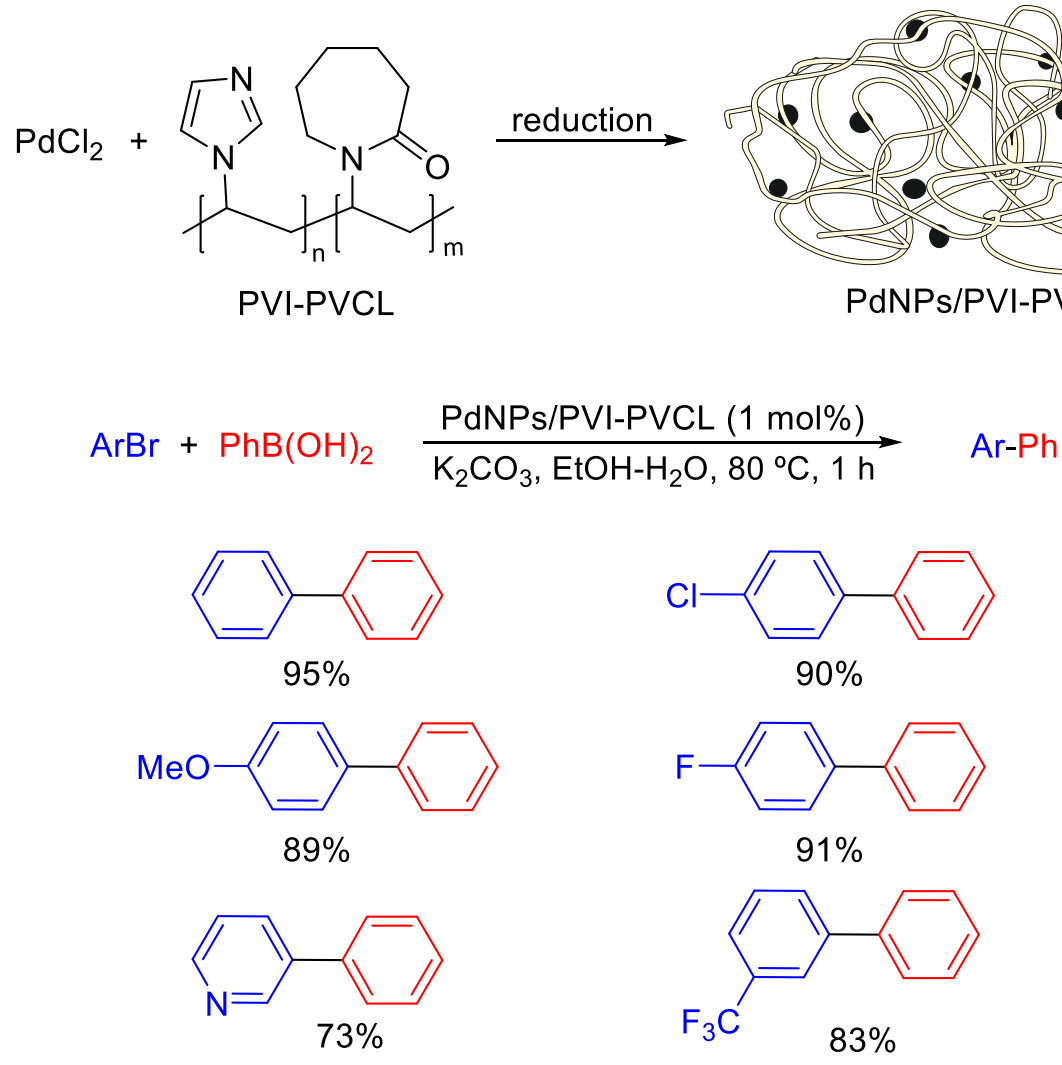

Scheme 36. Suzuki-Miyaura reaction catalyzed by PdNPs/PVI-PVCL.

The statistical copolymer of $\mathrm{N}$-vinylimidazole and $\mathrm{N}$-isopropylacrylamide P(NIPAM-co-VI), in a 1:5 ratio, was used as a support for PdNPs of $4.9 \pm 2.5 \mathrm{~nm}$ size [90a]. The resulting catalyst showed impressive activity in the Suzuki-Miyaura reaction of aryl iodides, bromides and even deactivated aryl chlorides in water at $100{ }^{\circ} \mathrm{C}$ (Scheme 37). The cross coupling of $p$-tolyl chloride with phenylboronic acid was catalyzed by $0.0066 \mathrm{~mol} \% \mathrm{Pd}$, leading to the corresponding biaryl in $96 \%$ yield after $22 \mathrm{~h}$. Remarkable TON $\left(3.6 \times 10^{6}\right)$ and TOF $\left(1.2 \times 10^{5} \mathrm{~h}^{-1}\right)$ were achieved with $p$-tolyl iodide. The catalyst was reused five times in the reaction with $p$-methoxychlorobenzene at 0.1 mol\% loading, preserving the high catalytic activity with no detectable palladium leaching.

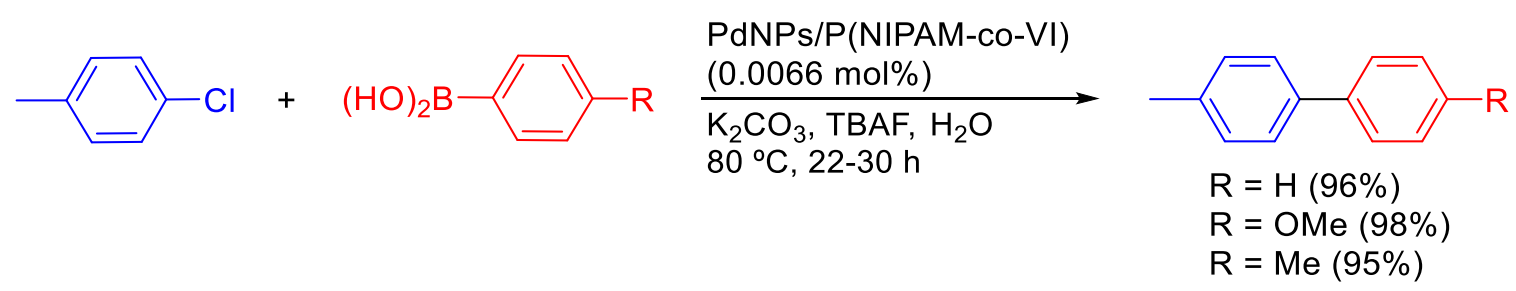

Scheme 37. Suzuki-Miyaura reaction catalyzed by PdNPs/P(NIPAM-co-VI). 
Radhakrishnan and Hariprasad conceived a very easy-to-use catalyst consisting of a poly(vinyl alcohol) (PVA) film containing 15-30 nm PdNPs, which can be simply dipped into the reaction mixture and retrieved after the reaction (Scheme 38) [91]. The leaching of palladium from the film into the solution was negligible. The catalyst was recycled thirty times in the reaction of iodobenzene and phenylboronic acid in ethanol at $80{ }^{\circ} \mathrm{C}$, using $0.06 \mathrm{~mol} \% \mathrm{Pd}$ for $1.5 \mathrm{~h}$. A slight decrease in the product yield was only observed for the last ten cycles, albeit quantitative yield of the product could be achieved in the 30th cycle by increasing the reaction time. The total TON was about 50,000, with an average TOF of $1100 \mathrm{~h}^{-1}$. However, the catalyst activity was found to be significantly lower for aryl bromides: it took $10 \mathrm{~h}$ to complete the reaction with $p$ bromomethoxybenzene $\left(\mathrm{TOF}=165 \mathrm{~h}^{-1}\right)$.

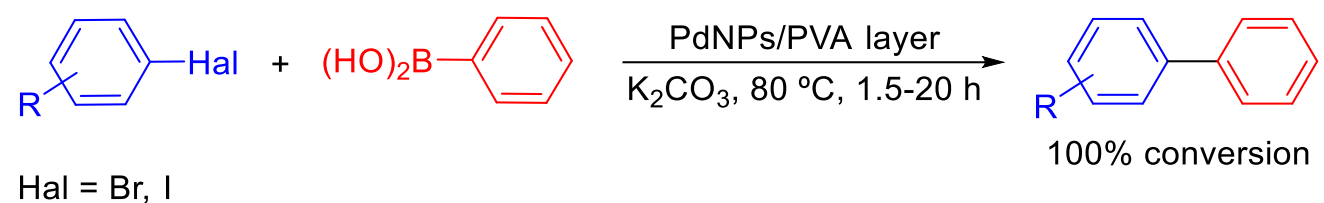

$\mathrm{R}=\mathrm{H}, 4-\mathrm{Ac}, 4-\mathrm{NO}_{2}, 4-\mathrm{NH}_{2}$, 4-Me, 4-OMe, 2-OMe

Scheme 38. Suzuki-Miyaura reaction catalyzed by PdNPs/PVA layer.

Monguchi et al. treated the commercially-available and dimethylamino-functionalized ion-exchange resin WA30 with palladium acetate, followed by reduction with hydrazine to obtain supported PdNPs of 3-20 nm [92]. The PdNPs/WA30 catalyzed the cross-coupling of aryl chlorides and arylboronic acids in $N, N$-dimethylacetamide (DMA) at $80{ }^{\circ} \mathrm{C}$ for $6-24 \mathrm{~h}$ (Scheme 39). Palladium leaching was not detected when recycling the catalyst and the PdNPs morphology was almost unchanged; that is why the yield decrease noted after each cycle was ascribed to an increase in the $\mathrm{Pd}(0) / \mathrm{Pd}(\mathrm{II})$ ratio, as proven by XPS.

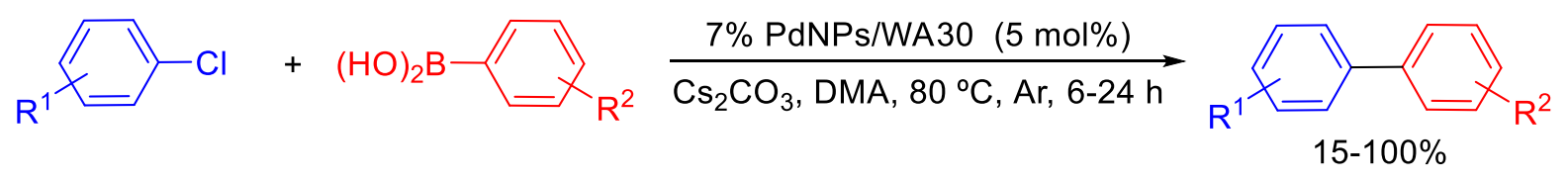

$\mathrm{R}^{1}=$ 2-Me, 3-Me, 4-Me, 2-OMe, 3-OMe, 4-OMe, 2-Ac, 3-Ac, 4-Ac, 4-CO $\mathrm{Ct}_{2}$, 4- $\mathrm{NO}_{2}$, 4-CF 3 $\mathrm{R}^{2}=\mathrm{H}, 4-\mathrm{OMe}, 4-\mathrm{Ac}$

Scheme 39. Suzuki-Miyaura reaction catalyzed by PdNPs/WA30.

De Clercq et al. compared several catalysts comprised of PdNPs on commercial macroporous ion exchange resins bearing several functional groups (thiol, sulfonic and ammonium) in the reaction of iodobenzene with phenylboronic acid in aqueous DMF [93]. It was shown that the type of functional group significantly affected the size of the PdNPs, their distribution, catalytic activity and palladium leaching. The catalyst based on Lewatit MP500 OH (ammonium-functionalized styrene-divinylbenzene copolymer) led to the highest conversion with minimum leaching (1.1\%) (Scheme 40).

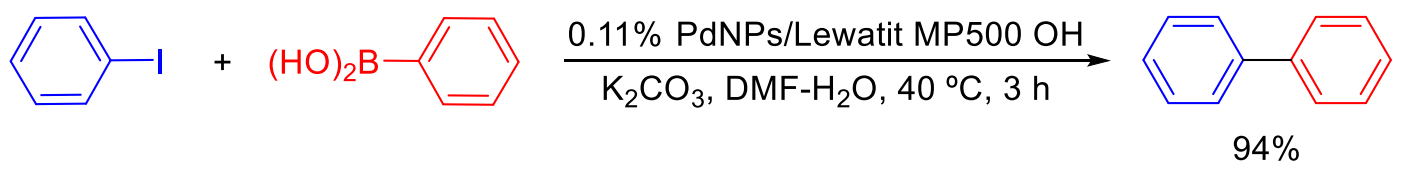

Scheme 40. Suzuki-Miyaura reaction catalyzed by PdNPs/Lewatit MP500 OH.

Albéniz et al studied polynorbornene functionalized with imidazolium groups as an appropriate support for palladium [94]. A number of polynorbornene-immobilized palladium carbene complexes were synthesized, among which, a polymer with high palladium content (8.9\%) was 
obtained (VA-PNB-Pd). Its catalytic activity was tested in the reaction of 4(trifluoromethyl)bromobenzene and phenylboronic acid (Scheme 41). The catalyst was reused in four runs giving the product in nearly quantitative yields, though the reaction time had to be increased from one run to the next one; the yield decreased to $91 \%$ in the 5 th cycle with $1.3 \%$ metal leaching. The decomposition of the immobilized carbene complex with formation of PdNPs (65 nm average size), as well as the change of the palladium structure on the polymer surface were evidenced by SEM studies. The authors proposed that the high catalytic activity (TOF $=10^{5} \mathrm{~h}^{-1}$ ) was the result of leaching homogeneous palladium.

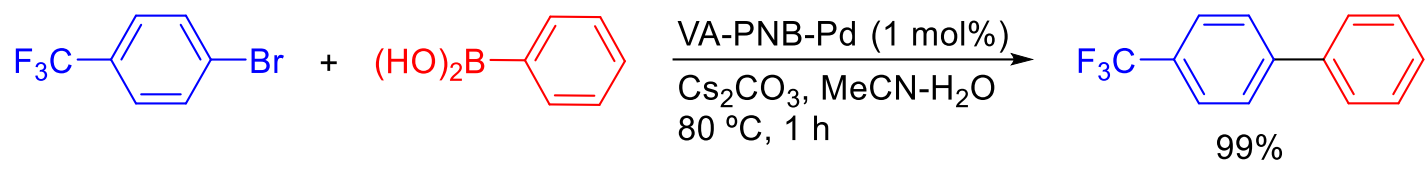

Scheme 41. Suzuki-Miyaura reaction catalyzed by VA-PNB-Pd.

Kobayashi et al. introduced a catalyst consisting of PdNPs $(2-3 \mathrm{~nm})$ immobilized on polystyrenecontaining NHC units (PICB-NHC-PdNPs), where the latter played a double role as a cross-linker and stabilizer for PdNPs (Figure 2) [95]. A wide array of biaryls were synthesized from the reaction of aryl iodides and bromides with arylboronic acids, using $0.25 \mathrm{~mol} \% \mathrm{Pd}, \mathrm{K}_{2} \mathrm{CO}_{3}$ as a base in EtOH at $80{ }^{\circ} \mathrm{C}$ for $36 \mathrm{~h}$ (30 examples, 66->99\% yield). The catalyst was reusable with no apparent loss of activity and applicable to a gram-scale synthesis.

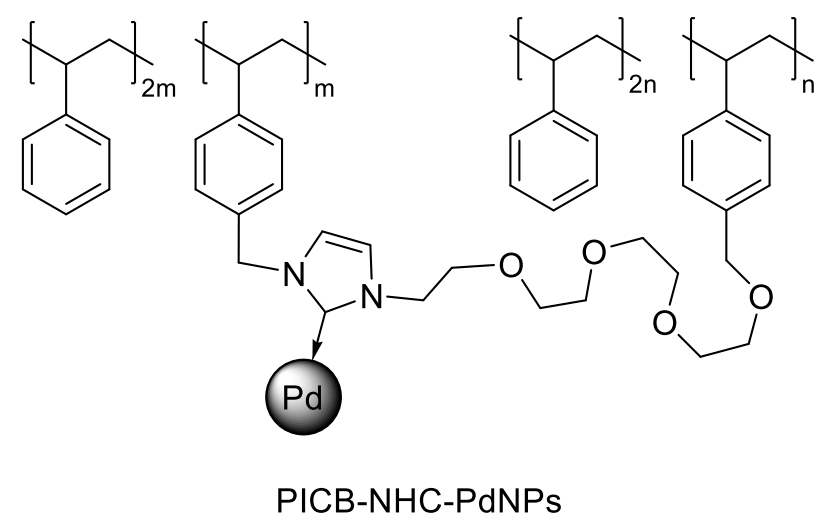

Figure 2. PdNPs immobilized on polystyrene-containing NHC units.

\subsubsection{Dendrimers}

Dendrimers can be used as alternative supports to soluble polymers for PdNPs. Their main advantage is that they have a well-defined composition and structure. Like micelles, dendrimers can serve as nanoreactors where reagents are concentrated, accelerating reactions and allowing the use of smaller amounts of catalyst.

Astruc et al. obtained remarkable results when studying the catalytic activity of small PdNPs (1-2 $\mathrm{nm}$ ) immobilized in dendrimers containing 1,2,3-triazoles that were generated through click chemistry (Scheme 42) [96]. The heterocycles had a dual function: to link the hydrophobic core to the hydrophilic crown and to coordinate cations and PdNPs. The hydrophilic dendrimer periphery provides water solubility whereas the hydrophobic core concentrates organic substrates, performing the role of nanoreactors. The PdNPs coordinated by the triazole linkers are located at the interface of the hydrophobic and hydrophilic regions. The catalyst exhibited high activity in the SuzukiMiyaura reaction of aryl chlorides, bromides and iodides, recording high TONs (up to $10^{6}$ ) and TOFs (up to $10^{4} \mathrm{~h}^{-1}$ ) for aryl bromides and iodides. 

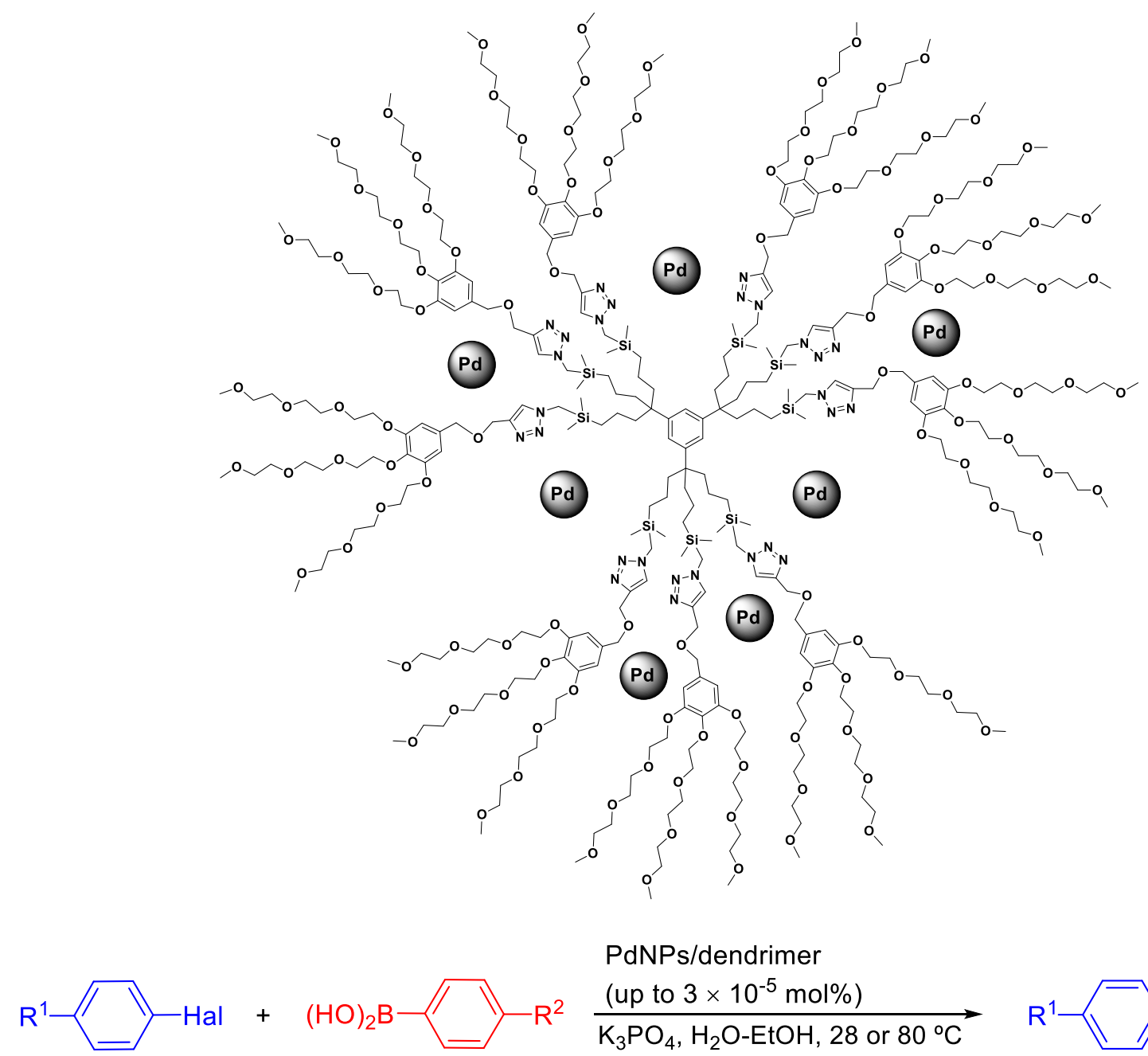

PdNPs/dendrimer

$\underset{\mathrm{K}_{3} \mathrm{PO}_{4}, \mathrm{H}_{2} \mathrm{O}-\mathrm{EtOH}, 28 \text { or } 80^{\circ} \mathrm{C}}{\longrightarrow}$

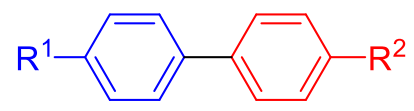

$$
\begin{aligned}
& \mathrm{Hal}=\mathrm{I}, \mathrm{Cl}, \mathrm{Br} \\
& \mathrm{R}^{1}=\mathrm{H}, \mathrm{Me}, \mathrm{OMe}, \mathrm{NO}_{2}, \mathrm{CHO}, \mathrm{NH}_{2} \\
& \mathrm{R}^{2}=\mathrm{H}, \mathrm{Me}, \mathrm{OMe}
\end{aligned}
$$

TON up to $2.7 \times 10^{-5}$ TOF up to $2.8 \times 10^{4} \mathrm{~h}^{-1}$

Scheme 42. Suzuki-Miyaura reaction catalyzed by PdNPs/dendrimer.

\subsubsection{Organometallic supports}

Metal organic frameworks (MOFs) represent a very promising class of heterogeneous catalysts for the stabilization of metal nanoparticles due their high surface area and well-defined pore structure [97]. For instance, MIL-53( $\mathrm{Al})-\mathrm{NH}_{2}$, consisting of aminoterephthalic acid anions and aluminum cations, was used to immobilize PdNPs with a diameter of $3 \mathrm{~nm}$. The resulting catalyst was successfully used in the Suzuki-Miyaura reaction of various aryl halides, though aryl chlorides gave low yields [98]. The reaction of phenylboronic acids with aryl bromides, including deactivated 2and 4-methoxybromobenzenes, was successfully carried out using $0.5 \mathrm{~mol} \%$ palladium loading under mild conditions in short reaction times (Scheme 43). The catalyst was recycled in five runs with an almost constant yield (97-95\%) and negative hot-filtration test.
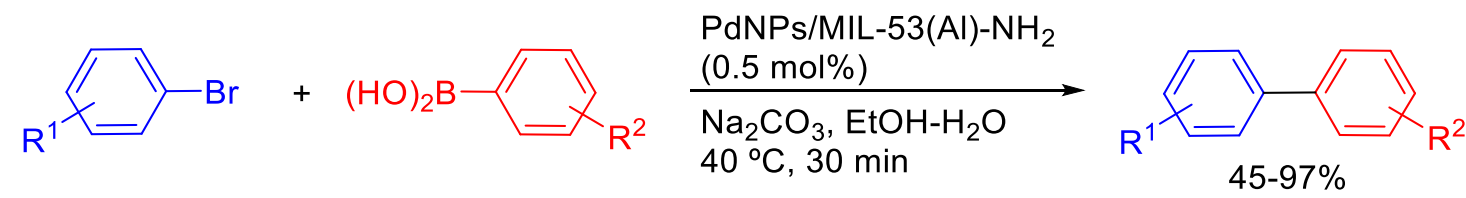

$\mathrm{R}^{1}=\mathrm{H}, 2-\mathrm{OMe}, 4-\mathrm{OMe} 4-\mathrm{Ac}, 4-\mathrm{NO}_{2}, 4-\mathrm{CF}_{3}$

$\mathrm{R}^{2}=\mathrm{H}, 2-\mathrm{OMe}, 4-\mathrm{OMe}, 4-\mathrm{NO}_{2}$

Scheme 43. Suzuki-Miyaura reaction catalyzed by PdNPs/MIL-53(Al)-NH 2 . 
A fluoride-containing framework of chromium(III) cations and terephthalic acid (MIL-101) was used as a support for PdNPs with an average size of $1.9 \mathrm{~nm} \mathrm{[70c].} \mathrm{This} \mathrm{material} \mathrm{showed} \mathrm{high}$ catalytic activity in the reaction of phenylboronic acid and aryl chlorides in water at $80{ }^{\circ} \mathrm{C}$ (Scheme 44). Interestingly, even deactivated 2- and 4-chloromethoxybenzenes reacted to give the expected products in high yields. $\mathrm{Pd} / \mathrm{C}$ and MOF ZIF-8 catalysts gave lower product yields when compared with PdNPs/MIL-101.
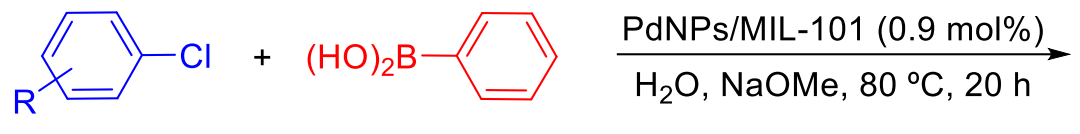

$\mathrm{R}=\mathrm{H}, 2-\mathrm{OMe}, 4-\mathrm{OMe} 4-\mathrm{Ac}$

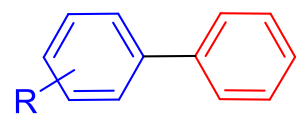

$81-97 \%$

Scheme 44. Suzuki-Miyaura reaction catalyzed by PdNPs/MIL-101.

Martín-Matute et al. modified MIL-101Cr with amino groups to obtain MIL-101Cr- $\mathrm{NH}_{2}$, which was used for PdNPs immobilization [70b]. In the search for optimal conditions in the SuzukiMiyaura reaction, the authors examined the effect of the content of palladium in the MOF on the catalytic activity and found out that $8 \mathrm{wt} \%$ loading was the most effective one; higher palladium loading led to particle agglomeration on the surface of the MOF, accompanied by pore reduction and problems of transport of the reactants. The catalyst was applied at room temperature for aryl bromides or $80^{\circ} \mathrm{C}$ for aryl chlorides in water or water-EtOH medium (Scheme 45). Moreover, the catalyst could be reused in ten cycles with an excellent and constant yield.

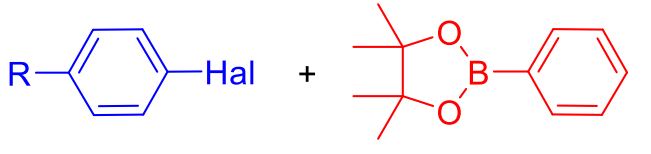

$H a l=C l$

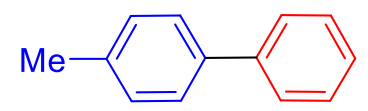

$99 \%(99 \%)$

$H a l=B r$

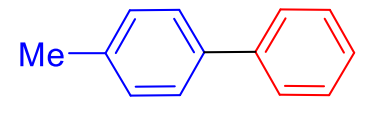

$4 \%(44 \%)$

$\frac{8 \text { wt } \% \text { Pd@MIL-101Cr- } \mathrm{NH}_{2}(3 \mathrm{~mol} \%)}{\mathrm{K}_{2} \mathrm{CO}_{3}, \mathrm{H}_{2} \mathrm{O}(6 \mathrm{~h}) \text { or } \mathrm{H}_{2} \mathrm{O}-\mathrm{EtOH}(30 \mathrm{~min})^{\mathrm{a}}}$ $23^{\circ} \mathrm{C}(\mathrm{X}=\mathrm{Br})$ or $80^{\circ} \mathrm{C}(\mathrm{X}=\mathrm{Cl})$

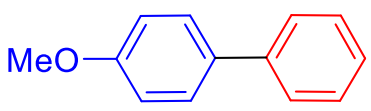

$99 \%(95 \%)$

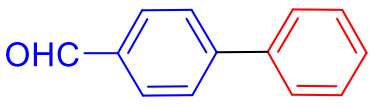

$99 \%(-)$
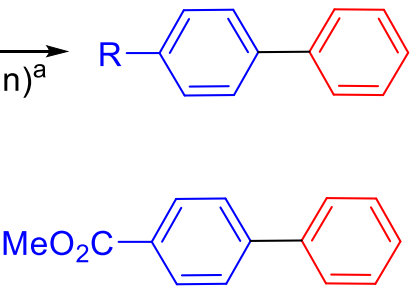

$84 \%(99 \%)$

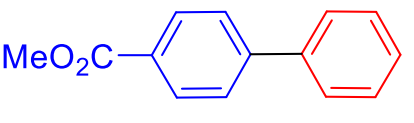

$70 \%(54 \%)$

a Yield in $\mathrm{H}_{2} \mathrm{O}$; yield in $\mathrm{H}_{2} \mathrm{O}-\mathrm{EtOH}$ in parentheses

Scheme 45. Suzuki-Miyaura reaction catalyzed by PdNPs/MIL-101Cr-NH 2 .

\subsubsection{Carbon materials}

Palladium on charcoal [99] was one of the first heterogeneous catalysts deployed for cross-coupling reactions. For instance, the reaction of phenylboronic acid and aryl bromides could be conducted in aqueous ethanol at room temperature using palladium on charcoal without any additives [100a] or in water at $65^{\circ} \mathrm{C}$ in the presence of TBAB [100b]; it is noteworthy that aryl chlorides also reacted when using aqueous $N, N$-dimethylacetamide as a solvent at $80{ }^{\circ} \mathrm{C}$ [100c]. More recently, in the search for more efficient catalysts, researchers have developed other more complex carbon materials as supports for palladium. Such is the case of ordered carbon materials with large surface area and porous structure that provide better transport of reagents and products. Ordered oxides, metal organic frameworks (MOFs) and block copolymers have been used as templates to obtain 
ordered carbon structures. For instance, it was reported that thermolysis of sucrose using an ordered mesoporous silica SBA-15 as a template led to the formation of an ordered mesoporous carbon material suitable for PdNPs immobilization. The resulting catalyst allowed to perform the SuzukiMiyaura reaction of phenylboronic acid and chlorobenzene under rather harsh conditions $\left(150{ }^{\circ} \mathrm{C}\right)$ in aqueous DMF for $10 \mathrm{~min}$ [101]. Feng and Wang described a catalyst consisting of PdNPs supported on MOF-5-derived nanoporous carbon (MOF-5-NPC) [102]. This material catalyzed the Suzuki-Miyaura reaction of aryl bromides at room temperature and that of aryl chlorides at $78^{\circ} \mathrm{C}$ in aqueous ethanol (Scheme 46). The catalyst was recycled in five runs with a progressive decrease in the yield (98-80\%) that was attributed to some loss of Pd upon reuse (from 4.85 to $4.4 \%$ ).

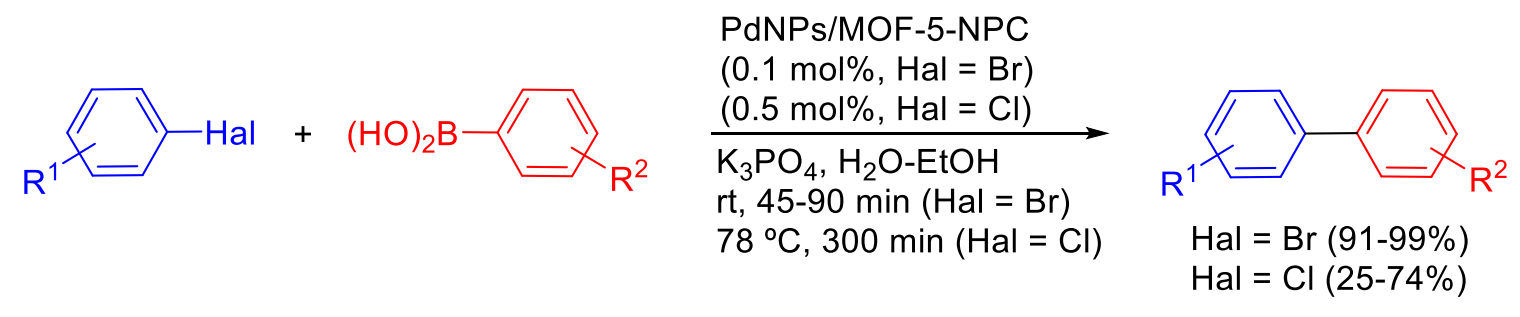

$\mathrm{Hal}=\mathrm{Br} ; \mathrm{R}^{1}=\mathrm{H}, 2-\mathrm{Me}, 4-\mathrm{Me}, 4-\mathrm{OMe}, 4-\mathrm{Ac}, 4-\mathrm{OH}, 4-\mathrm{CHO} ; \mathrm{R}^{2}=\mathrm{H}$, 2-Me, 3-Me, 4- $\mathrm{NO}_{2}$

$\mathrm{Hal}=\mathrm{Cl} ; \mathrm{R}^{1}=\mathrm{H}, 2-\mathrm{Me}, 4-\mathrm{OMe} ; \mathrm{R}^{2}=\mathrm{H}$

Scheme 46. Suzuki-Miyaura reaction catalyzed by PdNPs/MOF-5-NPC.

Nájera and Cazorla-Amorós et al. obtained PVP-stabilized PdNPs and bimetallic Pd-NiNPs that were immobilized on multi-walled carbon nanotubes ( $\left.\mathrm{Pd}_{50} \mathrm{Ni}_{50} @ \mathrm{MWCNT}\right)$ [103]; MWCNTs have been considered better support than single-walled nanotubes [69b]. The reaction of phenylboronic acid and $p$-bromomethoxybenzene proceeded relatively fast in water at $120{ }^{\circ} \mathrm{C}$, under the catalysis of $\mathrm{Pd}_{50} \mathrm{Ni}_{50} @ \mathrm{MWCNT}$ in the presence of a base and TBAB (Scheme 47). The catalyst showed good recyclability in four runs, with a slight increase in the particle size $(3.7 \mathrm{~nm})$ being noticed after the fourth run when compared with the original size $(2.4 \mathrm{~nm})$.

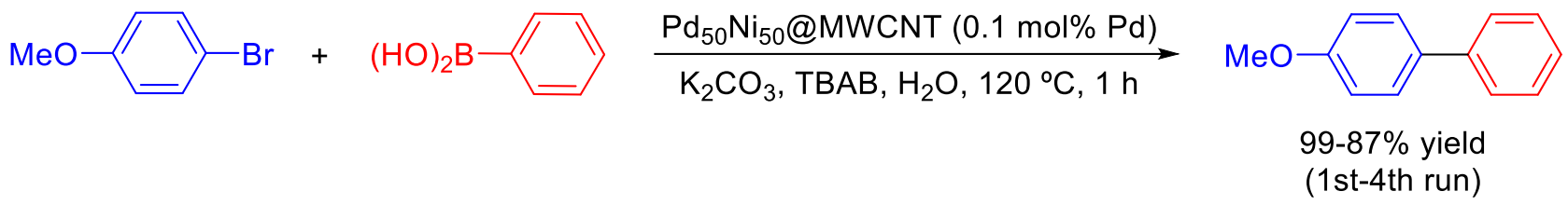

Scheme 47. Suzuki-Miyaura reaction catalyzed by $\mathrm{Pd}_{50} \mathrm{Ni}_{50} @ \mathrm{MWCNT}$.

PdNPs immobilized on graphene did not show high activity in the Suzuki-Miyaura reaction [69a]. Graphene oxide (GO) was found to be a more efficient support as, in this case, aryl bromides reacted with arylboronic acids in aqueous ethanol at room temperature (Scheme 48) [104]. Very high TON and TOF $(237,000)$ were reached for the reaction of iodobenzene and phenylboronic acid, albeit the isolated yield of the product was modest (40\%). A progressive decrease in the catalytic activity was observed after three cycles, with the palladium leached into solution being only $0.21 \mathrm{ppm}$. 


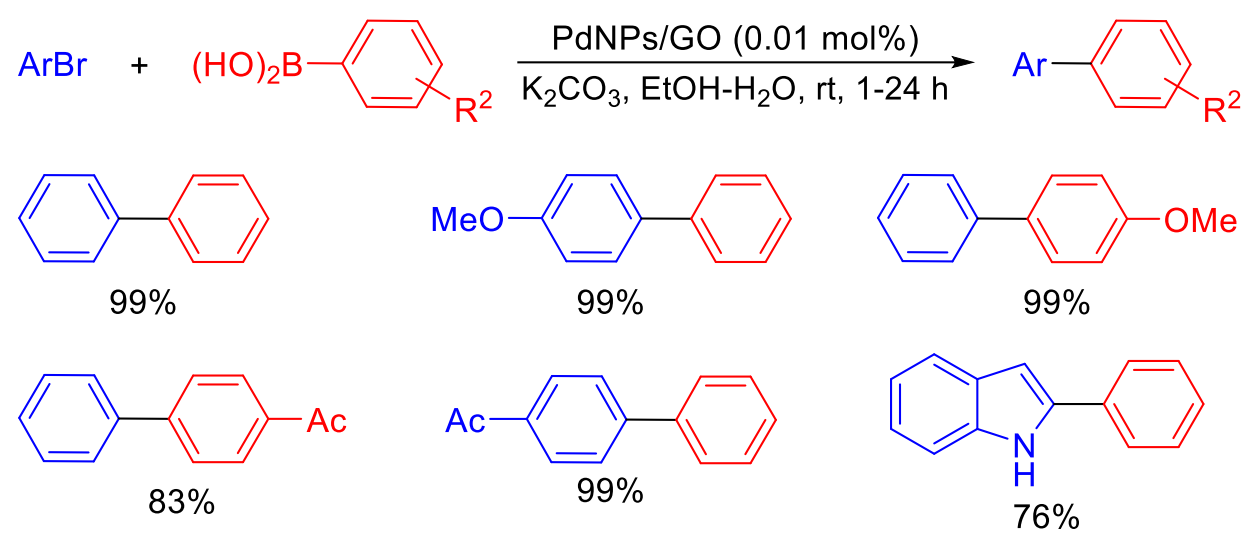

Scheme 48. Suzuki-Miyaura reaction catalyzed by PdNPs/GO.

Ghost and Putta obtained amphiphilic colloidal spherical carbon particles (CSP) by the hydrothermal carbonization of glucose, as a support for PdNPs [105]. The resulting material catalyzed the Suzuki-Miyaura reaction in water of aryl iodides, bromides and chlorides at $90{ }^{\circ} \mathrm{C}$, generally in high yields (Scheme 49); aryl chlorides and some aryl bromides required longer reaction times, with the electron-rich aryl chlorides reacting more sluggishly. The catalyst was recycled four times in the reaction of $\mathrm{PhB}(\mathrm{OH})_{2}$ and $p-\mathrm{BrC}_{6} \mathrm{H}_{4} \mathrm{CHO}$ with a gradual but slight decrease in the activity.

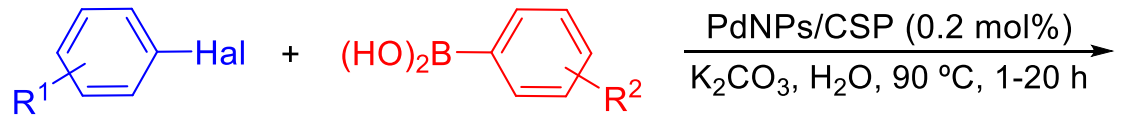

$$
\begin{aligned}
& \left.\mathrm{Hal}=\mathrm{I} ; \mathrm{R}^{1}=\mathrm{H}, 4-\mathrm{Me}, 4-\mathrm{OMe}, 4-\mathrm{OH}, 4-\mathrm{NO}_{2} \text {, 4-Br, 2-pyridyl, 3-I, 2,3-(Me }\right)_{2} \\
& \mathrm{R}^{2}=\mathrm{H}, 4-\mathrm{OMe}, 4-\mathrm{CN}, 4-\mathrm{NO}_{2}, 2,3,4-(\mathrm{OMe})_{3} \\
& \mathrm{Hal}=\mathrm{Br} ; \mathrm{R}^{1}=\mathrm{H}, 4-\mathrm{Me}, 4-\mathrm{OMe}, 4-\mathrm{OH}, 4-\mathrm{NO}_{2}, 4-\mathrm{CHO}, 2 \text {-pyridyl, 2,3-(Me) }{ }_{2} \\
& \mathrm{R}^{2}=\mathrm{H}, 4-\mathrm{OMe} \\
& \mathrm{Hal}=\mathrm{Cl} ; \mathrm{R}^{1}=\mathrm{H}, 4-\mathrm{Me}, 4-\mathrm{OH}, 4-\mathrm{NO}_{2}, 4-\mathrm{CHO} ; \mathrm{R}^{2}=\mathrm{H}
\end{aligned}
$$

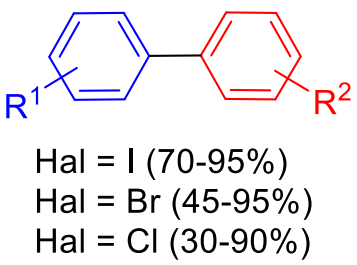

Scheme 49. Suzuki-Miyaura reaction catalyzed by PdNPs on amphiphilic colloidal spherical carbon particles.

More exotic was the preparation of spherical carbon particles, as carbon nanodots (C-dots), by thermolysis of clotted cream reported by Dey and Sarma et al. [106]. Treatment of the C-dots with $\mathrm{H}_{2} \mathrm{PdCl}_{4}$ in boiling water resulted in the formation of PdNPs coated with an ultrathin C-dot shell. However, the $\mathrm{C}$-dots were incapable of preventing Pd agglomeration during the catalytic reaction; for this reason, poly-( $N$-vinyl-2-pyrrolidinone) (PVP) had to be added as a co-stabilizer. This Pd@C-dot-PVP system catalyzed the coupling of differently substituted aryl bromides and arylboronic acids in water at $60{ }^{\circ} \mathrm{C}$ (Scheme 50). The catalyst maintained good activity in three cycles.

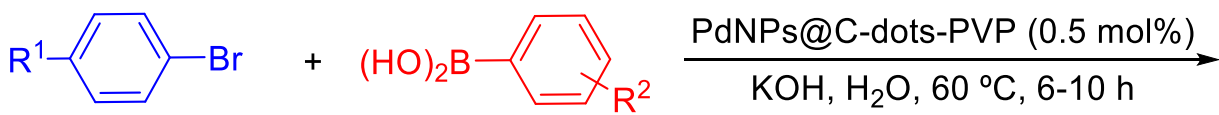

$\mathrm{R}^{1}=\mathrm{H}, 4-\mathrm{Me}, 4-\mathrm{Et}$, 4-vinyl, 4-OMe, 2-CHO

$\mathrm{R}^{2}=\mathrm{H}, 4-\mathrm{Me}, 4-\mathrm{Br}$

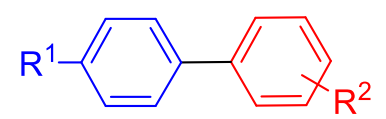

$67-95 \%$

Scheme 50. Suzuki-Miyaura reaction catalyzed by PdNPs@C-dots-PVP. 
PdNPs (4-12 nm) electrochemically deposited on a Nafion-graphene (Nf-G) composite exhibited good results in the Suzuki-Miyaura reaction of aryl bromides and aryl iodides with arylboronic acids in aqueous ethanol at $80{ }^{\circ} \mathrm{C}$ (Scheme 51) [107]. The catalyst was reused in five reaction cycles with a good performance in the case of coupling iodobenzene with phenylboronic acid (94$91 \%)$<smiles></smiles>

$\mathrm{Hal}=\mathrm{I}, \mathrm{Br}$

$\mathrm{R}^{1}=\mathrm{H}, \mathrm{Me}, \mathrm{OMe}, \mathrm{OH}, \mathrm{Ac}, \mathrm{NO}_{2}$

$\mathrm{R}^{2}=\mathrm{H}, \mathrm{Me}, \mathrm{OMe}, \mathrm{Cl}$

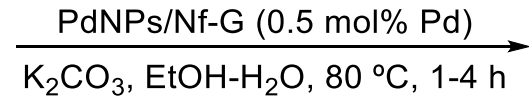

$\mathrm{K}_{2} \mathrm{CO}_{3}, \mathrm{EtOH}-\mathrm{H}_{2} \mathrm{O}, 80^{\circ} \mathrm{C}, 1-4 \mathrm{~h}$

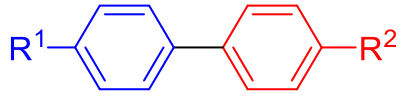

$88-95 \%$

Scheme 51. Suzuki-Miyaura reaction catalyzed by PdNPs/Nafion-graphene.

In order to make a heterogeneous ligandless catalyst capable of activating aryl chlorides, it is necessary to increase the electron density at the PdNPs immobilized on the support surface, something that can be attained by surface functionalization. In this sense, Wan et al. obtained a composite consisting of cobalt(II) oxide nanoparticles intercalated in a mesoporous carbon matrix, on which palladium was immobilized in the form of small clusters $(\sim 1.3 \mathrm{~nm})$ [108]. The authors suggested that the partial unsaturated coordinative palladium could account for the possibility of cross-coupling aryl chlorides with phenylboronic acid in the absence of ligands and additives. The yield of biphenyl in the reaction with chlorobenzene was $49 \%$ and lower for the electron-rich chloroaromatics (Scheme 52). High yields were obtained for aryl bromides, even when bearing substituents with acidic hydrogens. In addition, the catalyst was successfully reused in ten cycles in the bromobenzene reaction without any loss of activity.

$$
\begin{aligned}
& \mathrm{R} \\
& \mathrm{Hal}=\mathrm{Br} ; \mathrm{R}=\mathrm{H}, \mathrm{OH}, \mathrm{CO}_{2} \mathrm{H} \\
& \left.\mathrm{Hal}=\mathrm{Cl} ; \mathrm{R}=\mathrm{H}, \mathrm{CN}, \mathrm{NO}_{2}, \mathrm{Me}, \mathrm{OMe}\right)_{2} \mathrm{OMNP} / \mathrm{CoO}-\mathrm{C}(1 \mathrm{~mol} \%)
\end{aligned}
$$

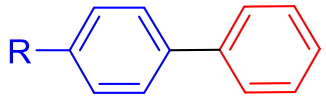

$\mathrm{Hal}=\mathrm{Br}(89-97 \%)$

$\mathrm{Hal}=\mathrm{Cl}(19-94 \%)$

Scheme 52. Suzuki-Miyaura reaction catalyzed by PdNPs/CoO-C.

\subsubsection{Inorganic oxides}

Inorganic oxides, among which silica gel and its modifications are most often used, are inexpensive and stable and are, therefore, widely used as supports for palladium immobilization. For instance, Okumura et al. observed that, by subjecting to hydrogenation palladium loaded on very stable USY zeolites, the atomic Pd generated achieved extremely high TONs (up to $13 \times 10^{6}$ ) and TOFs (up to 9 $\times 10^{6} \mathrm{~h}^{-1}$ ) in the reaction of phenylboronic acid with aryl bromides in $o$-xylene at $110^{\circ} \mathrm{C}$ [109]. In a related research, Özkar et al. prepared PdNPs confined on zeolite NaY, which allowed to couple phenylboronic acid and aryl bromides in short reaction times at room temperature in aqueous DMF (Scheme 53) [110]. The catalyst was recycled fifteen times with a smooth decrease in yield, ranging from near quantitative to $80 \%$.

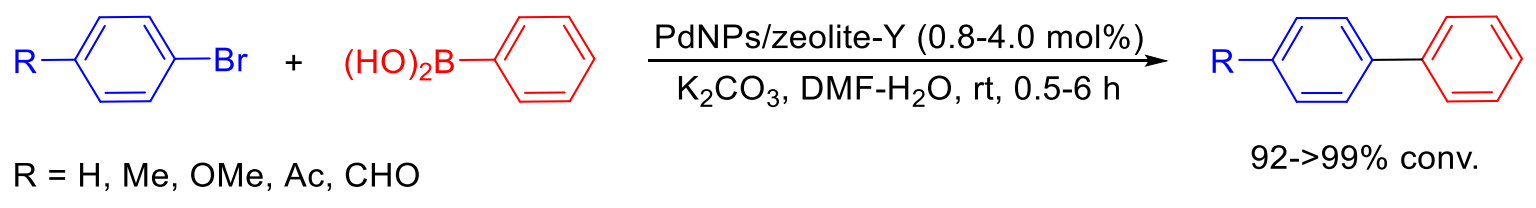


Scheme 53. Suzuki-Miyaura reaction catalyzed by PdNPs/zeolite-Y.

Equally interesting results were obtained by Parada et al. using PdNPs (2-5 nm) immobilized on an ethylenediamine-functionalized layered double hydroxide (Zn-Al LDH) [111]. The catalyst was applied to the reaction of aryl iodides, bromides and chlorides with three arylboronic acids at $80{ }^{\circ} \mathrm{C}$ in dioxane-water, providing the products in good-to-high yields (Scheme 54); the amount of $\mathrm{Pd}$ used was ill-defined. The catalyst was reusable without palladium leaching or particle agglomeration.

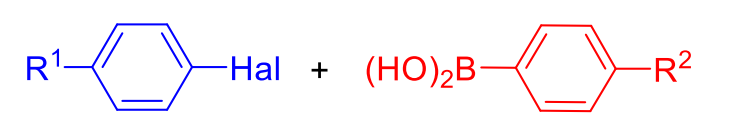

$\mathrm{Hal}=\mathrm{I}, \mathrm{Br}, \mathrm{Cl}$

$\mathrm{R}^{1}=\mathrm{H}, \mathrm{Me}, \mathrm{OMe}, \mathrm{NO}_{2}$

$\mathrm{R}^{2}=\mathrm{H}, \mathrm{Me}, \mathrm{OMe}$

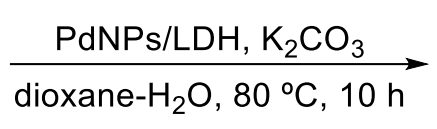

dioxane- $\mathrm{H}_{2} \mathrm{O}, 80^{\circ} \mathrm{C}, 10 \mathrm{~h}$

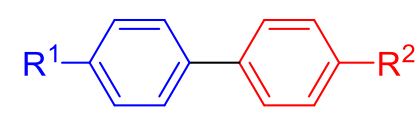

$64-96 \%$

Scheme 54. Suzuki-Miyaura reaction catalyzed by PdNPs/LDH.

H. Veisi et al. prepared a complex of $\mathrm{PdCl}_{2}$ with 1,3-dicyclohexylguanidine immobilized on the surface of mesoporous silica SBA-15 [112], the reduction of which with hydrazine led to the formation of immobilized PdNPs $(10 \mathrm{~nm})$. This catalyst was effective in the reaction of phenylboronic acid with differently substituted aryl chlorides, bromides and iodides. The product yields were high even with deactivated substrates, such as $o$-chloromethoxybenzene (Scheme 55). Recycling studies revealed a stable catalytic activity in five cycles and absence of palladium leaching was suggested on the basis of a negative hot filtration test.

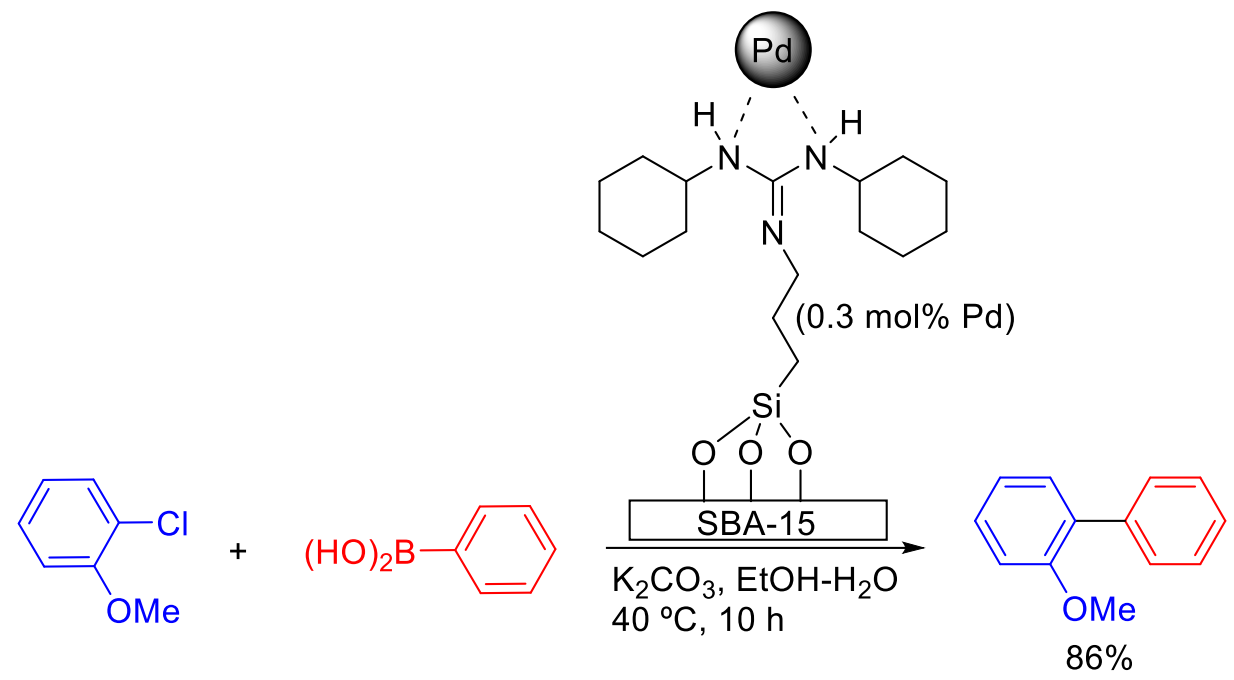

Scheme 55. Suzuki-Miyaura reaction catalyzed by immobilized PdNPs.

The commercially available catalyst SiliaCat consists of small $\operatorname{Pd}(0) \mathrm{NPs}(2-5 \mathrm{~nm})$ dispersed in the internal pores of an organosilica matrix. This catalyst successfully catalyzed the cross-coupling of aryl iodides, bromides and chlorides with phenylboronic acid in alcoholic solvents [72a]. It is noteworthy that the reaction time could be substantially decreased under microwave irradiation, even for aryl chlorides (Scheme 56), with aryl bromides reaching TOFs of up to $12,000 \mathrm{~h}^{-1}$. The catalyst retained its catalytic activity in seven consecutive cycles with low $(<7 \mathrm{ppm})$ and inactive palladium leaching. 


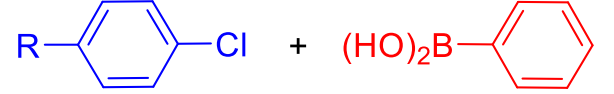

$\mathrm{R}=\mathrm{H}, \mathrm{Me}, \mathrm{OMe}, \mathrm{NO}_{2}, \mathrm{Ac}, \mathrm{CHO}$

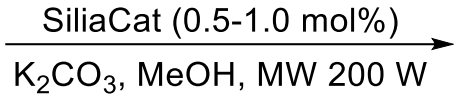

$100-120^{\circ} \mathrm{C}, 5-15 \mathrm{~min}$

Scheme 56. Suzuki-Miyaura reaction catalyzed by SiliaCat.

\subsubsection{Magnetic oxides}

Magnetic metal oxides have attracted a great deal of attention as supports for catalytically active metals because of their very easy separation from the reaction mixture [113]. For instance, Li et al. immobilized PdNPs on the surface of magnetite nanoparticles coated with silica, followed by functionalization with glycerol and chlorodiphenylphosphine $\left(\mathrm{Fe}_{3} \mathrm{O}_{4} / \mathrm{SiO}_{2} / \mathrm{HPG}-\mathrm{OPPh}_{2}\right)$ [114]. The coupling of aryl iodides and bromides with arylboronic acids in the presence of the resulting catalyst was very fast (10-15 $\mathrm{min})$ at room temperature, producing the expected biaryls in high yields (83-95\%). Aryl chlorides were more reluctant to react and needed higher temperature and longer reaction time at the same catalyst loading $(0.76 \mathrm{~mol} \%)$ (Scheme 57$)$. The catalyst could be reused in six cycles in the reaction of $p-\mathrm{MeOC}_{6} \mathrm{H}_{4} \mathrm{I}$ and $\mathrm{PhB}(\mathrm{OH})_{2}$ with no apparent loss of activity (93-92\% yield).

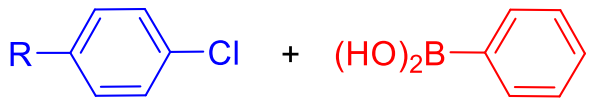

$\mathrm{R}=\mathrm{H}, \mathrm{Me}, \mathrm{OMe}, \mathrm{NO}_{2}, \mathrm{CN}$
$\mathrm{PdNPs} / \mathrm{Fe}_{3} \mathrm{O}_{4}-\mathrm{SiO}_{2}-\mathrm{HPG}-\mathrm{OPPh}$ $(0.76 \mathrm{~mol} \%)$

$\mathrm{K}_{2} \mathrm{CO}_{3}, \mathrm{DMF}, 130^{\circ} \mathrm{C}, 36 \mathrm{~h}$

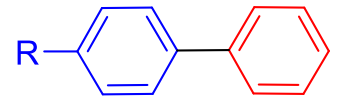

$31-91 \%$

Scheme 57. Suzuki-Miyaura reaction catalyzed by $\mathrm{PdNPs} / \mathrm{Fe}_{3} \mathrm{O}_{4}-\mathrm{SiO}_{2}-\mathrm{HPG}-\mathrm{OPPh}_{2}$.

In order to upgrade the separation properties of the previously developed PdNPs (3.25 nm) on graphitic carbon $\left(\mathrm{g}-\mathrm{C}_{3} \mathrm{~N}_{4}\right)$ catalyst [115a], Tang et al. incorporated magnetite nanoparticles $\left(\mathrm{Fe}_{2} \mathrm{O}_{3}\right.$, 5-18 nm) into the original material to obtain $\operatorname{PdNPs}(2.55 \mathrm{~nm}) / \mathrm{Fe}_{2} \mathrm{O}_{3} / \mathrm{g}-\mathrm{C}_{3} \mathrm{~N}_{4}[115 \mathrm{~b}]$. With the action of this catalyst, the Suzuki-Miyaura coupling $p$-tolylboronic acid with aryl iodides and bromides was successfully accomplished at room temperature in $25 \mathrm{~min}$ (Scheme 58); modest yields were recorded for aryl chlorides after $10 \mathrm{~h}$. The catalyst could be recycled in five runs with no apparent loss of activity in the case of $o$-bromobenzonitrile.

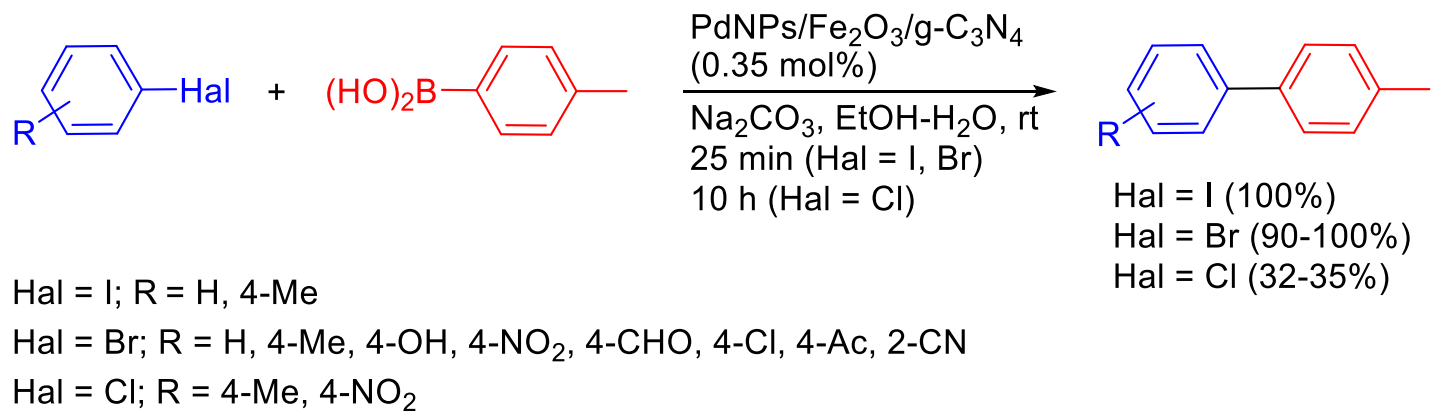

Scheme 58. Suzuki-Miyaura reaction catalyzed by PdNPs/ $/ \mathrm{Fe}_{2} \mathrm{O}_{3} / \mathrm{g}-\mathrm{C}_{3} \mathrm{~N}_{4}$.

\section{Alternative metals, substrates and methods}

The fast expansion of the tools arsenal for organic synthesis has led to a wide range of catalytic systems, reaction conditions and techniques, other than the conventional ones, that can be implemented for the Suzuki-Miyaura reaction. It is worthwhile mentioning that this reaction is not exclusive for palladium and that other metals came into play with adapted reagents and conditions. Concerning the solvent, cross-coupling reactions in water or aqueous medium with the participation 
of "ligandless" palladium (simple palladium salts of the type $\mathrm{PdX}_{2}$ as pre-catalysts) were reported in 1989 [116]; in the early 2000s, water still remained an unconventional solvent. However, in the last decade, the use of aqueous solvents, especially in the catalysis by PdNPs, has become a usual procedure that meets the requirements of Green Chemistry (i.e., a cheap and abundant solvent in combination with a recyclable active catalyst). The same can be said about the many previously non-traditional substrates, such as aryl triflates, which are now widely used along with aryl halides. Amidoesters (e.g., MIDA boronate), 1,8-diaminonaphthylboramide or dialkylarylboranes (e.g., 9aryl-9-borabicyclononane) began to be used as nucleophiles along with the common arylboronic acids, their esters (e.g., pinacolborate), tetraarylborates and trifluoroborates. Each type of organoboron compound has specific characteristics that determine its use for the cross-coupling with different substrates. Lloyd-Jones and Lennox described the choice of a particular type of organoboron compound in a recent review [117]. As regards the different techniques, nowadays, microwave activation can be considered a traditional technique in Suzuki-Miyaura reactions, whereas the mechanochemical activation or the continuous flow processes are of more recent practice.

\subsection{Other metal catalysts}

\subsubsection{Nickel}

It is known that the history of the discovery of cross-coupling reactions began with the catalysis by nickel [118]. The use of nickel in the Suzuki-Miyaura reaction has been reflected in a review [119], that is why, herein, we will only cover the more recent advances in the field. For instance, halfsandwich cyclopentadienyl NHC nickel complexes catalyzed the reaction of aryl bromides and activated aryl chlorides with phenylboronic acid at $90{ }^{\circ} \mathrm{C}$ (Scheme 59) [120]. Unfortunately, electron-rich aryl bromides and chlorides (e.g., 4-Me and 4-MeO substituted) gave modest yields of the cross-coupled products, in some cases accompanied by the biaryls derived from the haloaromatic homocoupling.

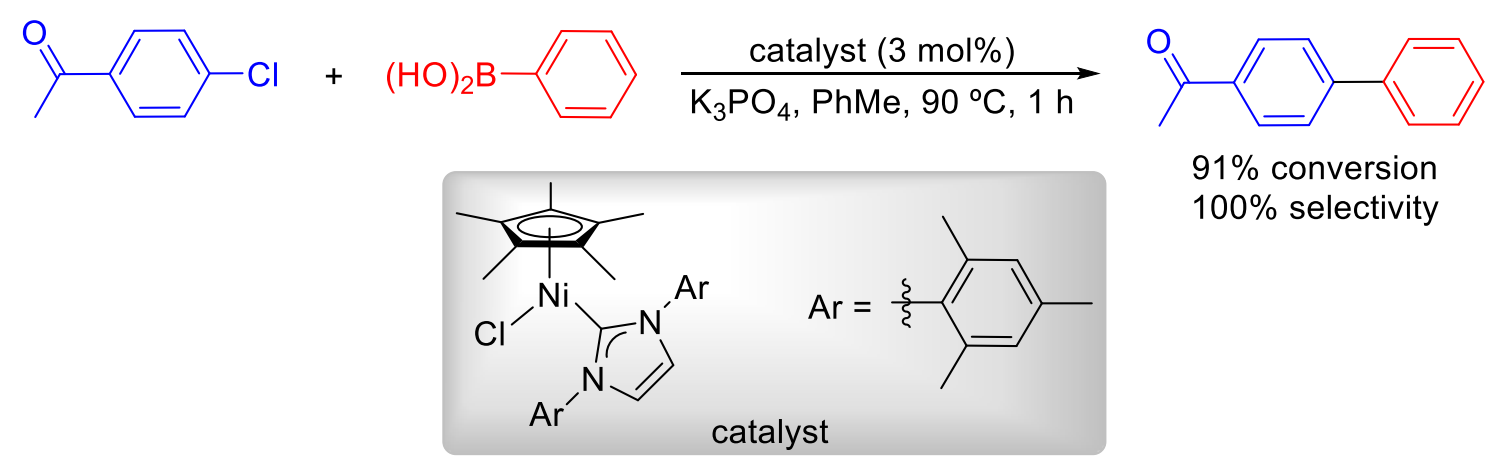

Scheme 59. Suzuki-Miyaura reaction catalyzed by a NHC-nickel complex.

Heteroaryl substrates are often troublesome because can interfere with some catalyst ligands or poison the surface of heterogeneous catalysts. Stradiottto et al. synthesized a diphosphine complex of mesitylnickelbromide, (DPEPhos)Ni(mesityl)Br, which catalyzed the Suzuki-Miyaura reaction of a wide variety of heteroaryl chlorides and bromides with heteroarylboronic acids at room temperature (Scheme 60) [121]. The coupling with pyridinylboronic acids required further optimization, being conducted with $10 \mathrm{~mol} \% \mathrm{Ni}$ and $\mathrm{KO}-t$-Bu in dioxane-EtOH at $60{ }^{\circ} \mathrm{C}$ for $16 \mathrm{~h}$. The yields ranged from good to excellent in all the reported examples. 


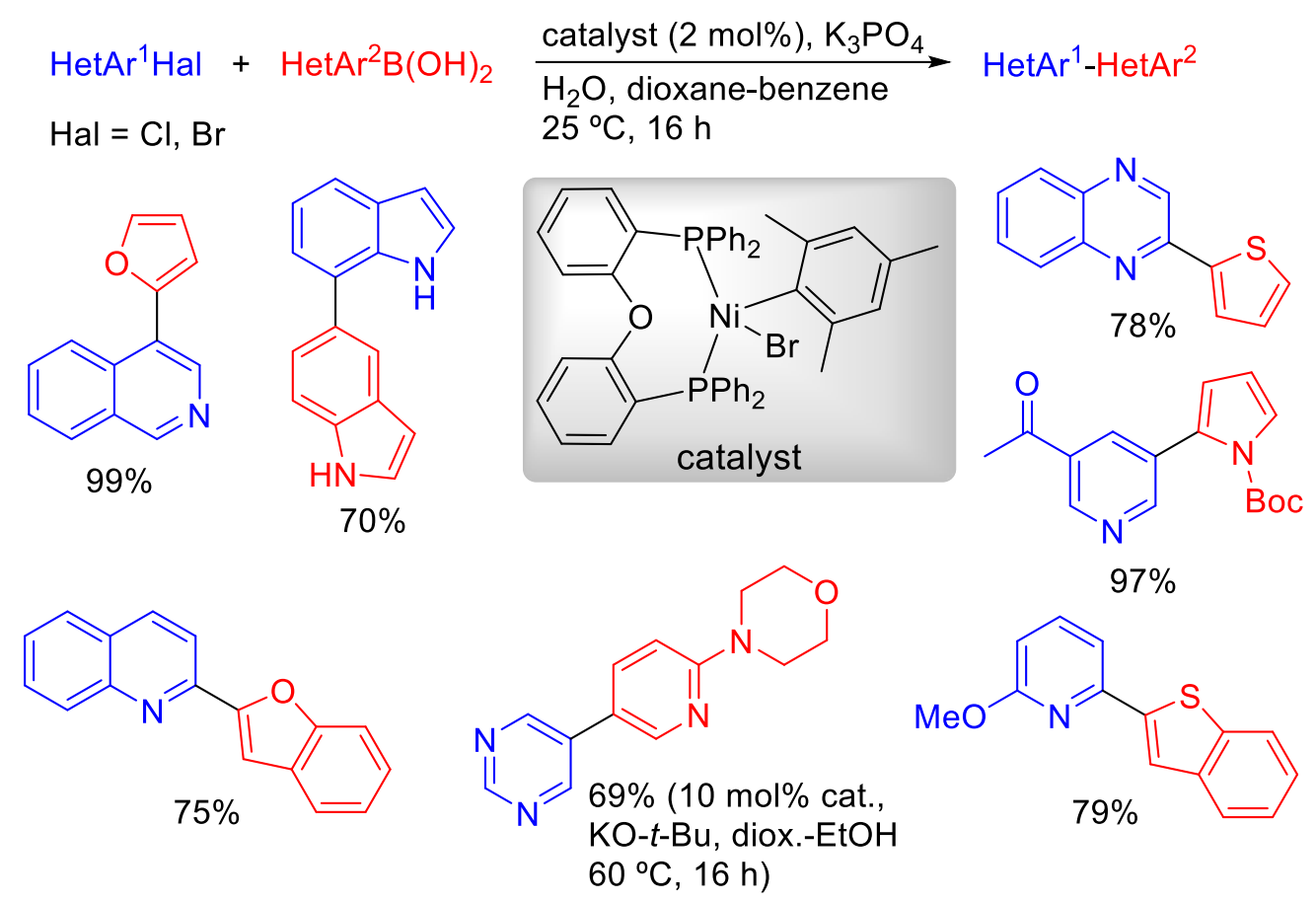

Scheme 60. Suzuki-Miyaura reaction catalyzed by (DPEPhos)Ni(mesityl)Br.

Radius and Marder et al. studied the cross-coupling of perfluorobenzene and other perfluorinated aromatics with a number of arylboronic esters under the catalysis of carbene complexes of nickel [122]. The best choice was considered that involving the neopentylglycol-derived boronates and the catalyst $\left[\mathrm{Ni}_{2}\left(i-\mathrm{Pr}_{2} \mathrm{Im}\right)_{4}(\mu\right.$-cod $\left.)\right]$ in combination with $\mathrm{CsF}$ in toluene (Scheme 61). Boronates with electron-withdrawing groups at the para-position did not react under these conditions.

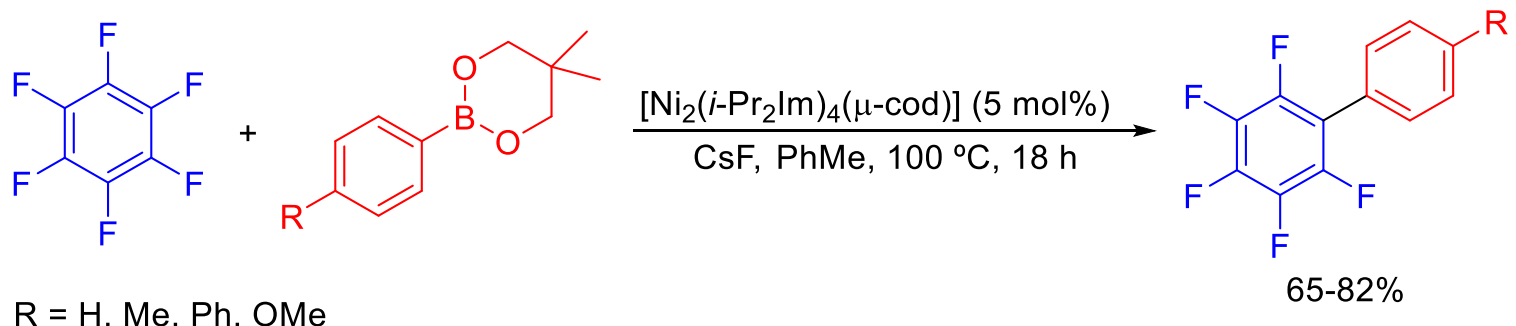

Scheme 61. Suzuki-Miyaura reaction catalyzed by $\left[\mathrm{Ni}_{2}\left(i-\mathrm{Pr}_{2} \operatorname{Im}\right)_{4}(\mu\right.$-cod $\left.)\right]$.

Vallribera et al. prepared carbon aerogels containing NiNPs $(50 \mathrm{~nm})$ or PdNPs $(20 \mathrm{~nm})$, with the former exhibiting slightly higher catalytic activity than the latter in the coupling of iodoarenes and bromoarenes with several arylboronic acids in water at $110{ }^{\circ} \mathrm{C}$ (Scheme 62) [123]. The Ni nanocomposite was found to be more robust than the Pd counterpart, being recyclable in six runs with consistent yields, no particle aggregation and no detectable leaching.

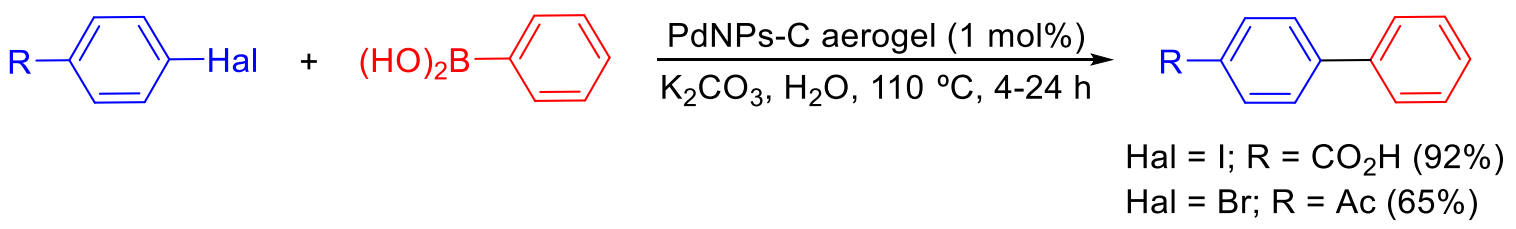

Scheme 62. Suzuki-Miyaura reaction catalyzed by PdNPs-C aerogel. 


\subsubsection{Iron}

Catalysts based on iron complexes have been rarely used in the Suzuki-Miyaura reaction and mainly applied to the cross-coupling of unusual substrates that cannot be coupled by standard methods. For instance, Nakamura et al. developed a procedure for the cross-coupling of deactivated alkyl halides and arylboronates by means of an iron(II) diarylphosphine complex in the presence of magnesium dibromide [124]. The process was high yielding and took place under mild conditions (Scheme 63).

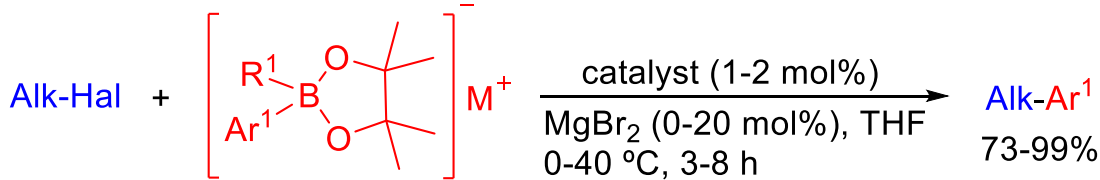

$$
\begin{aligned}
& \mathrm{Hal}=\mathrm{Cl}, \mathrm{Br} \text {, I } \\
& \mathrm{R}^{1}=\mathrm{Et}, \mathrm{Bu}, t-\mathrm{Bu} \\
& \mathrm{M}=\mathrm{Li} \text { or } \mathrm{MgBr} \\
& \mathrm{X}=\mathrm{N} ; \mathrm{R}^{2}=\mathrm{H}
\end{aligned}
$$
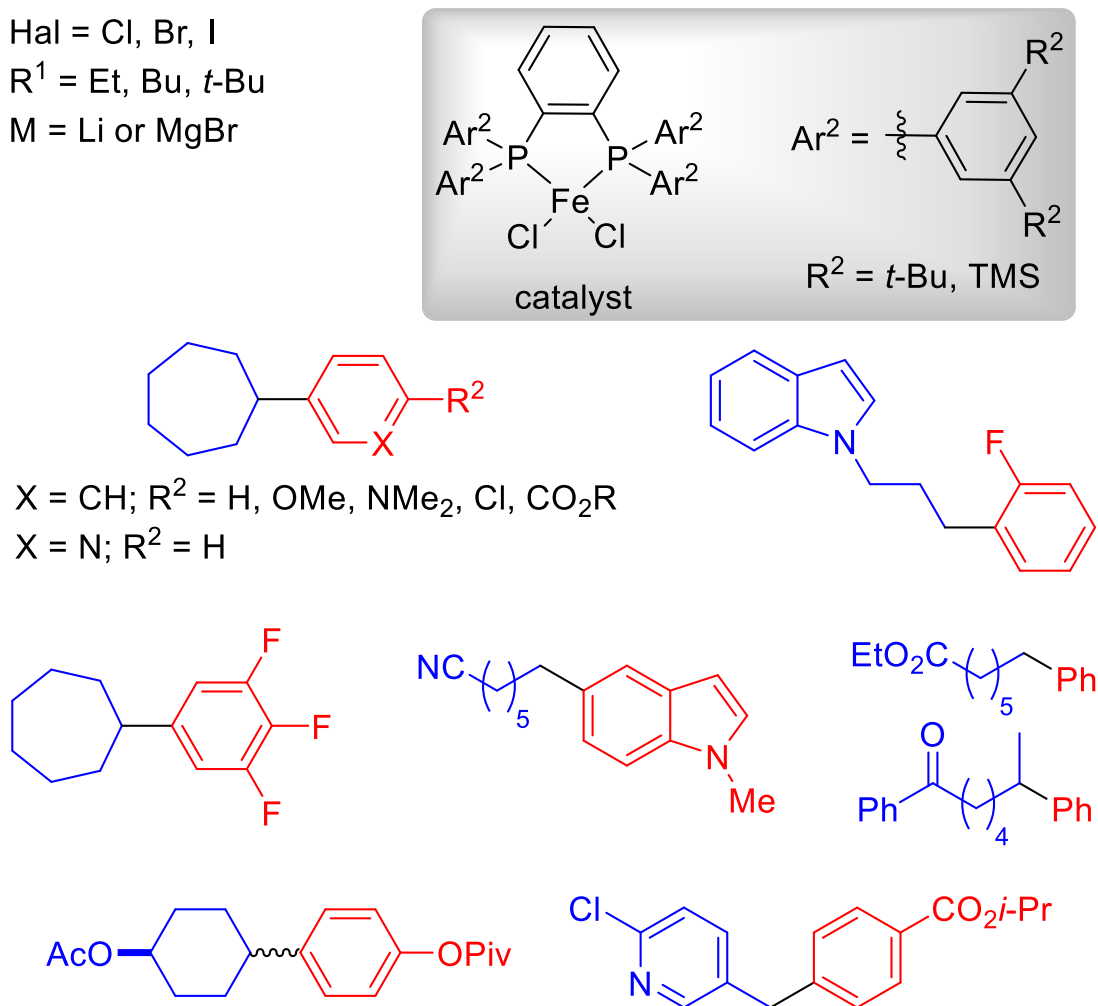

Scheme 63. Suzuki-Miyaura reaction catalyzed by an iron(II) diarylphosphine complex.

Later on, the same research group introduced a method for alkyl-alkyl cross coupling from alkyl bromides and magnesium tetraalkylborates in the presence of $\mathrm{Fe}(\mathrm{acac})_{3}$ and Xantphos [125]. The tetraalkylborates could be prepared from olefins, borane and a Grignard reagent. The procedure could be successfully extended to the synthesis of fatty-acid derivatives (Scheme 64). Bedford et al. demonstrated that even simple and affordable iron catalysts, such as iron(III) acetylacetonate $\left[\mathrm{Fe}(\mathrm{acac})_{3},(5 \mathrm{~mol} \%)\right]$, were effective in the coupling of primary and secondary alkyl bromides and iodides with arylboronic esters, properly activated with organolithium reagents without the need to add ligands [126]. 


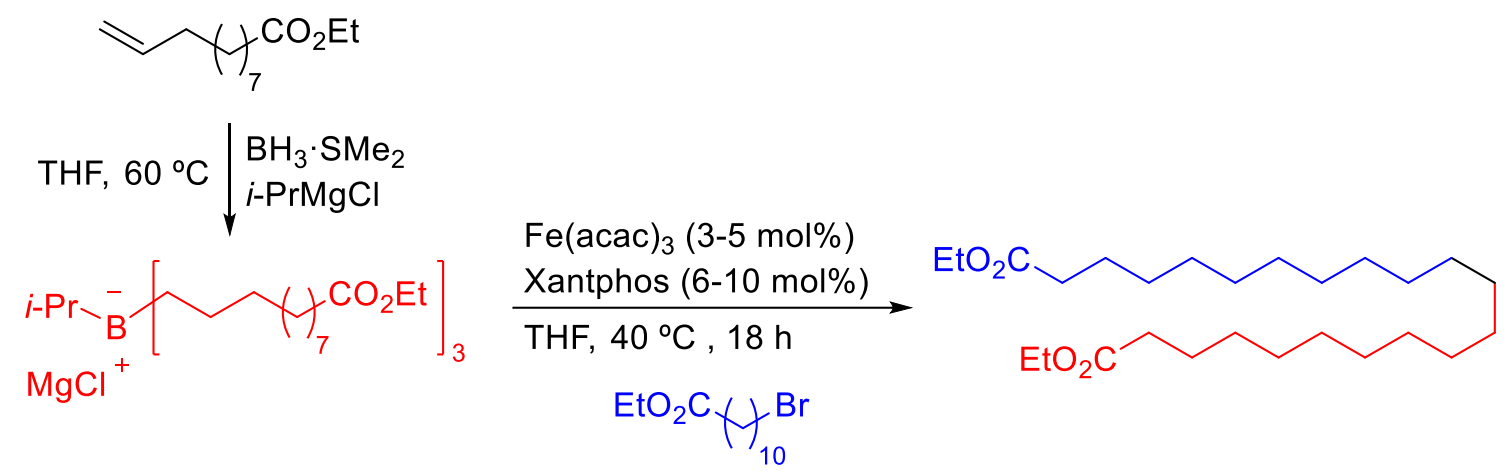

Scheme 64. Suzuki-Miyaura reaction catalyzed by Fe(acac) $)_{3}$-Xantphos.

\subsubsection{Copper}

The renaissance of Ullmann's chemistry has not put the Suzuki-Miyaura aside, with the possibility of catalysis by CuNPs being demonstrated by Rothenberg et al. back in 2002 [127]. More recently, Giri et al. developed an effective protocol for the Suzuki-Miyaura reaction of aryl(heteroaryl) iodides and aryl(heteroaryl)boronic esters catalyzed by $\mathrm{Cu}(\mathrm{I})$ complexes [128]. The reaction proceeded in the presence of $\mathrm{P}, \mathrm{N}$-ligands at low copper concentration $(2 \mathrm{~mol} \%)$. The best result was obtained with the electron-rich and sterically hindered ligand $o$-(di-tert-butylphosphino)- $N, N$ dimethylaniline (Scheme 65), though no ligand was required in the case of heterocyclic substrates. A large number of biaryl(heteroaryl) products was synthesized, albeit substrates with sensitive functional groups were not explored. The authors demonstrated the participation of species of the type $\left[(\text { ligand) } \mathrm{CuF}]_{2}\right.$ and (ligand) $\mathrm{CuAr}$ in the reaction course.

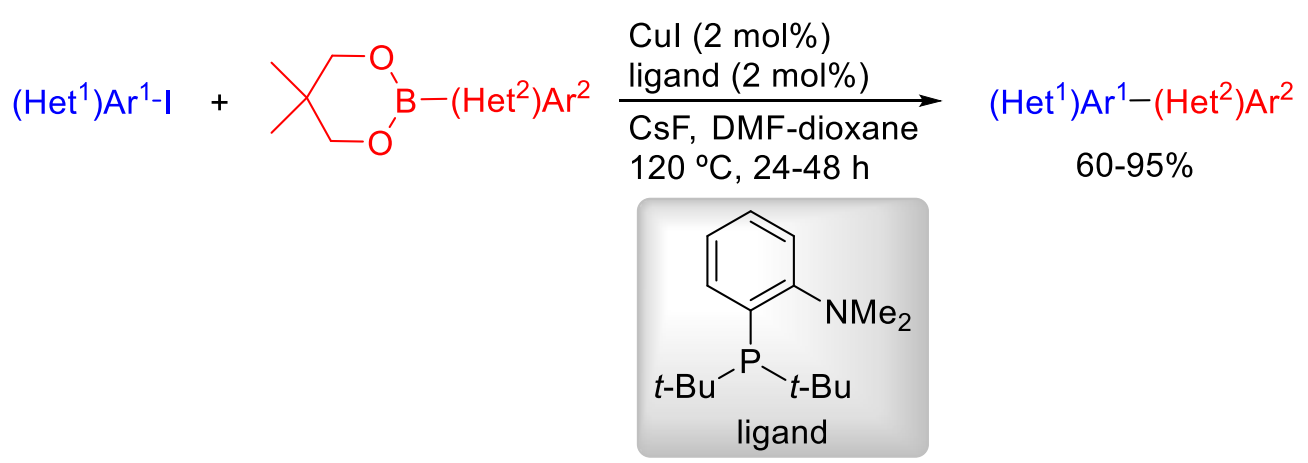

Scheme 65. Suzuki-Miyaura reaction catalyzed by CuI-P,N-ligand.

\subsubsection{Cobalt}

Bedford et al. used the complex of $\mathrm{CoCl}_{2}$ with the $\mathrm{N}$-heterocyclic carbene SIPr as a catalyst for the coupling of aryl chlorides and bromides with organolithium-activated arylpinacolboronates (Scheme 66) [129]. Biaryls were formed in high yields except in the case of heteroaryl halides (33$37 \%)$. The participation of $\mathrm{Co}(0)$ species was proposed on the basis of different experiments.
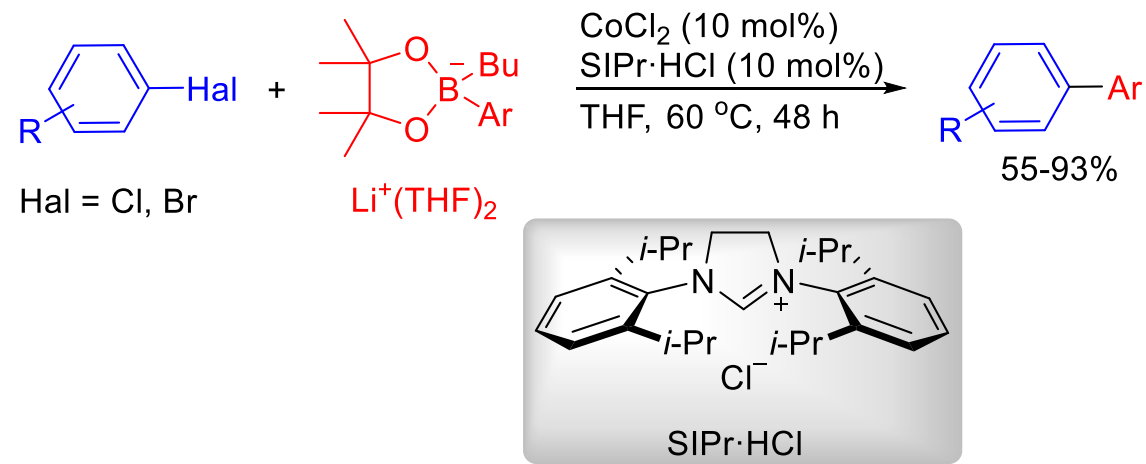
Scheme 66. Suzuki-Miyaura reaction catalyzed by $\mathrm{CoCl}_{2}-\mathrm{SIPr} \cdot \mathrm{HCl}$.

\subsubsection{Gold}

AuNPs have been widely used in different catalytic processes but their use in the Suzuki-Miyaura reaction is very scarce. The possibility of using AuNPs in this reaction was first reported by Guo et al. in 2009 [130]. AuNPs, when stabilized by poly(2-aminothiophenol) (PATP), allowed the highyielding coupling of differently-substituted aryl chlorides and arylboronic acids in water. Later on, Gao et al. found out an unusual catalytic activity for AuNPs on the surface of graphene oxide (GO) [131]. Their activity was found to depend on the size and morphology of the particles, with those spherical $(4 \mathrm{~nm})$ catalyzing the reaction of chlorobenzene and phenylboronic acid in water in almost quantitative yield (Scheme 67). The catalyst was recycled in six runs with insignificant loss of activity (96-92\%).

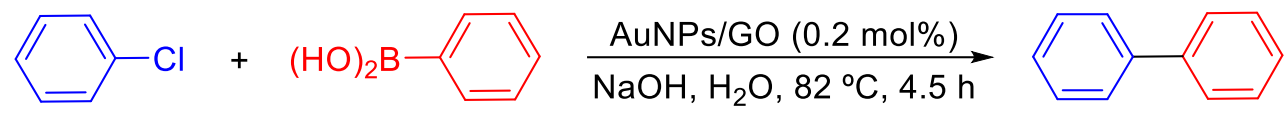

Scheme 67. Suzuki-Miyaura reaction catalyzed by AuNPs/GO.

\subsubsection{Zirconium}

Sepehraddin et al. prepared a core-shell Zr-based nanocomposite by immobilizing zirconocene on silica-coated magnetic copper ferrite nanoparticles $\left(\mathrm{CuFe}_{2} \mathrm{O}_{4} \mathrm{NPs}\right)$ [132]. This material catalyzed the Suzuki-Miyaura reaction of various aryl iodides, bromides and chlorides with phenylboronic acid in polyethylene glycol (PEG-400) at $70{ }^{\circ} \mathrm{C}$ (Scheme 68). All the substrates tested reacted in relatively short reaction times, producing the expected biaryls in high yields. The catalyst could be recovered by the action of an external magnet and reused in five consecutive cycles with no apparent loss of activity.
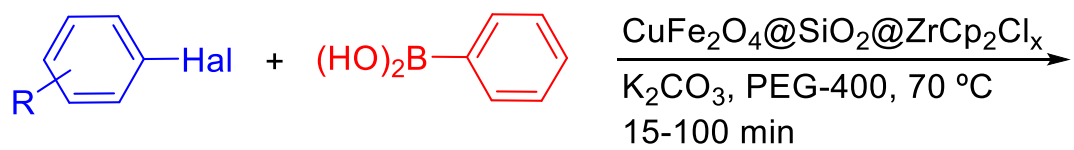
$15-100 \mathrm{~min}$

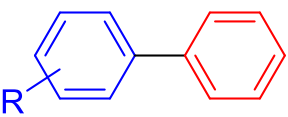

$70-98 \%$

$\mathrm{Hal}=\mathrm{I} ; \mathrm{R}=\mathrm{H}, 4-\mathrm{Me}$, 4-OMe; 1-iodonaphthalene

$\mathrm{Hal}=\mathrm{Br} ; \mathrm{R}=\mathrm{H}, 2-\mathrm{Me}, 4-\mathrm{Me}, 4-\mathrm{CN}, 4-\mathrm{NO}_{2} ;$ 1-bromonaphthalene

$\mathrm{Hal}=\mathrm{Cl} ; \mathrm{R}=\mathrm{H}, 4-\mathrm{NO}_{2}$

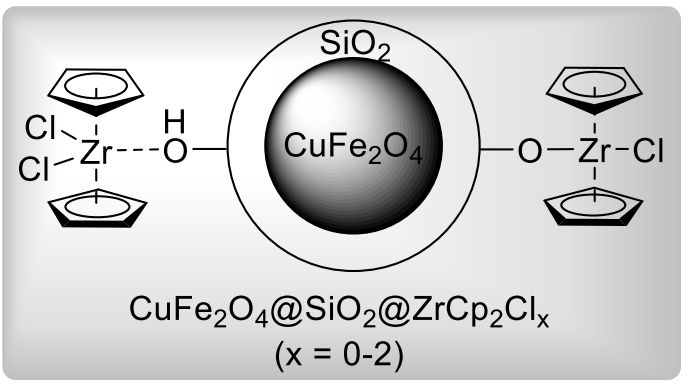

Scheme 68. Suzuki-Miyaura reaction catalyzed by $\mathrm{CuFe}_{2} \mathrm{O}_{4} @ \mathrm{SiO}_{2} @ \mathrm{ZrCp}_{2} \mathrm{Cl}_{\mathrm{x}}$.

\subsection{Unconventional substrates}

There has been an increasing interest in expanding the range of electrophilic substrates suitable for the Suzuki-Miyaura reaction by including leaving groups other than the classical halogens. For instance, triflates have been extensively used in cross-coupling reactions; other sulfonates, such as pentafluorophenylsulfonates [133] and imidazolylsulfonates [134], also served as good leaving groups in Suzuki-Miyaura reactions. Numerous papers deal with aryldiazonium salts, which are the strongest electrophilic substrates and have been particularly effective in the cross-coupling of 
heteroarylboronic acids [135]. Oger and Felpin have recently published a mini-review on the Suzuki-Miyaura reaction of aryldiazonium substrates catalyzed by heterogeneous palladium catalysts [136].

In the more recent literature, Postnikov and Felpin et al. took advantage of the super-electrophilic properties of aryldiazonium salts to perform ultrafast cross-coupling reactions with vinyltrifluoroborates and obtain an array of styrenes [137]. The products were formed in seconds at room temperature under $\mathrm{Pd}(\mathrm{OAc})_{2}$ catalysis in aqueous acetonitrile without any base or additive (Scheme 69). Interestingly, stilbenes could be synthesized through a sequential Suzuki-Heck process. The reactions were tolerant to some sensitive functional groups and were chemoselective towards the C-diazonium center in the presence of a $\mathrm{Ar}-\mathrm{Br}$ bond.

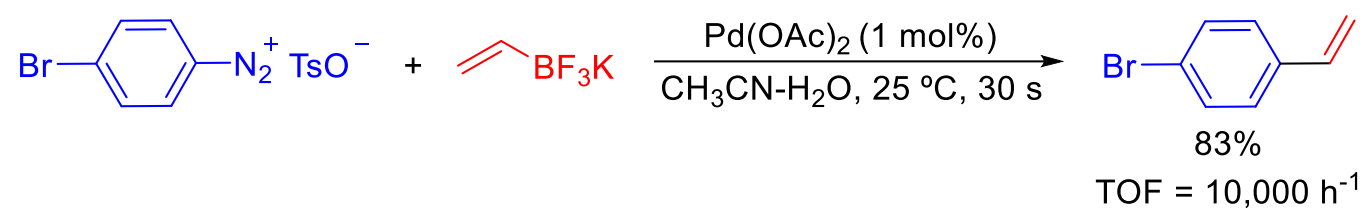

Scheme 69. Pd-catalyzed cross-coupling of aryldiazonium salts and vinyltrifluoroborates.

The acylating version of the Suzuki-Miyaura reaction was reported by Zou et al. by the crosscoupling of carboxylic acids (through the corresponding anhydrides) and diarylborinic acids or tetraarylboronates, in the presence of dimethyl dicarbonate at room temperature (Scheme 70). A large family of alkyl aryl ketones or diaryl ketones was synthesized in moderate-to-high yields [138].

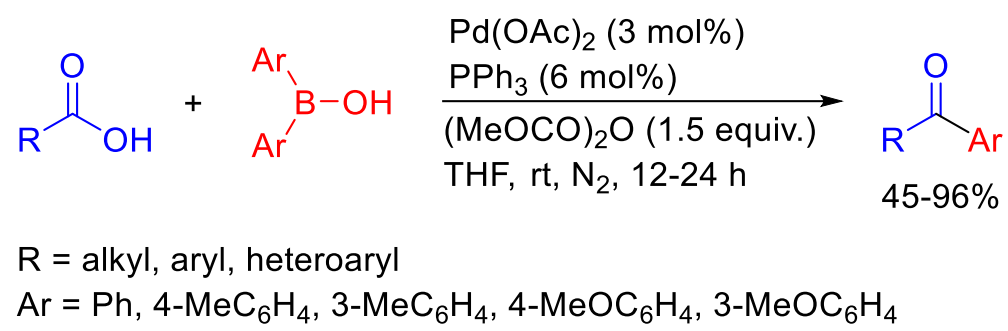

Scheme 70. Pd-catalyzed cross-coupling of carboxylic acids and diarylborinic acids.

Newman et al. [139] developed a new approach to diaryl and alkyl aryl ketones based on the crosscoupling of phenyl esters and arylboronic acids under the catalysis of Nolan's NHC-Pd complex $\operatorname{Pd}(\mathrm{IPr})$ (cinnamyl)Cl (Scheme 71) [140]. The authors noted that the combination of a weak inorganic base, a nonpolar solvent and a small amount of water was necessary to attain high yields. Apparently, the bulky NHC prevents the decarbonylation of the acyl-Pd intermediate, allowing the desired coupling.

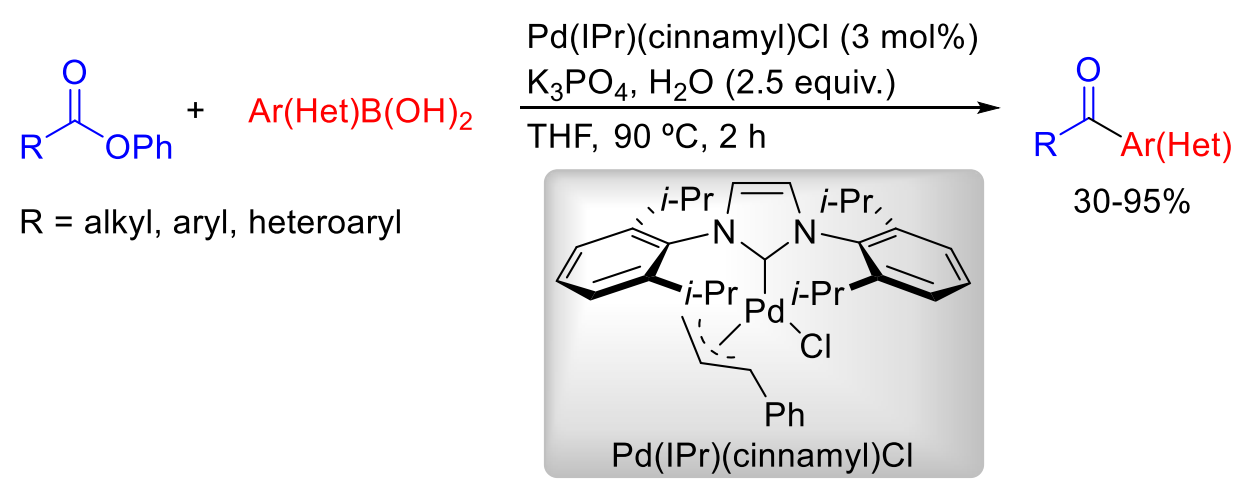

Scheme 71. Pd-catalyzed cross-coupling of phenyl esters and arylboronic acids. 
Hazari et al. improved the aforementioned method by replacing the cinnamyl ligand in the NHCcomplex of the precatalyst with the $\left(\eta^{3}-1-t\right.$-Bu-indenyl) $\operatorname{Pd}(\operatorname{IPr})(\mathrm{Cl})$ ligand [141]. In this way, and in the presence of a stronger base, the reaction could be conducted with less amount of $\mathrm{Pd}$ at room temperature (Scheme 72).

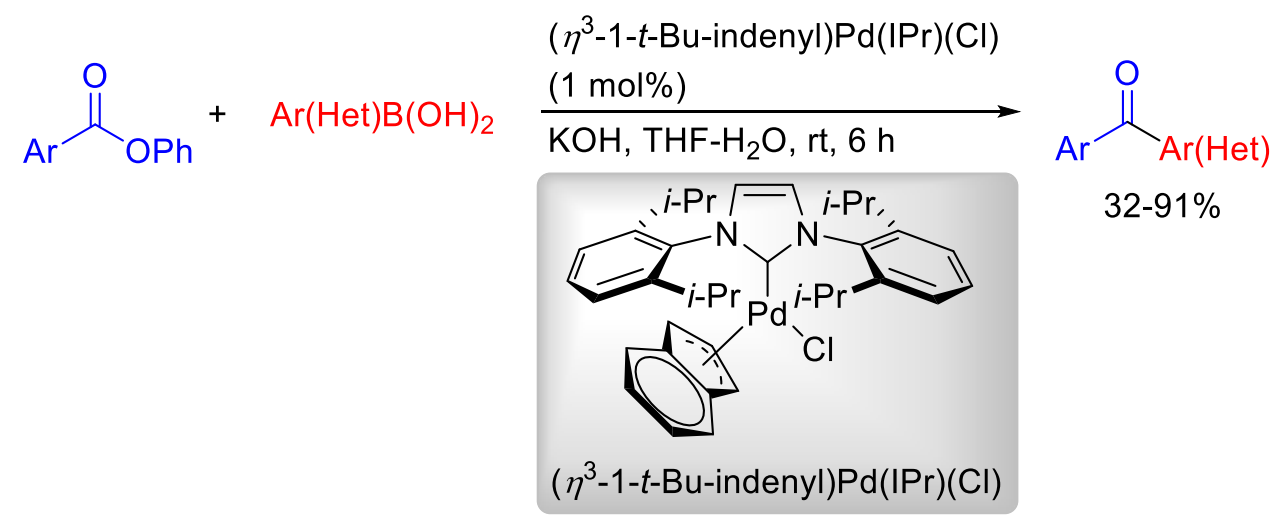

Scheme 72. Pd-catalyzed cross-coupling of phenyl esters and arylboronic acids.

Suzuki-Miyaura-type reactions based on the cleavage of $\mathrm{C}-\mathrm{N}$ bonds have been also reported by different research groups. For instance, Szostak et al. demonstrated that the incorporation of a mesyl group to the nitrogen atom of an amide facilitated the oxidative addition of the metal to the C-N bond. This finding was exploited to prepare a large variety of unsymmetrical diaryl ketones (Scheme 73); alkyl aryl ketones required higher temperature [142a]. The reaction was chemoselective leaving untouched the $\mathrm{C}-\mathrm{Cl}$ bond in the amide. In addition, the sterically hindered 2,4,6-trimethylphenylboronic acid also reacted with amides though in modest yield. The same group used N-Boc-activated amides as substrates in the Suzuki-Miyaura reaction with a large variety of arylboronic acids; reactions proceeded at room temperature under the catalysis of the aforementioned $\mathrm{Pd}(\mathrm{IPr})$ (cinnamyl)Cl complex, generally, in good-to-excellent yields (Scheme 74) [142b]. Moreover, not only aromatic but aliphatic amides could be successfully coupled in the presence of Pd-PEPSI pre-catalyst (Scheme 75) [142c].

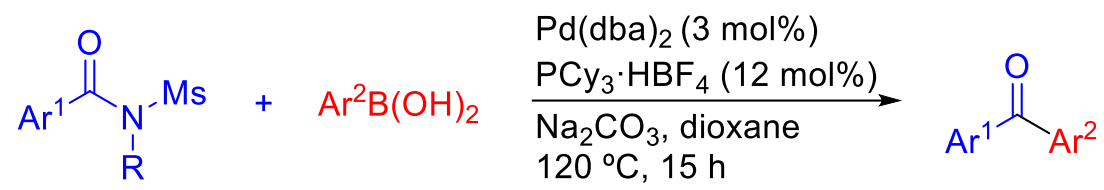

Scheme 73. Pd-catalyzed cross-coupling of $N$-mesyl aromatic amides and arylboronic acids.

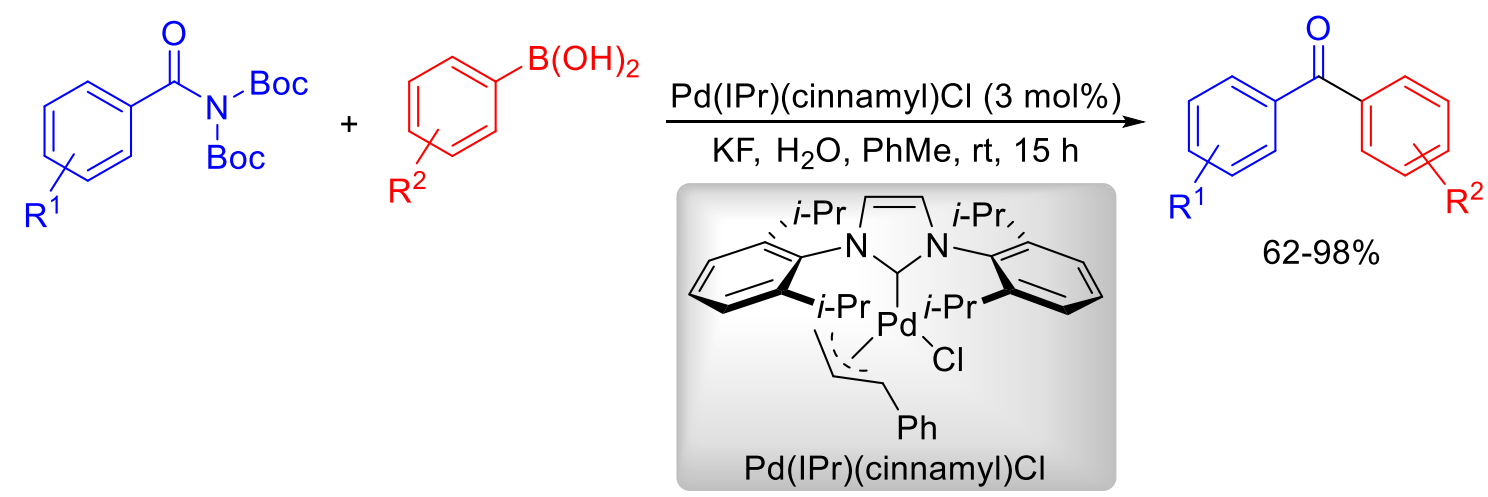

Scheme 74. Pd-catalyzed cross-coupling of $N$-Boc aromatic amides and arylboronic acids. 


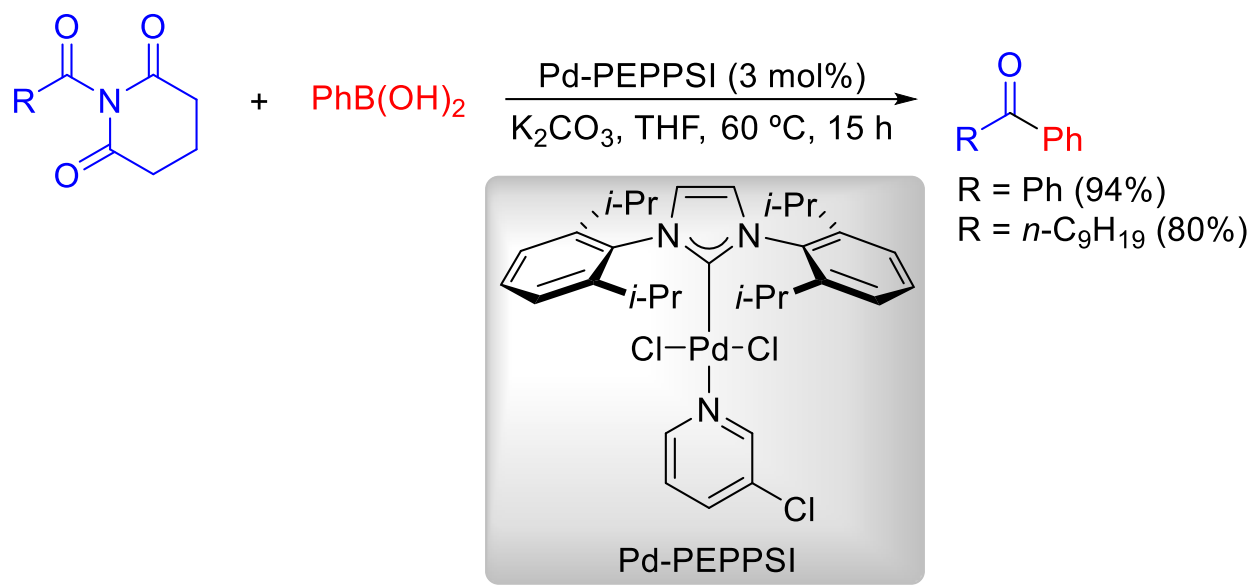

Scheme 75. Pd-catalyzed cross-coupling of aromatic and aliphatic amides with phenylboronic acid.

Garg et al. made an outstanding contribution to the transformation of the C-N bond of amides into $\mathrm{C}-\mathrm{C}$ bonds through the nickel-catalyzed Suzuki-Miyaura-type reaction [143a]. For instance, the reaction of $\mathrm{N}$-Bn- $\mathrm{N}$-Boc amides with $\mathrm{PhBpin}$, in the presence of $\mathrm{Ni}(\mathrm{cod})_{2} / \mathrm{SIPr}$, efficiently gave the corresponding ketones under mild conditions $\left(50{ }^{\circ} \mathrm{C}\right)$ [143b]. Notably, aliphatic amides also reacted with aryl pinacolboronates under the catalysis of a Ni-NHC complex, though under harsher reaction conditions $\left(120^{\circ} \mathrm{C}\right)$ (Scheme 76$)$ [143c]. A DFT theoretical study on the activation of the amide C$\mathrm{N}$ bond in the reaction with ArBpin catalyzed by Ni-NHC complexes was carried out by Zho and Zhy et al. [144]. The possibility of oxidative addition of nickel to the $\mathrm{C}(\mathrm{O})-\mathrm{N}(\mathrm{Boc}) \mathrm{Bn}$ bond facilitated by the coordination of nickel to the carbonyl oxygen atom was proven. The reaction rate determining step was shown to be the transmetalation, in which water and base $\left(\mathrm{K}_{3} \mathrm{PO}_{4}\right)$ played a crucial role. Apparently, amide protonation by water led to the easy-to-remove HN(Boc)Bn leaving group.

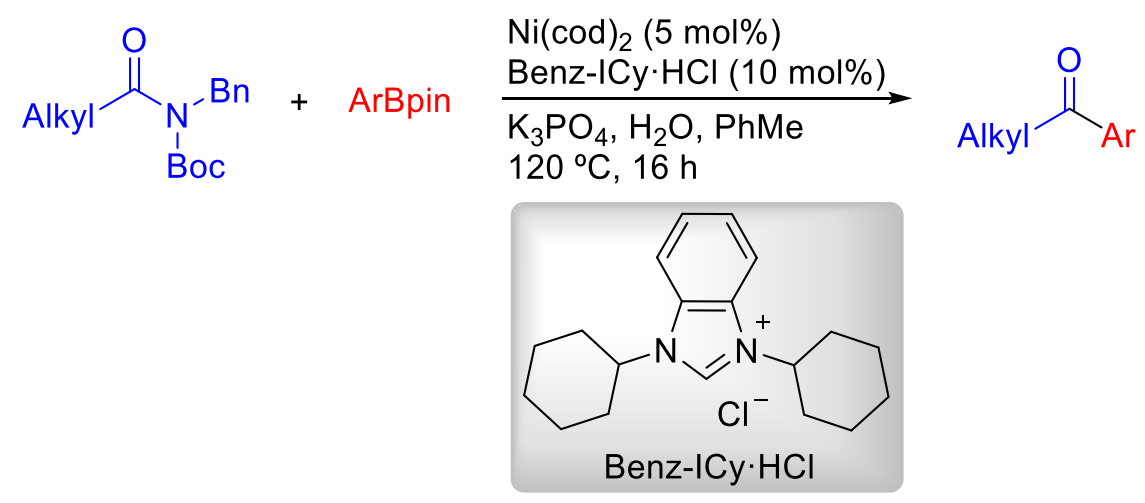

Scheme 76. Ni-catalyzed cross-coupling of aliphatic amides and ArBpin.

Namba and Cruden et al. demonstrated that benzylic fluorinated sulfones were effective electrophilic components in the palladium-catalyzed Suzuki-Miyaura reaction with aryl and heteroarylboronic acids, leading to structurally diverse diarylmethanes, generally, in good yields (Scheme 77) [145]. 


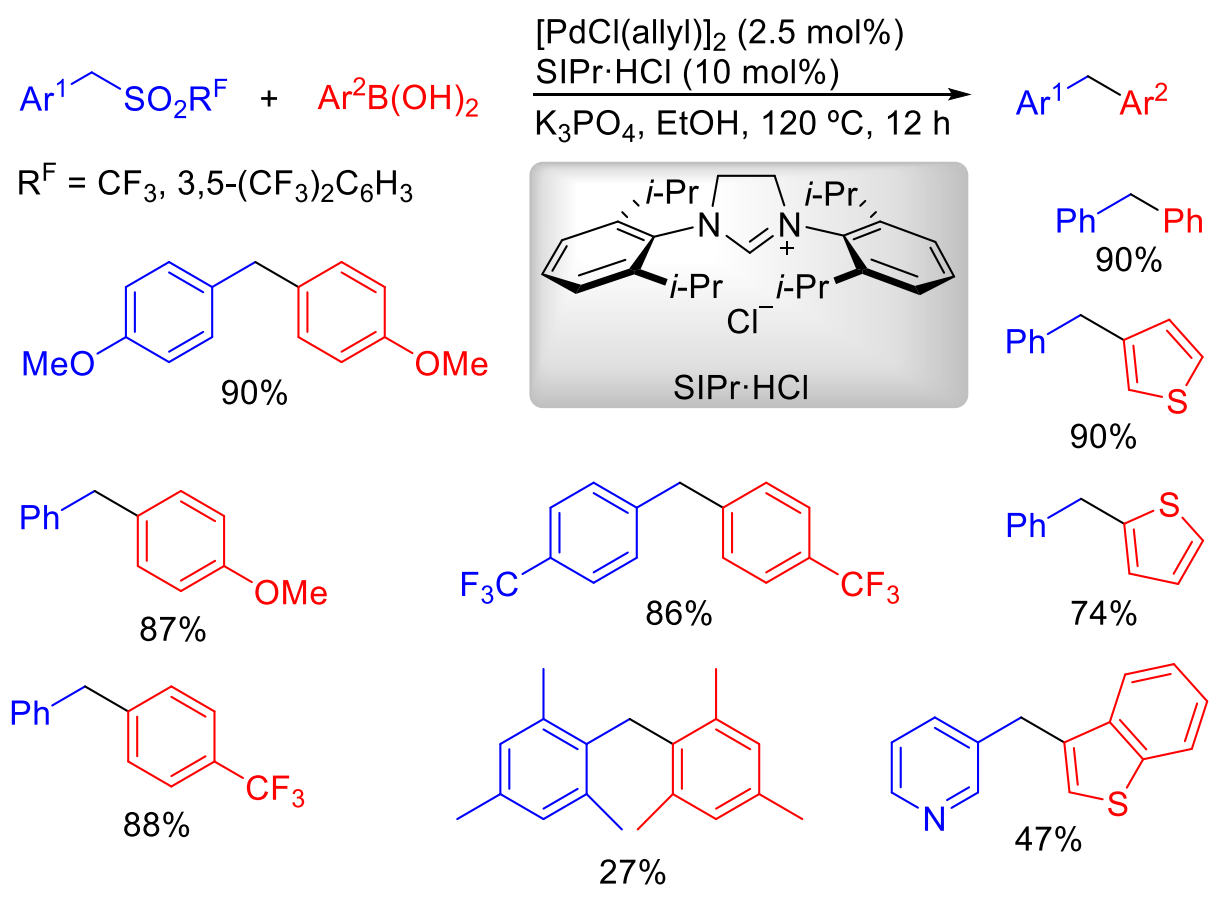

Scheme 77. Pd-catalyzed cross-coupling of benzylic fluorinated sulfones and arylboronic acids.

A simple catalytic system, including $\mathrm{Pd}\left(\mathrm{NH}_{3}\right)_{2} \mathrm{Cl}_{2}$ and $\mathrm{CuCl}_{2}$, was deployed for the cross-coupling of arylhydrazine hydrochlorides and aryltrifluoroboronates (Scheme 78) [146]. Reactions proceeded in water at room temperature in the presence of air for $12 \mathrm{~h}$. A large variety of aromatic substrates was tested giving good yields of the expected biaryls. Copper(II) chloride was proposed to have a double oxidant role, in-situ transforming the hydrazines into aryldiazenes and $\operatorname{Pd}(0)$ into $\operatorname{Pd}(\mathrm{II})$; the air oxygen could reoxidize $\mathrm{Cu}(\mathrm{I})$ to $\mathrm{Cu}(\mathrm{II})$.

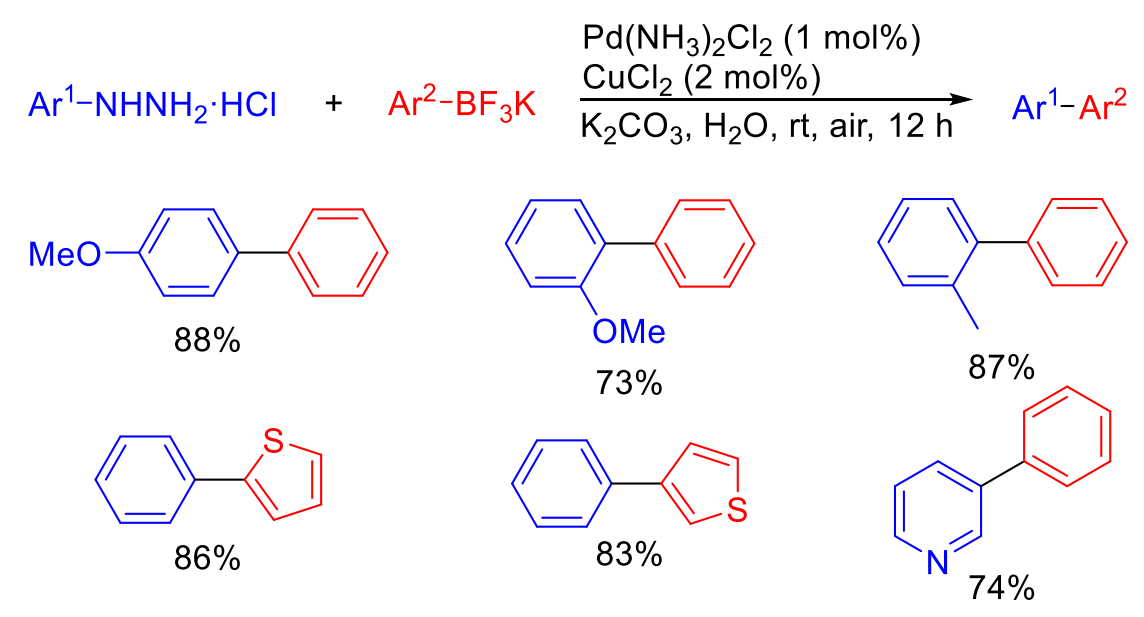

Scheme 78. Pd-catalyzed cross-coupling of arylhydrazine hydrochlorides and aryltrifluoroboronates.

Recently, Nakao and Sakaki et al. have reported the use of aromatic nitrocompounds as the electrophilic partners of arylboronic acids in the Suzuki-Miyaura reaction, in this case catalyzed by palladium in the presence of BrettPhos ligand (Scheme 79) [147]. An unprecedented oxidative addition of $\mathrm{Pd}(0)$ onto the $\mathrm{C}_{\mathrm{sp} 2}-\mathrm{NO}_{2}$ bond was suggested as the first step in the catalytic cycle. 


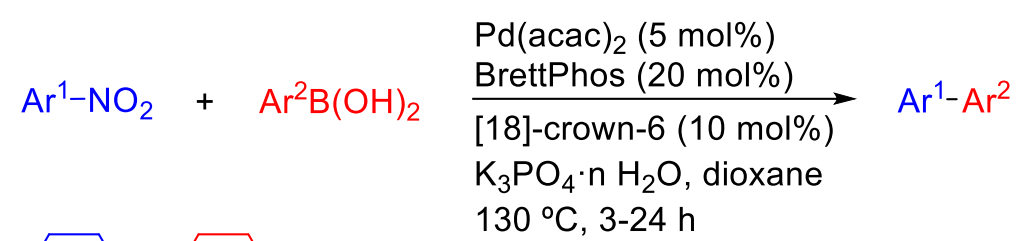

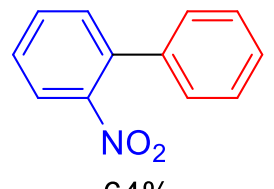

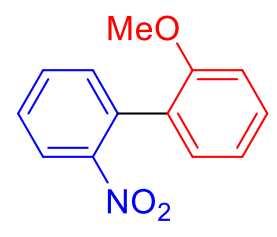

$67 \%$

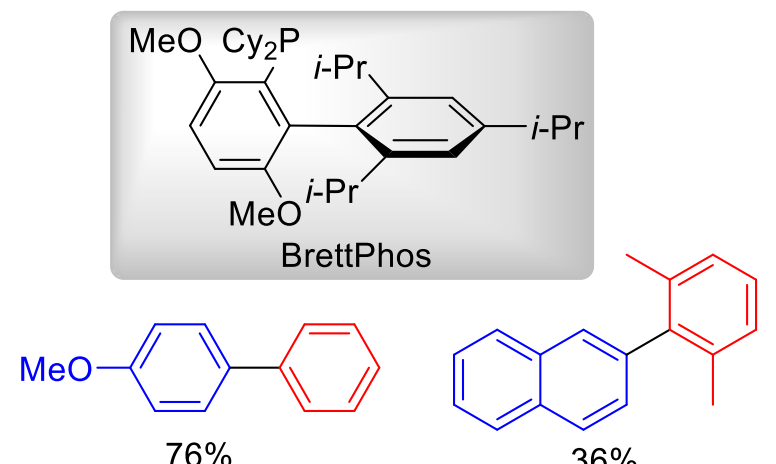

$76 \%$<smiles>COc1ncccc1-c1cccs1</smiles>

Scheme 79. Pd-catalyzed cross-coupling of aromatic nitrocompounds and arylboronic acids.

McNally and Zhang used the phosphonium group as a pseudohalogen in the Suzuki-Miyaura reaction [148]. The phosphonium salts were obtained by direct $\mathrm{C}-\mathrm{H}$ functionalization of pyridines and diazines. The resulting triphenylheteroarylphosphonium triflates reacted with arylboronic acids under the catalysis of the aforementioned nickel NHC-complex. A wide range of biaryls was successfully synthesized, including biologically-active derived and complex molecules (Scheme 80).

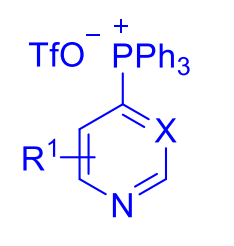<smiles>[R][R]1cccc([18OH])c1</smiles>

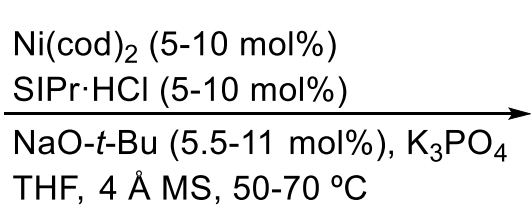<smiles>Cc1ccc(-c2cnc3cc4c(cc3n2)C2CCC4CC2Cc2ccccc2)cc1</smiles>

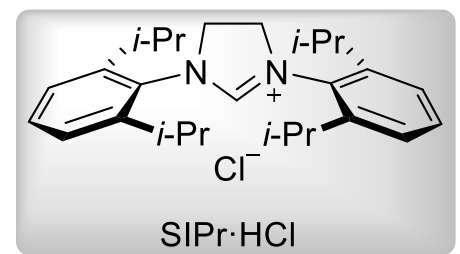
$86 \%$<smiles>Cc1ccc(-c2ccncc2CN2CCN(c3ncccn3)CC2)cc1</smiles><smiles>Cc1ccc(-c2ccncc2COCC2CN(C(c3ccccc3)c3ccccc3)C2)cc1</smiles>

Scheme 80. Ni-catalyzed cross-coupling of triphenylheteroarylphosphonium triflates with arylboronic acids. 


\subsection{Non-traditional reaction conditions}

\subsubsection{Continuous flow processes}

Continuous flow processes are more convenient that batch processes for industrial applications [149]. The flow method is usually carried out by passing the reagent mixture in solution through a column with a stationary phase on which the catalyst is fixed. In this case, it is very important to prevent catalyst leaching, otherwise, the flow can wash the catalyst away with the concomitant loss of its efficiency. Research on the Suzuki-Miyaura reaction under continuous-flow conditions is scarce [150]. The problem associated with the practically unavoidable leaching has been addressed by applying a reverse flow; in this way, the palladium accumulated at one end of the column can be shifted back.

Buchwald et al. developed a lithiation/borylation/Suzuki-Miyaura reaction sequence for the synthesis of biaryls in a microflow system [151]. The cross-coupling reaction was effected by injecting a solution of aqueous $\mathrm{KOH}$ and a solution of the aryl halide and Pd-XPhos precatalyst in the THF stream containing the boronate reagent; the mixture entered a third reactor subjected to ultrasound irradiation at $60{ }^{\circ} \mathrm{C}$. The method showed a wide substrate scope, with a variety of biaryls being synthesized from aryl bromides and chlorides of different electronic nature in good-toexcellent yields. Generally, very short residence times were needed, even for heterocyclic substrates (Scheme 81).
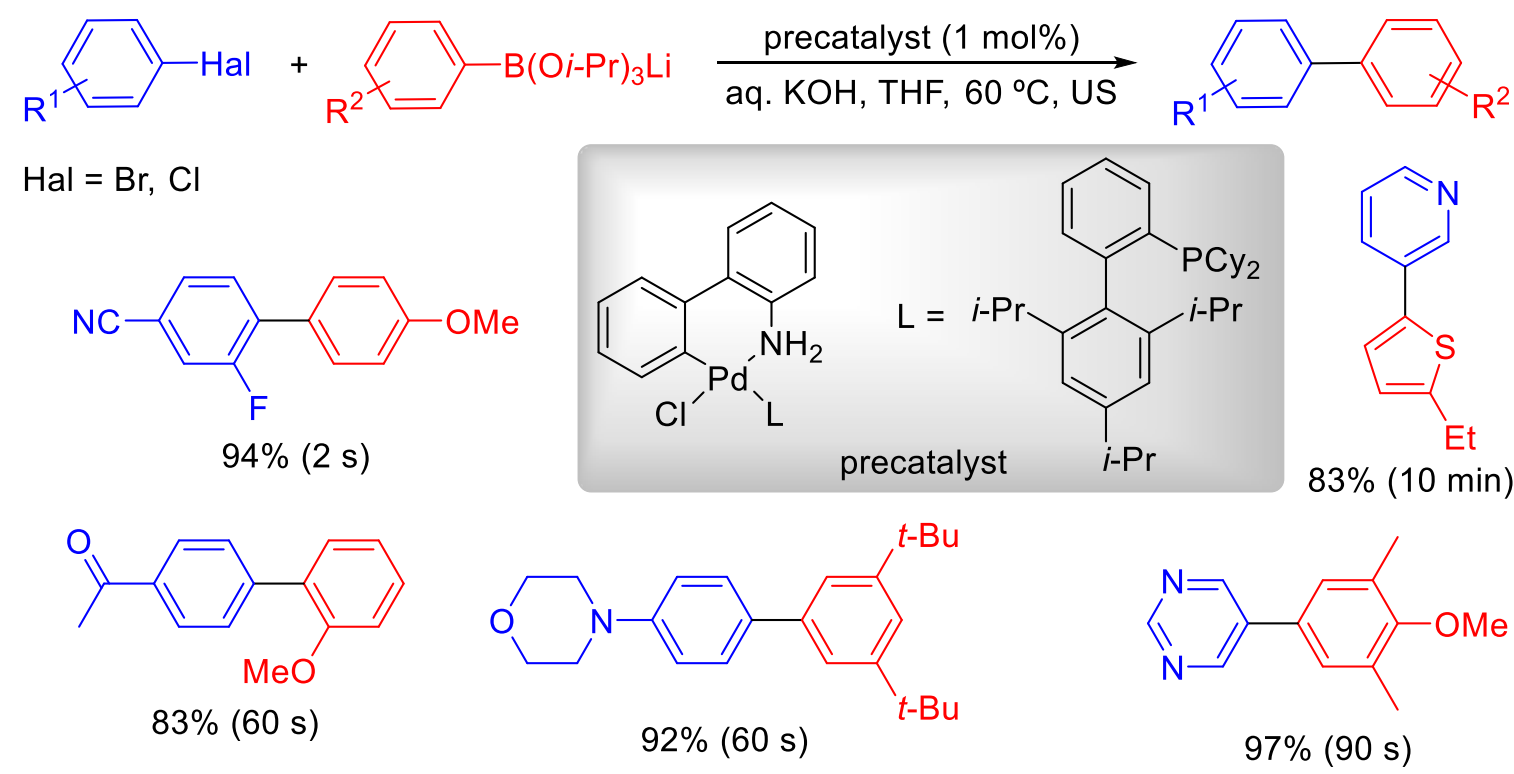

Scheme 81. Suzuki-Miyaura reaction in a microflow system.

Alcázar et al. designed a continuous-flow system involving the previously mentioned silicasupported palladium catalyst SiliaCat [152]. The solutions of the aryl halide or triflate and the organoboron and base were independently pumped through a T-shaped mixer and, then, into a column containing SiliaCat DPP-Pd [i.e., as diphenylphosphine palladium(II)]. A biphasic THF$\mathrm{H}_{2} \mathrm{O}$ solvent system was used at $60{ }^{\circ} \mathrm{C}$ with a residence time of $5 \mathrm{~min}$. Generally, high yields were attained, irrespective of the aryl halide and organoboron used (Scheme 82). 


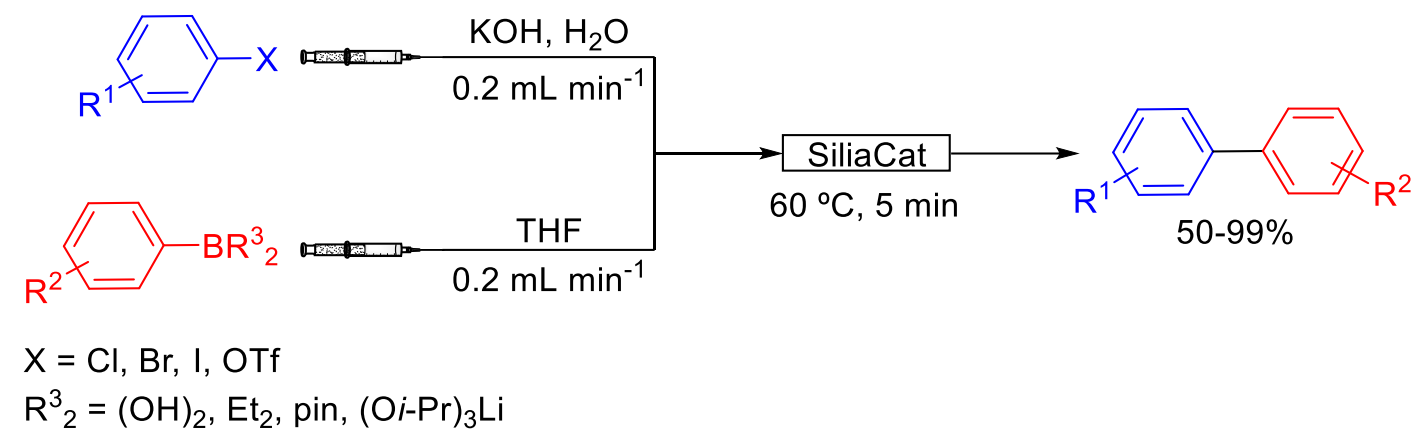

Scheme 82. Suzuki-Miyaura reaction catalyzed by SiliaCat in a continuous flow system.

Seeberger et al. applied a capture-and-release strategy in an alternating flow process for the SuzukiMiyaura reaction [153]. Two columns were packed with single-walled carbon nanotubes (SWNT) bound to a pyrene-derived NHC-palladium complex. Iodobenzene was passed through the first column heated at $100{ }^{\circ} \mathrm{C}$; the thermal treatment released the palladium complex into a homogeneous reactor sector (Scheme 83). The phenylboronic acid was inserted into the flow after the first column and the mixture reacted while passing through a spiral tube heated at $60{ }^{\circ} \mathrm{C}$. Then, the flow entered the second column, where the catalyst was captured at room temperature; after some time, the flow was reversed. Quantitative conversion and no leaching were observed in the forward direction of the flow. In the opposite direction, $21 \%$ loss of palladium was recorded, attributed to a possible competitive binding between the resulting biaryl and the pyrene moiety of the complex for the SWNT.
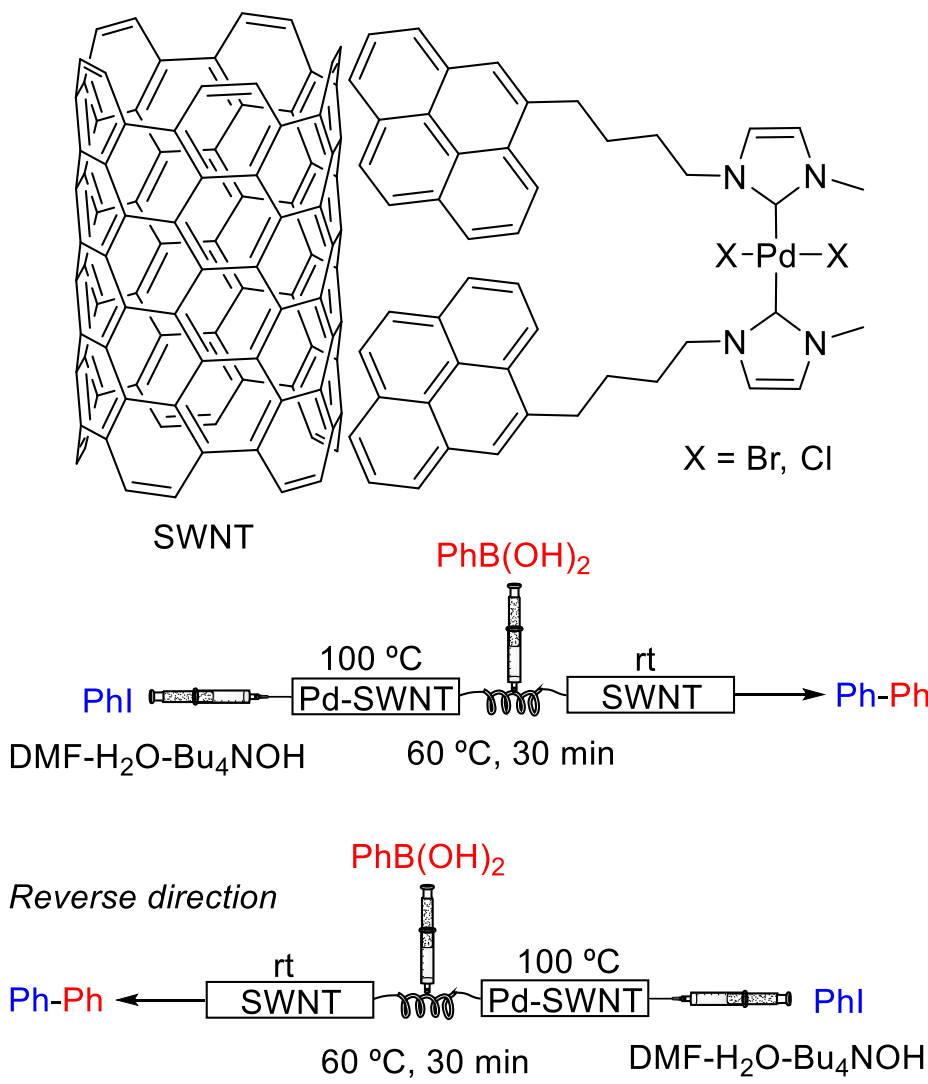

Scheme 83. Suzuki-Miyaura reaction catalyzed by Pd-SWNT in a alternating flow system.

Gram-scale Suzuki-Miyaura reactions in continuous flow were described by Das et al. using polymer-supported $\mathrm{Pd}(0) \mathrm{NPs}$ in combination with ultrasound irradiation [154]. The reagents, base and solvent were introduced altogether into a reservoir (Scheme 84). The mixture was pumped into 
the reaction vessel containing the catalyst and two exits, one to deliver the product into the aforementioned reservoir and another to drain the system after the reaction. Several iodides, bromides and electron-deficient aryl chlorides where coupled with phenylboronic acid at room temperature $(2-4 \mathrm{~h})$ in good yields. The catalytic system showed good recycling capability in five cycles with minimum palladium leaching.

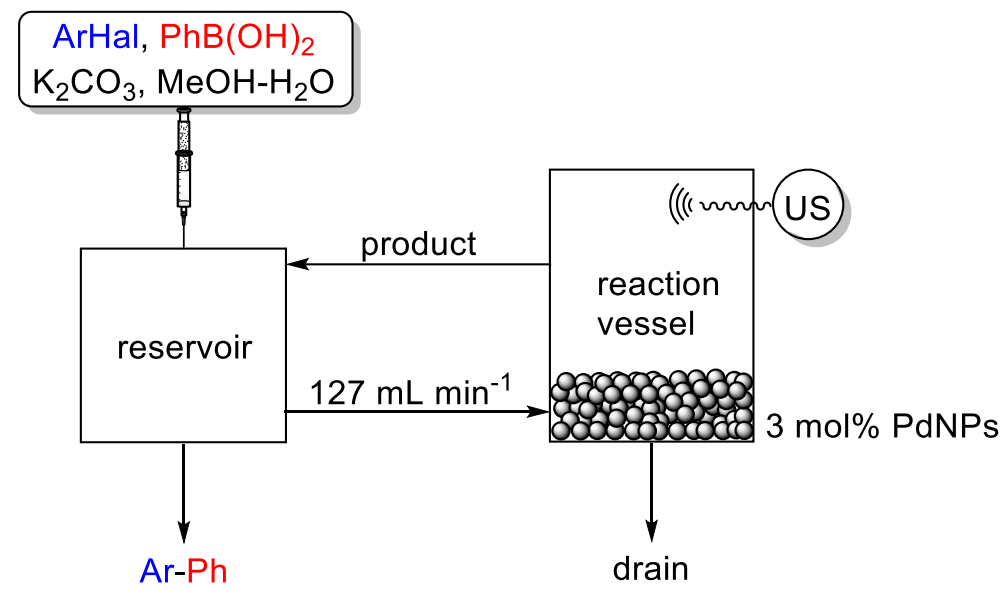

Scheme 84. Suzuki-Miyaura reaction catalyzed by PdNPs in a continuous flow system.

Verboom et al. immobilized PdNPs on poly(amidoamine) (PAMAM-Gn) dendrimers covalently bound to the inner surface of glass capillaries (Scheme 85) [155]. The capillaries were used as flow microreactors for the reaction of iodobenzene and $p$-tolylboronic acid in ethanol at $80{ }^{\circ} \mathrm{C}$, with tetrabutylammonium hydroxide as a base. The PAMAM-G3 catalyst gave the best results, running continuously over seven days with total TON $=39,560$ and TOF $=11,340 \mathrm{~h}^{-1}$; a $10 \%$ loss of palladium confirmed the homogeneous nature of the process.
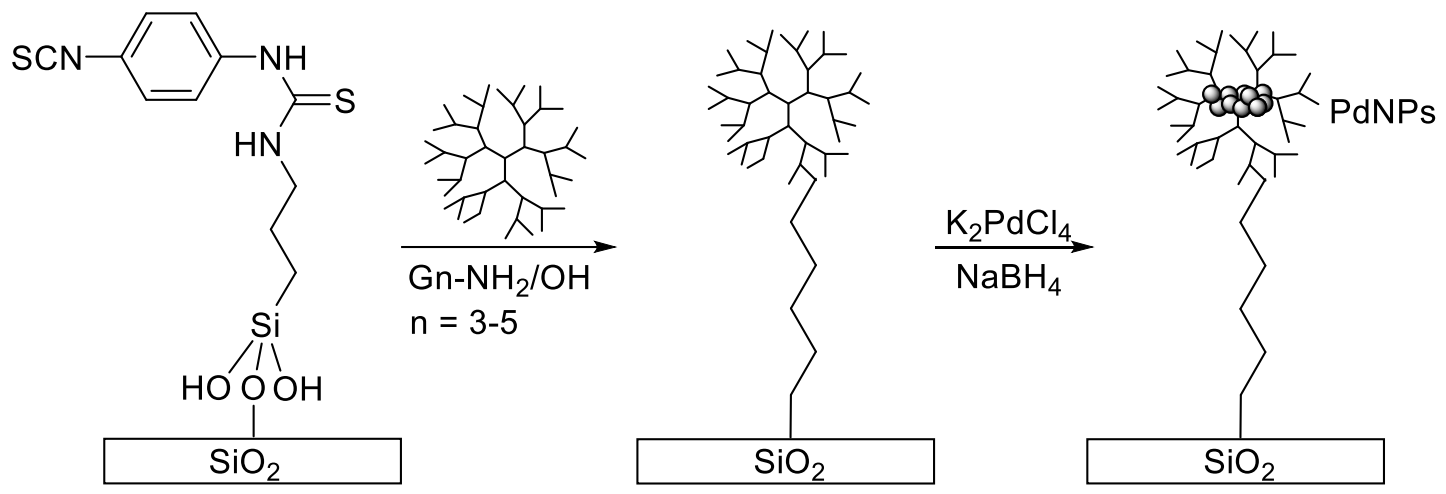

Scheme 85. Immobilization of PdNPs on PAMAM-Gn dendrimers bound to glass capillaries.

Martín-Matute et al. prepared PdNPs supported on a functionalized mesoporous MOF [8 wt\% Pd@MIL-101(Cr)-NH2 $\mathrm{NH}_{2}$, that was packed into a microflow reactor [156]. A series of eleven biaryls were prepared, in a single experiment, by coupling arylboronic acids or aryl boronates and aryl bromides in flow at room temperature (Scheme 86). Decrease in the productivity was not observed until the $12^{\text {th }}$ product, something that might be correlated with the loss of palladium measured for the recovered catalyst (from 7.29 to $6.81 \mathrm{wt} \%$ ). 


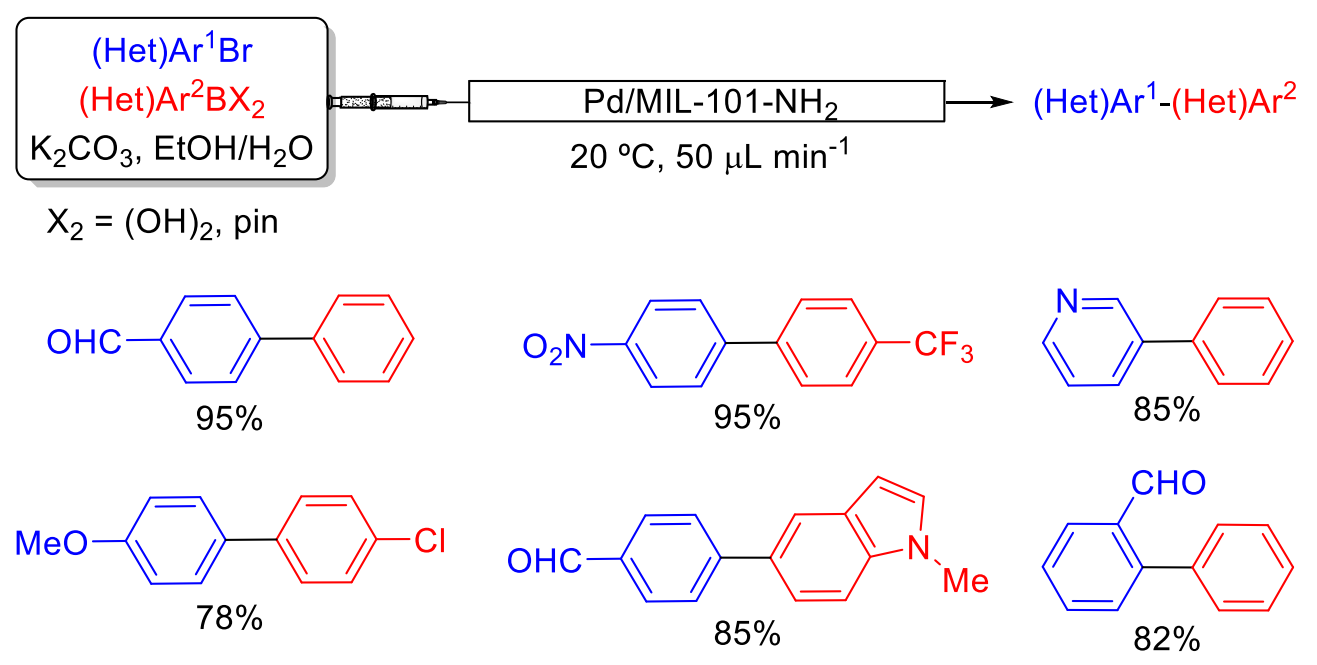

Scheme 86. Suzuki-Miyaura reaction catalyzed by PdNPs/MOF in a microflow reactor.

\subsubsection{Mechanoactivation}

It is known that the mechanical activation of reagents under ball-milling conditions is an alternative way to accelerate chemical reactions, where friction can produce an inversion of states population in comparison with the normal population under thermal conditions [157]. In some cases, the addition of a small amount of a solvent can improve the reaction results. Su at al. investigated the reasons of this effect in more detail, using the Suzuki-Miyaura coupling of $p$-chloroacetophenone and phenylboronic acid as a model reaction [158]. In the absence of solvent, 55\% and $21 \%$ yields were recorded with the ligand DavePhos and $\mathrm{PCy}_{3}$, respectively. However, the addition of $\mathrm{MeOH}$ or EtOH exerted a strong beneficial effect in both cases, that was particularly pronounced in the case of $\mathrm{PC}_{3}$ (yield increased from 21 to 97\%). High yields of biaryls were obtained in the reaction of various aryl chlorides and arylboronic acids under these conditions (Scheme 87).

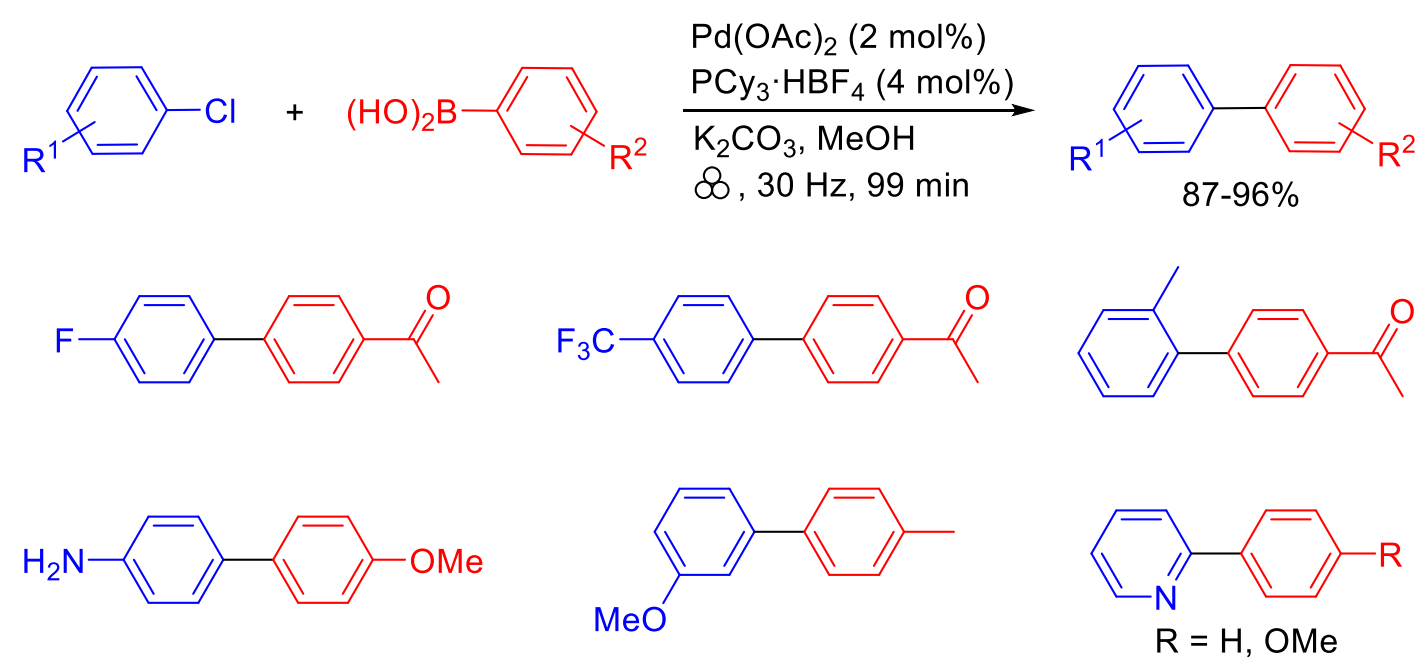

Scheme 87. Pd-catalyzed Suzuki-Miyaura reaction under ball-milling conditions.

\section{Stereoselective reactions}

Chiral moieties can be introduced in Suzuki-Miyaura products by using chiral substrates (organoboron compound or electrophile) or through asymmetric cross-couplings. In the first case, the substrate must contain a stereogenic $\mathrm{C}_{\mathrm{sp} 3}-\mathrm{B}$ or $\mathrm{C}_{\mathrm{sp} 3}-\mathrm{X}$ center. These kind of studies are quite recent and scarce because such substrates are prone to $\beta$-hydride elimination. For instance, in 2009, Crudden et al. succeeded in the Suzuki-Miyaura coupling of chiral benzyl pinacolboronate 
derivatives and aryl iodides, maintaining the original configuration of the benzylic carbon atom [159]. The reaction was catalyzed by a conventional palladium complex and triphenylphosphine in the presence of silver oxide as a base (Scheme 88).

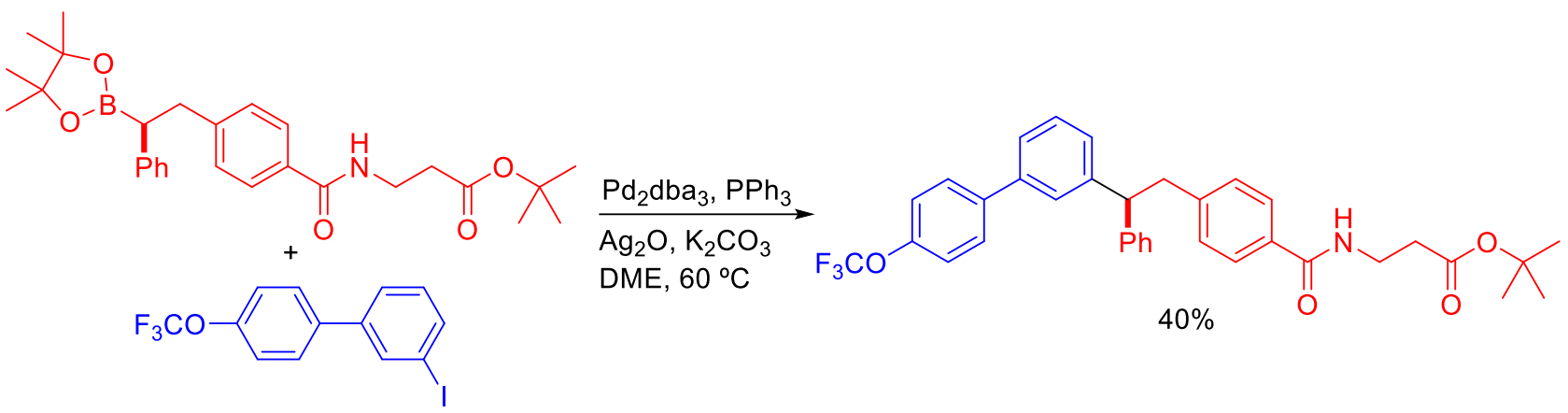

Scheme 88. Pd-catalyzed cross coupling of chiral benzyl pinacolboronate derivatives and aryl iodides.

Crudden and Aggarwal et al. demonstrated that, when starting from secondary allylic boronic esters, the coupling occurred through a syn-S $\mathrm{S}_{\mathrm{E}}$ transmetalation process to furnish the products with high $\gamma$ regioselectivity and in an enantiospecific manner (Scheme 89) [160].

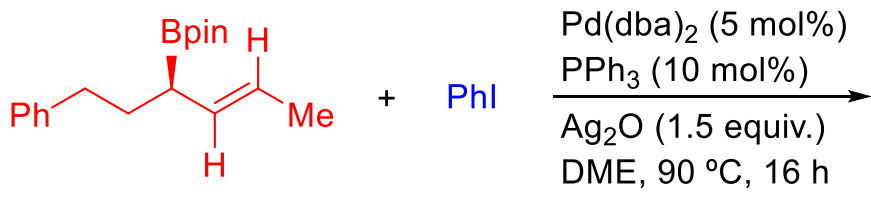

$(R, E)$<smiles>C/C=C\C(Br)CCc1ccccc1</smiles>

$(R, Z)$<smiles>C[C@H](/C=C/CCc1ccccc1)c1ccccc1</smiles>

$75 \%(S, E)$

$$
\begin{aligned}
& \mathrm{Pd}(\mathrm{dba})_{2}(5 \mathrm{~mol} \%) \\
& \mathrm{PPh}_{3}(10 \mathrm{~mol} \%) \\
& \underset{\mathrm{Ag}_{2} \mathrm{O}(1.5 \text { equiv. })}{\mathrm{DME}, 90^{\circ} \mathrm{C}, 16 \mathrm{~h}}
\end{aligned}
$$

Scheme 89. Pd-catalyzed cross coupling of secondary allylic boronic esters and iodobenzene.

Suginome et al. found that the arylation of chiral $\alpha$-acetamidobenzylboronic esters leading to $N$ (diarylmethyl)acetamides occurred in an enantiodivergent fashion, with retention or inversion of the configuration depending on the additives [161]. The addition of the Lewis acid $\mathrm{Zr}(\mathrm{O} i-\mathrm{Pr})_{4}$ in $i$ $\mathrm{PrOH}$ led to retention of the configuration in 78-93\% yield, whereas the presence of phenol caused inversion with high enantiospecificity (up to 99\%) (Scheme 90).

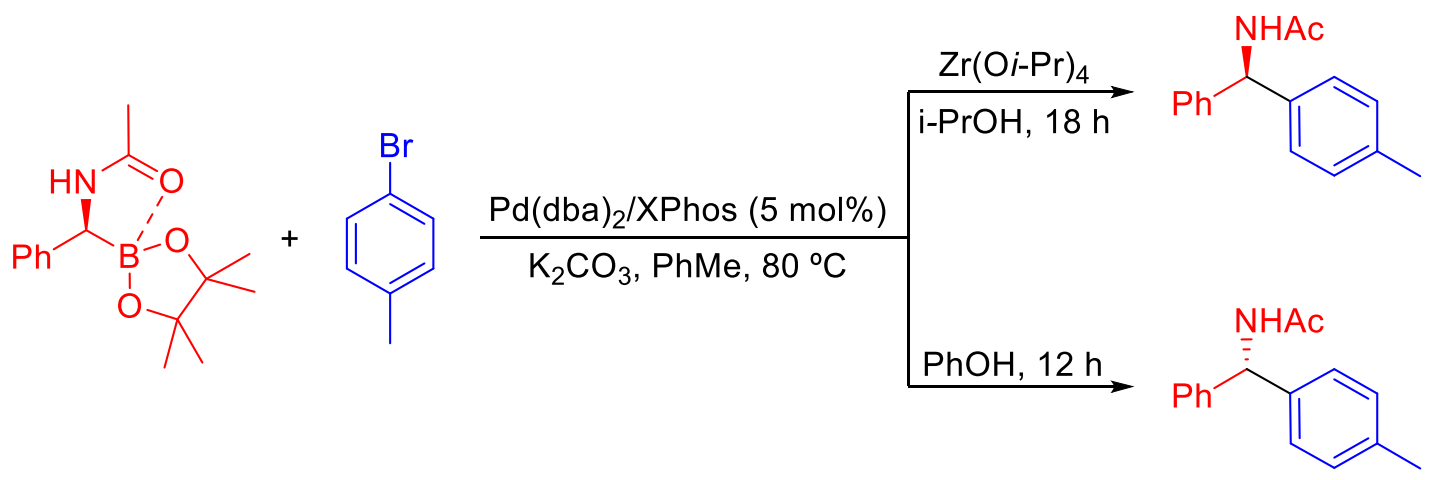

Scheme 90. Pd-catalyzed cross coupling of a chiral $\alpha$-acetamidobenzylboronic ester and 4-bromotoluene. 
Molander et al. introduced the amide group into the structure of trifluoroorganoborates in order to allow the first cross-coupling of non-benzylic secondary alkylborates with aryl chlorides and bromides [162]. Apparently, the intramolecular coordination of the carbonyl amide to boron first and, then, to palladium, promoted transmetalation with inversion of the configuration and inhibited $\beta$-hydride elimination in the intermediate RPdAr, respectively [162]. As a result, the reaction proceeded in high yield with inversion of the configuration and without any loss of enantiomeric purity (Scheme 91).

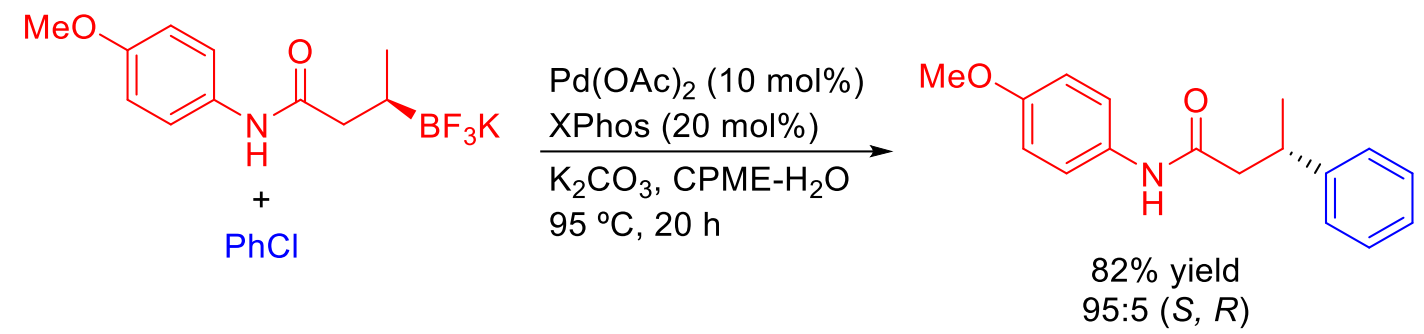

Scheme 91. Pd-catalyzed cross coupling of a chiral trifluoroorganoborate and chlorobenzene.

Chiral electrophiles with varied leaving groups have also been subjected to the Suzuki-Miyaura reaction. In the case of a triflate cyanohydrin, $\beta$-hydride elimination was suppressed by nitrilegroup coordination to the palladium atom (Scheme 92). As expected, the reaction took place with inversion of the configuration, something that usually occurs at the oxidative-addition stage [163].

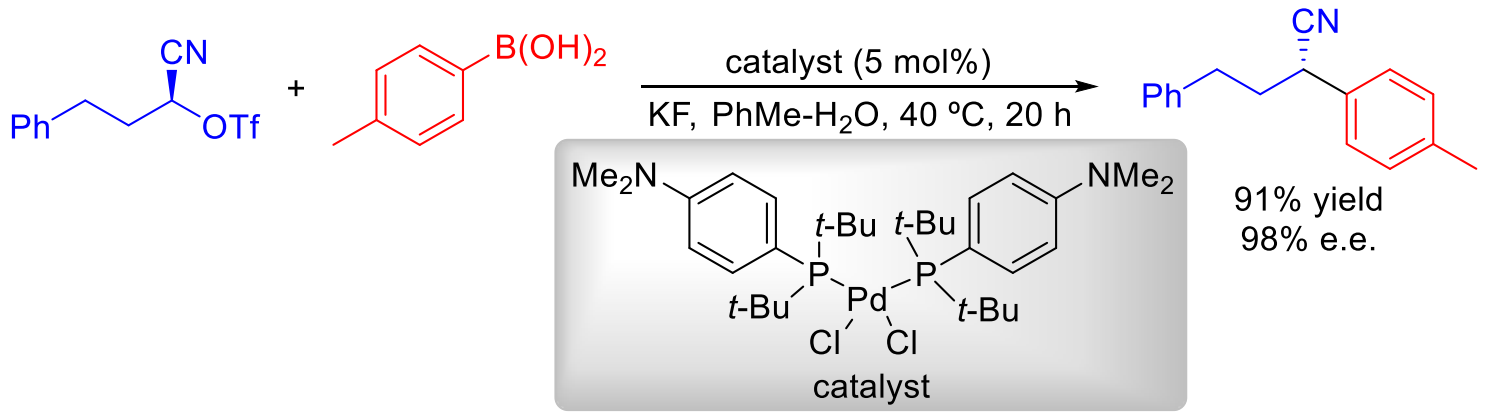

Scheme 92. Pd-catalyzed cross coupling of a triflate cyanohydrin and $p$-tolylboronic acid.

In another example, Jarvo et al. demonstrated that the stereochemistry of the nickel-catalyzed crosscoupling of a chiral benzylcarbamate with arylboronates could be controlled by the nature of the achiral ligand [164] (Scheme 93). Xie et al. performed a quantum chemical study on the mechanism of this enantiodivergent reaction and explained the influence of the ligand in the absolute configuration of the product [165].

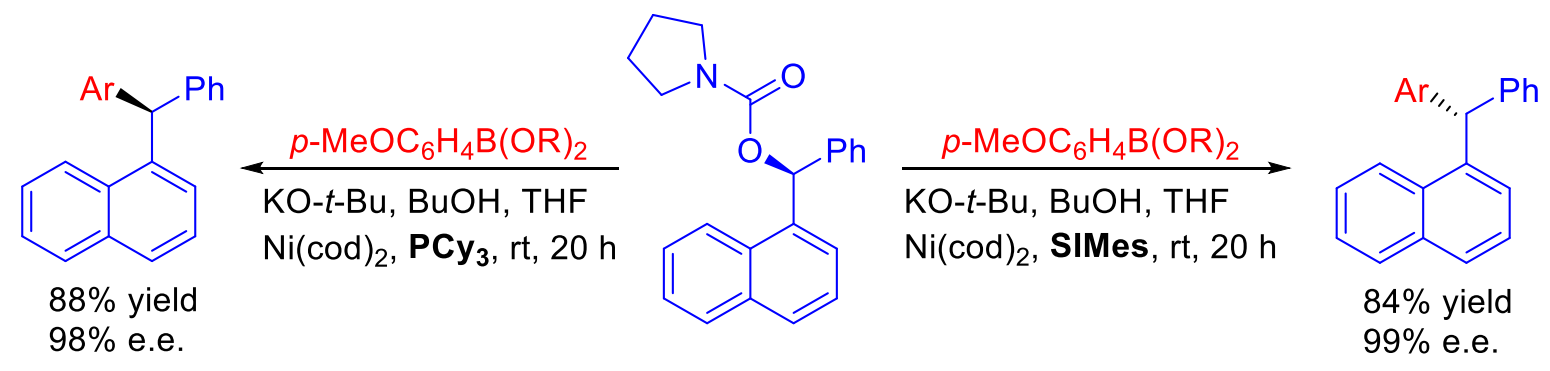

Scheme 93. Ni-catalyzed cross coupling of a chiral benzylcarbamate and arylboronates.

The cross-coupling of achiral aromatic substrates to form chiral non-racemic biaryls has also been reported. Thus, the enantioselective Suzuki-Miyaura reaction between naphthyl bromides and naphthylboronic acids was catalyzed by a ferrocene-derived phosphine-NHC palladium complex 
with planar chirality (Scheme 94). Unfortunately, the expected chiral binaphthyls were obtained with low enantioselectivity [166].

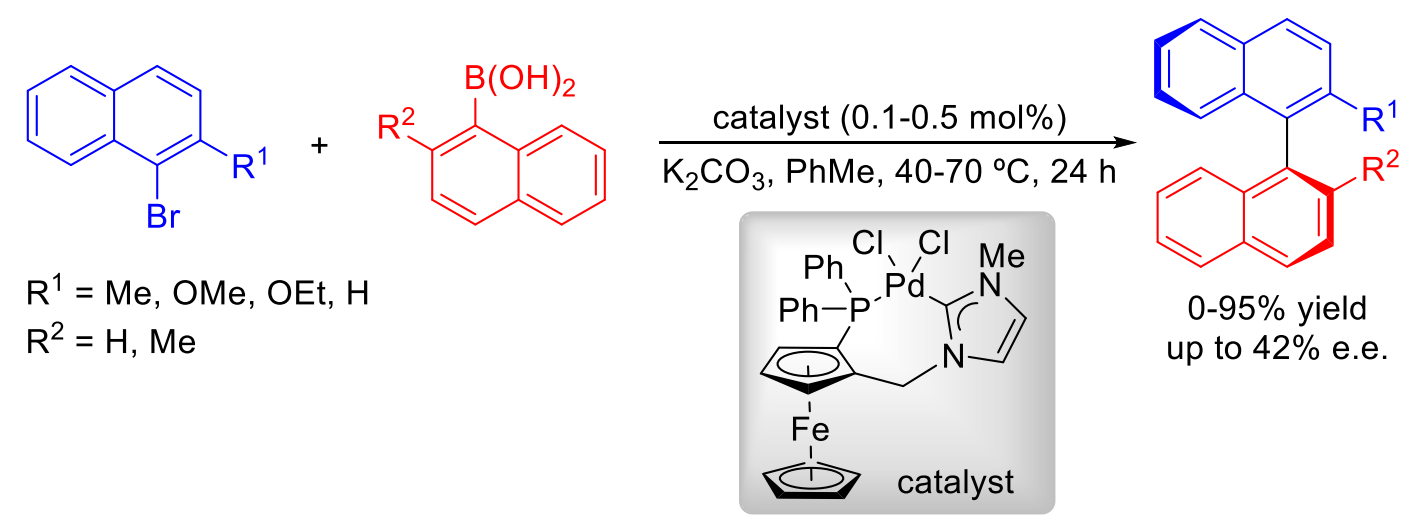

Scheme 94. Pd-catalyzed enantioselective cross coupling of naphthyl bromides and naphthylboronic acids.

Fletcher et al. described the rhodium-catalyzed asymmetric Suzuki-Miyaura coupling of allylic halides with vinyl, aryl and heteroarylboronic acids using BINAP or related ligands with axial chirality [167]. The method was shown to have a vast scope, being suitable to couple even two heterocyclic substrates with excellent enantioselectivities (Scheme 95).

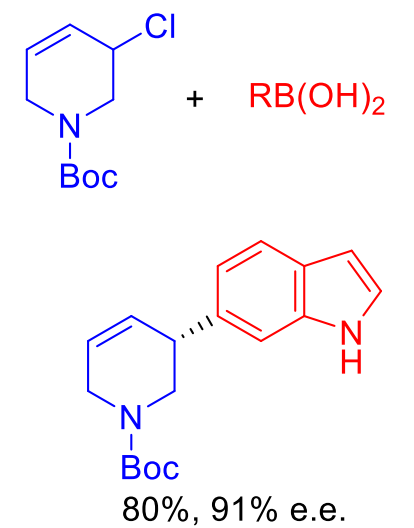<smiles>O=C(c1ccccc1)N1CC=C[C@H](c2ccccc2)C1</smiles>

$76 \%, 96 \%$ e.e.

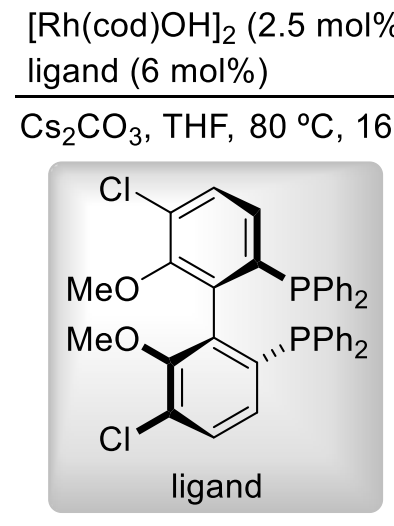<smiles>O=C(O)N1CC=C[C@H](c2ccsc2)C1</smiles>

$74 \%, 93 \%$ e.e.<smiles>O=C(c1ccccc1)N1CC=C[C@H](c2ccoc2)C1</smiles>

$52 \%, 99 \%$ e.e.<smiles>[R]C1C=CCN(C(=O)OCc2ccccc2)C1</smiles><smiles>CC(=O)OC(=O)N1CC=C[C@H](/C=C/c2ccccc2)C1</smiles>

$91 \%, 96 \%$ e.e. [with $(R)$-BINAP]<smiles>O=[R6]OC(=O)N1CC=C[C@H](c2cccc(Cl)n2)C1</smiles>

Scheme 95. Rh-catalyzed asymmetric cross coupling of an allylic chloride with boronic acids.

\section{Some synthetic applications}

The Suzuki-Miyaura reaction has found uncountable applications in organic synthesis, both in onestage and in multistage protocols, being normally the key step toward the target products [1a, 1c, 1d]. Particularly important is its application in the synthesis biologically-active heterocycliccontaining molecules for drug discovery [2a, 168]. Its exploitation in the total synthesis of natural products has been recently reviewed [3]. In this section, we provide some examples to highlight the fundamental role of the Suzuki-Miyaura reaction in the total synthesis of some natural and pharmacologically active products. 
Knölker et al. subjected three substituted bromocarbazoles to the palladium-catalyzed coupling with tert-prenylboronate to give a direct precursor of carquinostatin A (Scheme 96), $O$-methylsiamenol and $O$-methylmicromeline [169]. These carbazole derivatives are known to exhibit anti-tubercular activity. Although the method is superior to others involving more steps, it must be noted that the amount of catalyst and ligand, as well as the reaction time are relatively large.

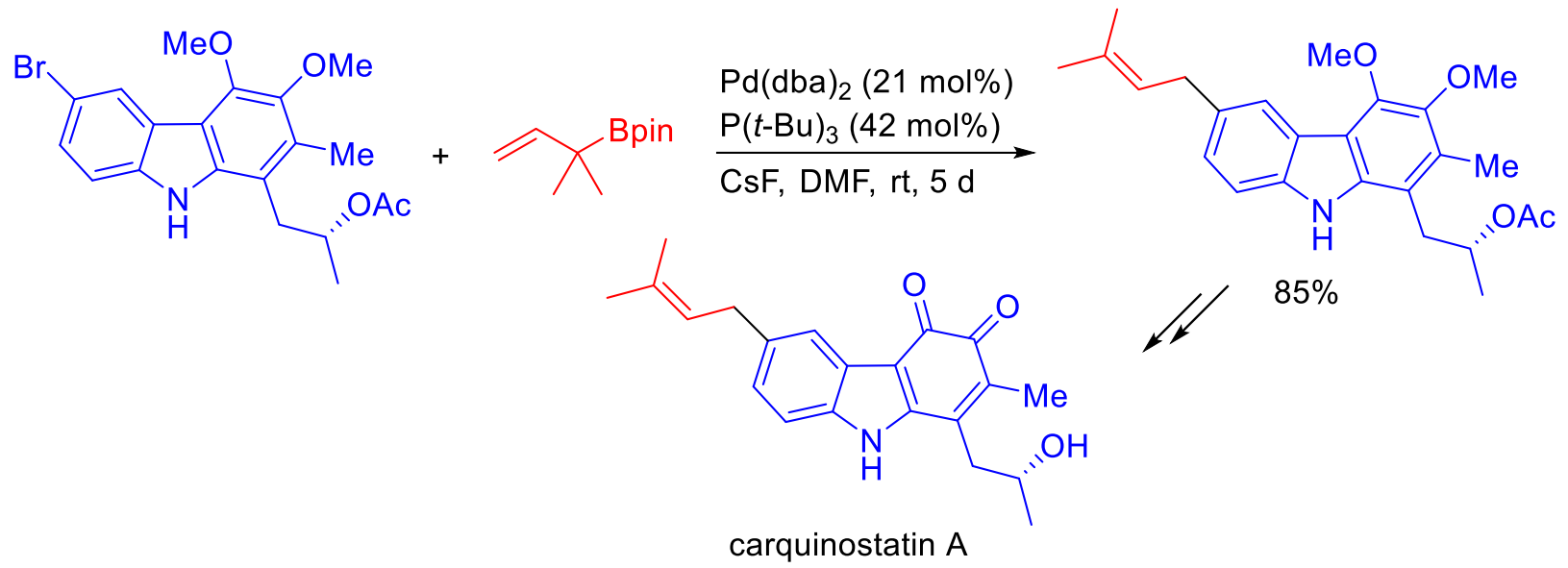

Scheme 96. Synthesis of a precursor of carquinostatin A.

Buchwald et al. reported the high-yielding preparation of a key intermediate in the synthesis of diflunisal, based on the aforementioned continuous-flow lithiation/borylation and Suzuki-Miyaura cross-coupling reaction with 1-bromo-2,4-difluorobenzene [151] (Scheme 97).

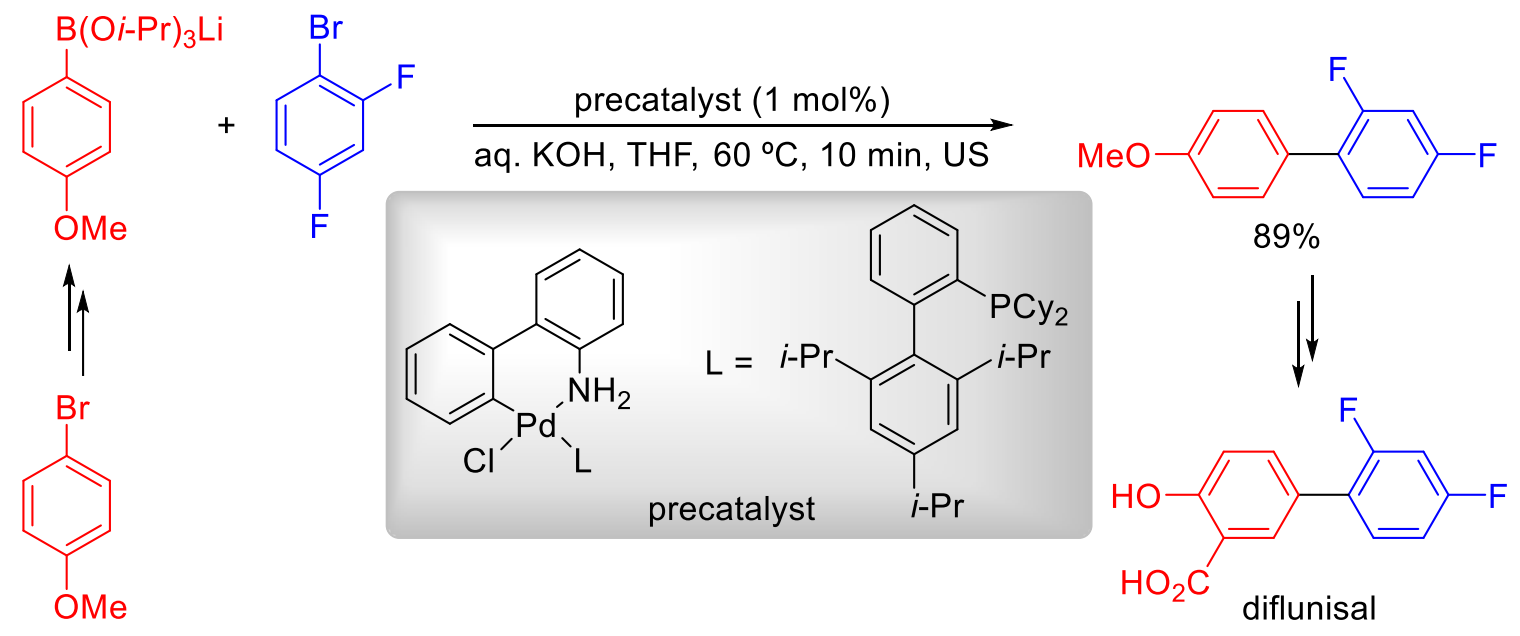

Scheme 97. Synthesis of a precursor of diflunisal.

Cruden et al. applied their palladium-catalyzed desulfonylative coupling of benzylic fluorinated sulfones with arylboronic acids to the synthesis of the synthetic thyroid hormone receptor $\beta$ selective analogue GC-24, which is a potential drug for the treatment of obesity and atherosclerosis. [145]. A one-pot sequential and regioselective double cross-coupling strategy allowed the introduction of two aryl moieties in the structure, derived from phenylboronic acid and benzyloxy2,6-dimethylphenylboronic acid, in a reasonable yield (Scheme 98). The total synthesis was accomplished in ten steps and $42 \%$ overall yield. 
<smiles>COc1ccc(CS(=O)(=O)c2cc(C(F)(F)F)cc(C(F)(F)F)c2)cc1CBr</smiles>

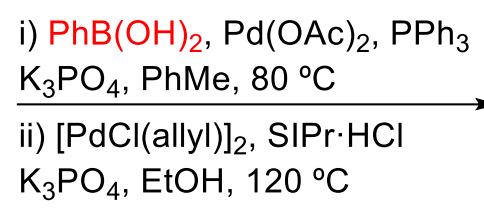<smiles>COc1ccc(Cc2c(C)cc(OCc3ccccc3)cc2C)cc1Cc1ccccc1</smiles>

$66 \%$

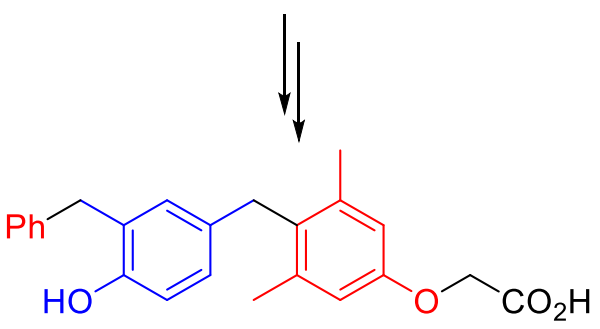

GC-24

Scheme 98. Synthesis of a thyroid hormone receptor $\beta$-selective analogue GC-24.

A glutamic acid-functionalized coumarin was obtained by the palladium-catalyzed coupling $O$ methoxyarylboronic acids with a properly protected glutamic acid $(Z)$-vinyltriflate and subsequent protecting groups removal (Scheme 99) [170]. These conjugates were previously prepared by the Pechmann reaction, which involves difficult purification and proceeds under rather severe conditions in a highly acidic environment incompatible with many functional groups. The synthetized products are valuable fluorescent protein labels that can be used to investigate biological processes occurring in low $\mathrm{pH}$ media.

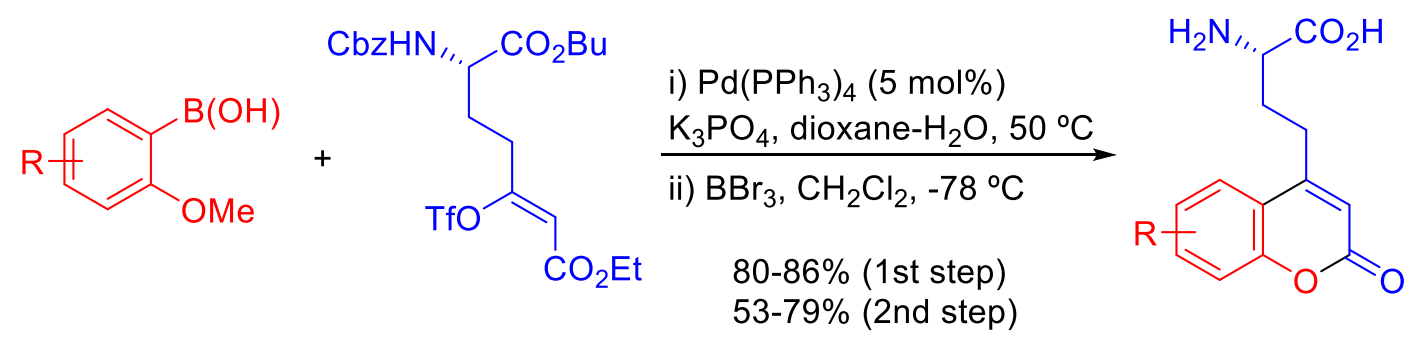

Scheme 99. Synthesis of a glutamic acid-functionalized coumarin.

The excellent catalytic properties of an acetanilido palladacycle combined with tri(1adamantyl)phosphine $\left(\mathrm{PAd}_{3}\right)[11 \mathrm{~d}]$ were further exploited by Carrow et al. to synthesize 2-cyano4'-methylbiphenyl and 4-chloro-2'-nitrobiphenyl [171]; these two compounds are fine chemicals demanded at industrial scale as precursors of valsartan (AT 1 -receptor antagonist) and coscalid (fungicide). The two cross-coupling reactions took place in high yields and high TONs and TOFs (Scheme 100). 


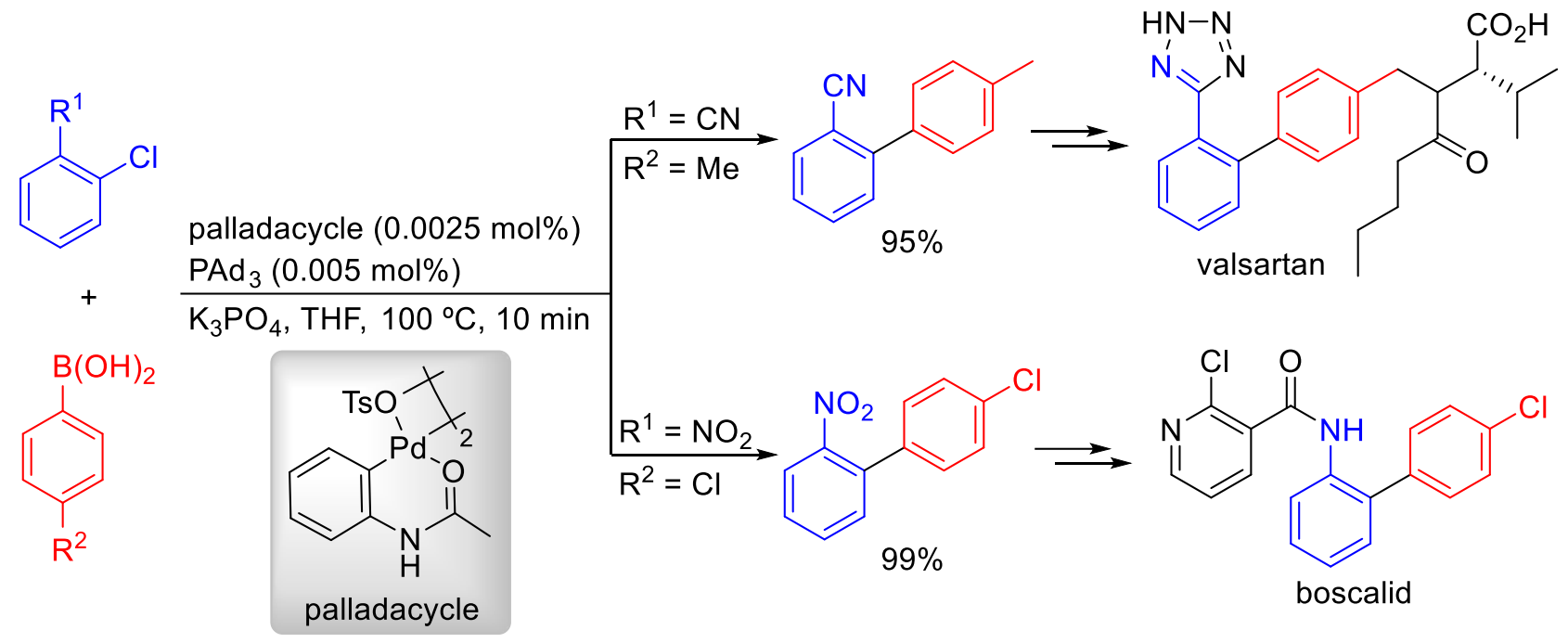

Scheme 100. Synthesis of the precursors of valsartan and boscalid.

Using the previously commented phosphine catalytic system with an oxide-oxaphosphacyclic ligand [17b], Tand and Xu et al. obtained a key intermediate in the synthesis of male contraceptive agent and PAF (platelet activation factor) antagonist gossypol (Scheme 101); gossypol is a natural phenol found in plants of the genus Gossypium. The coupling of the starting aryl triflate and isopropylboronic acid led to the expected intermediate in moderate yield and a branched-to-linear alkyl ratio $(i-\operatorname{Pr} / n-\operatorname{Pr})$ of $5.5: 1$. Nevertheless, this can be considered the shortest way to this gossypol precursor.

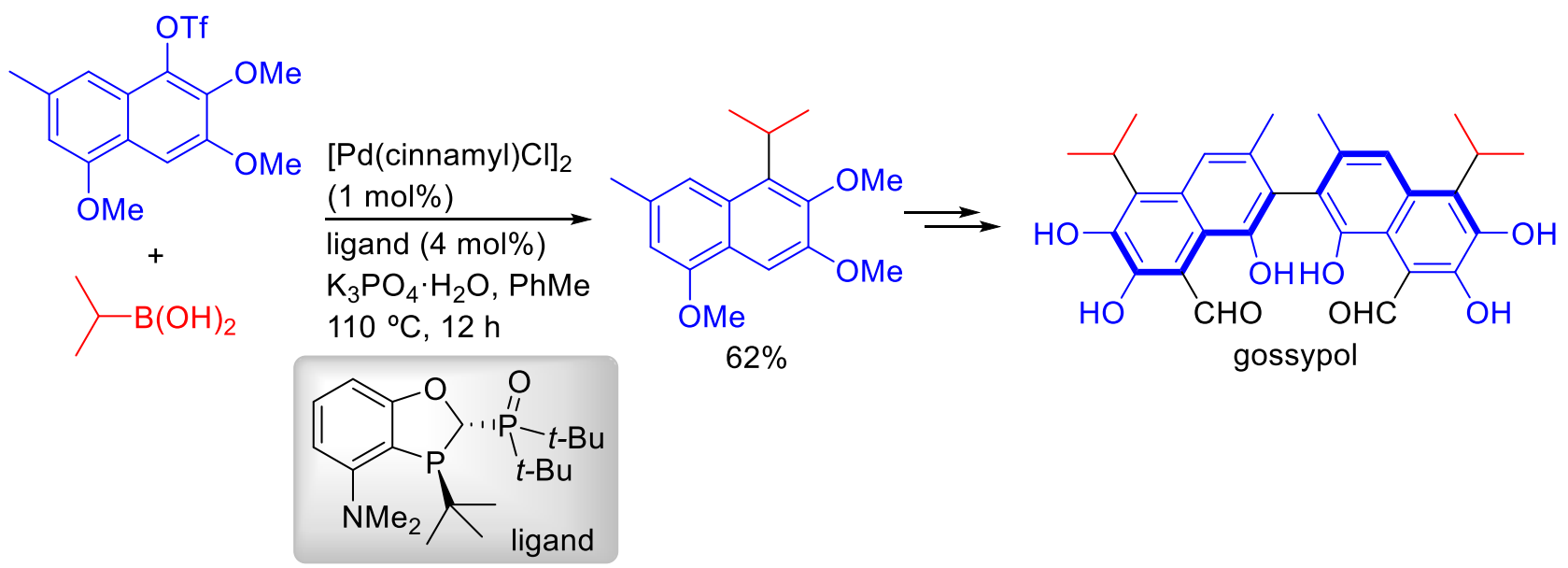

Scheme 101. Synthesis of a precursor of gossypol.

Cushman et al. developed a ligand-free Suzuki-Miyaura protocol for sterically demanding 2'bromo-2-arylbenzothiazoles [172]. The authors demonstrated that a palladacycle is involved in the reaction, which is formed by oxidative addition of palladium to the bromoheterocycle. The method was successfully applied to the synthesis of a potent selective COX-2 inhibitor (Scheme 102), which exhibited higher selectivity for COX-2 vs. COX-1 in comparison with the well-known drug celecoxib. 


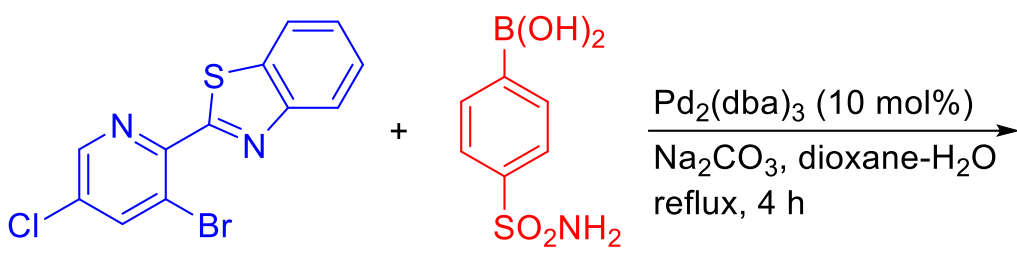<smiles>NS(=O)(=O)c1ccc(-c2cc(Cl)cnc2-c2nc3ccccc3s2)cc1</smiles>

Scheme 102. Synthesis of a potent selective COX-2 inhibitor.

\section{Mechanistic aspects}

The main question around the mechanism of the Suzuki-Miyaura reaction is the role of the base in the transmetalation step. The possibility of formation of the arylboronate $\operatorname{ArB}(\mathrm{OH})_{3}{ }^{-}$or $\operatorname{ArPd}(\mathrm{OH}) \mathrm{L}_{2}$ under the action of $\mathrm{OH}^{-}$(or other base) and their participation in the course of the reaction has been subject of debate for a long time [1a, 173]. At first glance, the formation of boronate seems to be energetically more favorable (almost barrier-free addition) than the transformation of the $\mathrm{Pd}-\mathrm{Hal}$ bond into a $\mathrm{Pd}-\mathrm{OH}$ bond. However, the two possible pathways, $\mathbf{A}$ and $\mathbf{B}$, have been taken into account in different studies (Scheme 103).

The well-known fact that boronates can react in the Suzuki-Miyaura reaction in the absence of base, seems to support the first single-stage mechanism [174]. However, the boronate is in equilibrium with the boronic acid and base. The fact that the stoichiometric reaction of arylpalladium hydroxide with the arylboronic acid was faster than the reaction of the halide palladium complex is more in agreement with the route $\mathbf{B}$ [175]; it must be noted, however, that the formation of arylpalladium hydroxide species from arylpalladium halides is a slow reaction under the catalytic conditions.

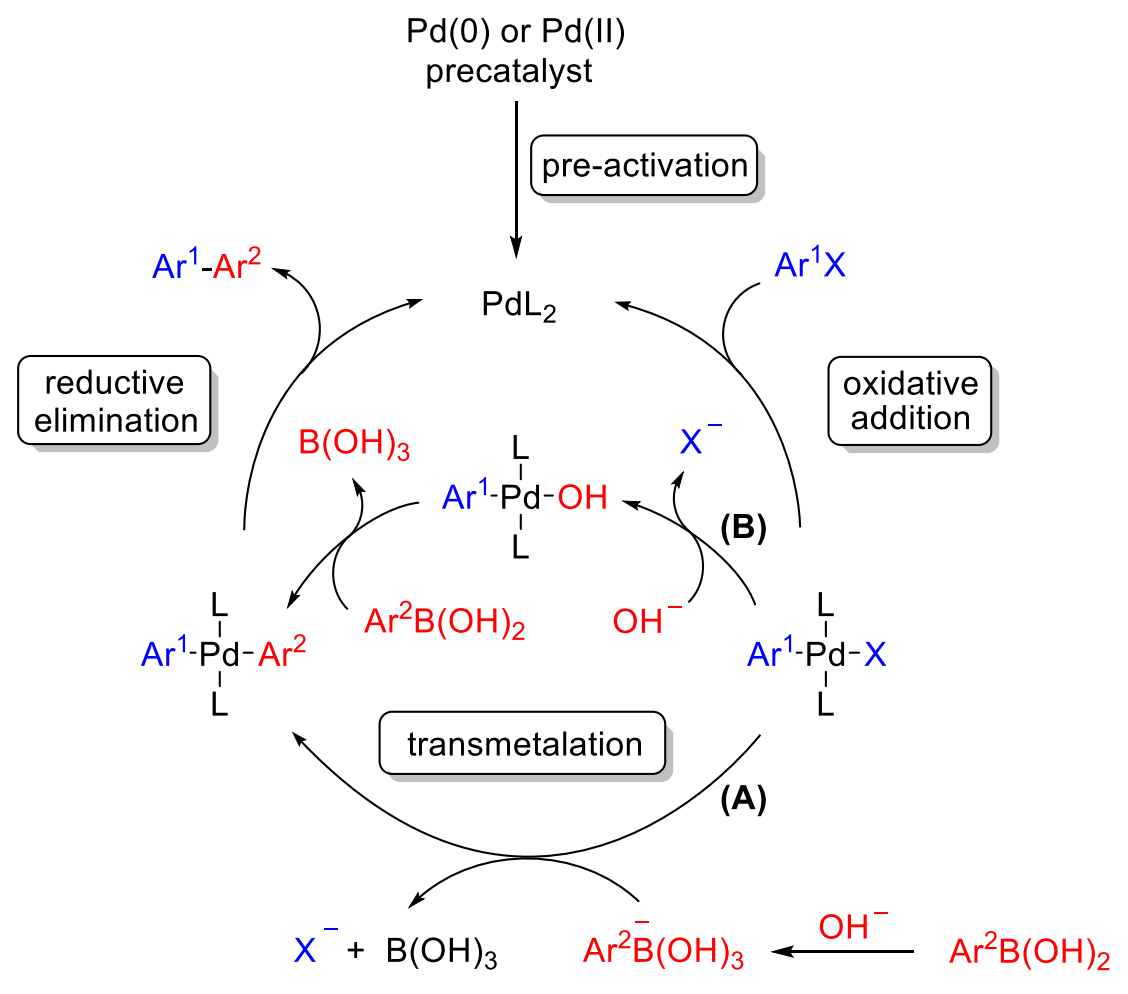

Scheme 103. Mechanims of the Suzuki-Miyaura reaction.

Although this issue is more fundamental than practical for users of the Suzuki-Miyaura reaction, there is an ongoing discussion and emergence of new arguments because of new experimental data. 
For instance, Lima et al. studied the product selectivity in the reaction of a mixture of two electronically different arylboronic acids and bromobenzene with different base concentrations (Scheme 104) [176]; the interesting data obtained were easily explained under the assumption of arylboronate participation in the reaction. The product ratio for a mixture of two arylboronic acids, with electron-withdrawing (EWG) and electron-donating groups (EDG), varied with the base concentration: $\mathrm{PhC}_{6} \mathrm{H}_{4} \mathrm{CHO}$ was mainly formed with an insufficient amount of base, whereas $\mathrm{PhC}_{6} \mathrm{H}_{4} \mathrm{OMe}$ dominated with large quantities of base. This result is consistent with the Lewis acidity of arylboronic acids and their ability to form boronate anions, as well as their nucleophilicity in substitution reactions (Scheme 105). As a general tendency, it could be seen that the nature of the catalyst and the base also affected the selectivity [176].

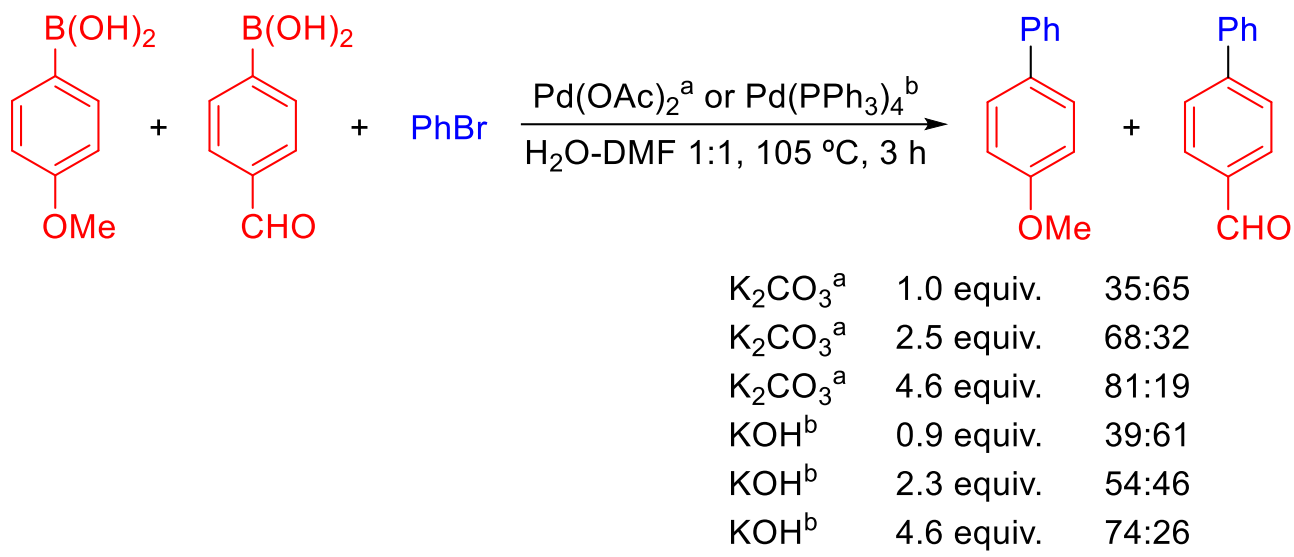

Scheme 104. Effect of the base in the Suzuki-Miyaura reaction.

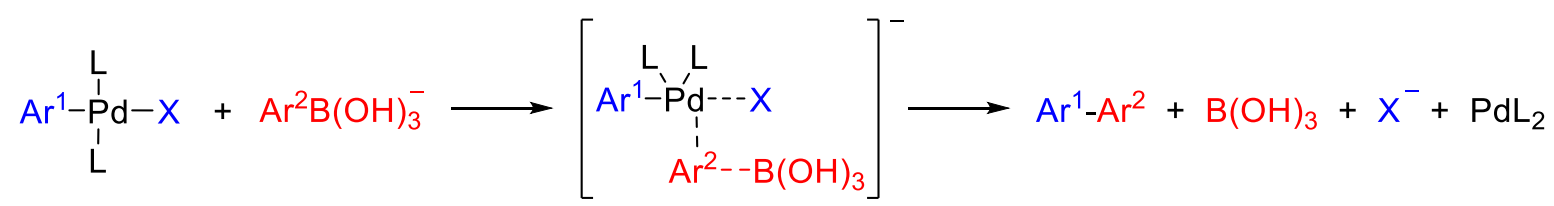

Scheme 105. Proposed intermediate in the Suzuki-Miyaura reaction.

DFT calculations of intermediates and transition states of alternative routes, carried out by Ujaque et al. [177], were also in agreement with route $\mathbf{A}$, i.e., the participation of the boronate-anion in the reaction. Given that both, boronates $\operatorname{ArB}(\mathrm{OH})_{3}{ }^{-}$and hydroxopalladium complexes $\operatorname{ArPd}(\mathrm{OH}) \mathrm{L}_{2}$ can be formed in the presence of a large amount of base, it is obvious that the influence of the nature and concentration of the base can be crucial for the choice of the reaction pathway. It is noteworthy that the complex influence of these factors was demonstrated repeatedly [178].

Amatore and Jutand et al. conducted a systematic study on the influence of various bases and their concentrations by using electrochemical measurements and heteronuclear NMR spectroscopy [179]. The reactions were carried out in DMF in the presence of $\mathrm{OH}^{-}$. It was revealed that the reaction of $\operatorname{ArB}(\mathrm{OH})_{2}$ with $\mathrm{ArPdX}\left(\mathrm{PPh}_{3}\right)_{2}$ did not proceed in the absence of $\mathrm{OH}^{-}$and that, particularly, $\mathrm{OH}^{-}$ was involved in the formation of trans- $\mathrm{ArPdOH}\left(\mathrm{PPh}_{3}\right)_{2}$, which interacted with $\operatorname{ArB}(\mathrm{OH})_{2}$. Thus, the authors ruled out the possibility of reaction between $\operatorname{ArB}(\mathrm{OH})_{2}$ and $\operatorname{ArPdBr}\left(\mathrm{PPh}_{3}\right)_{2}$ in the absence of base and the reaction of $\operatorname{ArPdOH}\left(\mathrm{PPh}_{3}\right)_{2}$ with $\operatorname{ArB}(\mathrm{OH})_{3}{ }^{-}$, something that was quite clear. However, they also discarded path $\mathbf{A}$ on the basis of the fact that the reaction with $\operatorname{ArB}(\mathrm{OH})_{3}{ }^{-}$did not proceed in the presence of an excess of the bromide anion, i.e., by inhibiting formation of $\operatorname{ArPd}(\mathrm{OH}) \mathrm{L}_{2}$. Path $\mathbf{B}$ remained as the only possibility, something that was to some extent consistent with Hartwig's data [175]: the rate constant of the reaction of the hydroxo complex with the boronic acid was several orders of magnitude higher than that of the halide complex with the boronate in 
THF- $\mathrm{H}_{2} \mathrm{O}$. An important observation of the authors for the practical implementation of the SuzukiMiyaura reaction was the determination of a bell-shaped curve of the dependence of the reaction rate on the concentration of the base, i.e., the rate dropped after reaching a certain concentration. Another important conclusion was the participation of the base in reductive-elimination stage.

It is worth noting that the catalyst, the high activity of which can contribute to unobserved processes in other conditions, can affect the choice of the reaction pathway. The tri(1-adamantyl)phosphine complex of arylpalladium chloride reacted with the arylboronic acid in THF in the absence of base and without any possibility of formation of either the boronate or the hydroxopalladium complex [180]. The authors explained this case by considering that the strong donor ligand promoted the dissociation of the complex, with departure of the chloride anion and formation of a highly reactive cationic palladium complex (Scheme 106); fluorobenzene was formed in this case as by-product, probably due to the reaction with the $\mathrm{HCl}$ released.

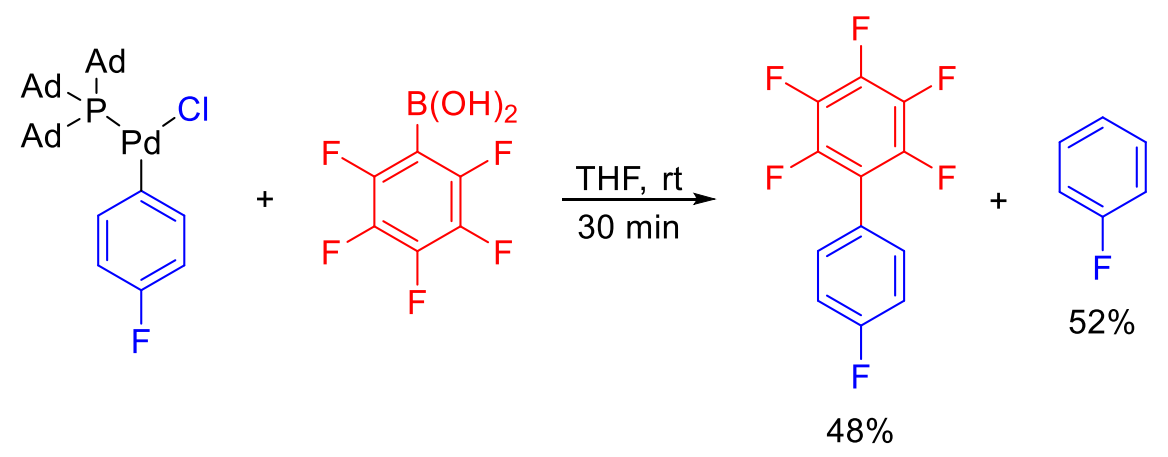

Scheme 106. Reaction of tri(1-adamantyl)phosphine complex of arylpalladium chloride with pentafluorophenylboronic acid in the absence of base.

There are several acid-base related processes involved in the catalytic cycle of the Suzuki-Miyaura reaction. Some of them are fast, like the arylboronic acid-arylboronate equilibrium. The transformation of the arylpalladium halide into arylpalladium hydroxide is slow and can be far from equilibrium. A number of interdependent reactions can produce complex kinetics that determine concentrations of reactants and intermediates which, in turn, can affect the rates of the parallel competing pathways. There are many factors that can affect the intermediates involved in the transmetalation step; the solvent is a principal factor, which in the Suzuki-Miyaura reaction can vary from fully aprotic to protic, including aqueous solvents and neat water. That is why authors using different catalytic systems can obtain different results concerning the implicated intermediates. Moreover, the presence or absence of ligands can also have strong influence in the mechanism. All these issues have been tackled in Lloyd-Jones's review [181], where the situation regarding the choice of the Suzuki-Miyaura reaction mechanism was defined as "a fork in the trail".

In order to get a deeper insight into the problem, considerable effort was devoted by Denmark et al. to identify the intermediate immediately preceding the transmetalation intermediate (pretransmetalation intermediate): the so-called "missing link" [182]. This was the intermediate with a Pd-O-B bond, which was detected using low temperature and a rapid injection NMR technique in the reaction of arylboronic acids and their esters. Such intermediate can be formed as a result of the implementation of both, route $\mathbf{B}$ and route $\mathbf{A}$ (Scheme 107).

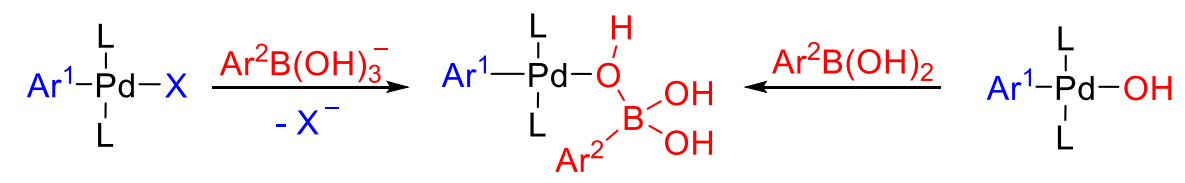


Scheme 107. Pd-O-B bond intermediate detected using low temperature and rapid injection NMR.

There is no doubt that the detection of the above intermediate was an important achievement, demonstrating both new research opportunities and a deeper understanding of the mechanism. However, such an intermediate reminds us an important phenomenon widely studied earlier (in the 1960s) and related to electrophilic substitution reactions involving organometallic compounds: in any given substitution, including those in transmetalation reactions, nucleophilic assistance from the reagent is necessarily required [183]. The need for this assistance explains why organomercury compounds undergo protonolysis easier with $\mathrm{HX}$ than with $\mathrm{RCO}_{2} \mathrm{H}$; the opposite occurs with the protodeboronation of organoboron compounds, proceeding easier with $\mathrm{RCO}_{2} \mathrm{H}$ than with $\mathrm{HX}$. Moreover, such assistance can be implemented either inter- or intramolecularly, being in the latter case more effective. When the nucleophilic assistance involves a cyclic transition state, retention of the configuration takes place in $\mathrm{S}_{\mathrm{E}} 2$-type reactions. This fact was described in Soderquist's study [184] on the reaction of the syn- and anti-deuterated isomers of 9-(3,3-dimethyl-1,2-dideuterio-1butyl)-9-borabicyclo[3.3.1]nonane with $\mathrm{PhBr}$, catalyzed by $\mathrm{Pd}\left(\mathrm{PPh}_{3}\right)_{4}$ in the presence of $\mathrm{NaOH}$ : full retention of the configuration was observed via a four-membered ring transition state (Figure 3 ).

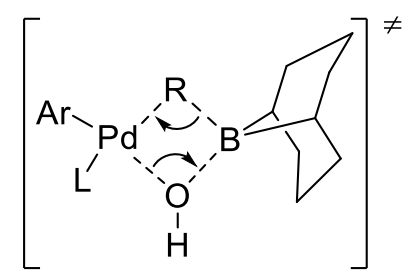

Figure 3. Transition state proposed in Pd-catalyzed reaction of the syn- and anti-deuterated isomers of 9(3,3-dimethyl-1,2-dideuterio-1-butyl)-9-borabicyclo[3.3.1]nonane with $\mathrm{PhBr}$.

No less important are the issues related to the mechanisms of the reactions taking place in the absence of bases [180, 185], reactions with aryldiazonium salts $\left(\mathrm{ArN}_{2} \mathrm{BF}_{4}\right)$ instead of arylhalides ArHal [136, 137, 180], "ligandless" reactions catalyzed by PdNPs [186] and soluble palladium clusters [83], not to mention reactions working with a "cocktail" of catalysts [35].

\section{Summary and outlook}

Throughout this report, we have tried to present a survey of some advances attained in the SuzukiMiyaura reaction after the corresponding Nobel prize in Chemistry. Since then, there has been a general upsurge of interest in this reaction, mainly aimed at improving the catalytic systems in terms of efficiency and sustainability. Palladium chemistry still dominates the field from both, the homogeneous and heterogeneous catalysis fronts.

As regards homogeneous catalysis, an array of properly designed and privileged ligands have made possible to overcome some of the hurdles inherent to this reaction, for instance: to deploy aryl chlorides (including deactivated ones) instead of the recurrent bromides and iodides, use of alkyl or unstable boronic acids, heterocyclic and sterically hindered substrates; to conduct reactions at room temperature in aqueous medium or in water; and to reach high TONs and TOFs. The coupling of alkylboronic acids under mild conditions is an underdeveloped point in this field.

The reusability issue has been addressed by the heterogenization of complexes and the irruption in the scenario of new complexation agents for palladium, such as COFs and MOFs. However, probably the major growing area in this reaction has been the development of catalytic systems based on palladium nanoparticles. They have gained ground to palladium complexes, reaching in some cases comparable catalytic activities, even at room temperature, in water, and using deactivated aryl chlorides. Palladium nanoparticles have also shown excellent performance when 
supported, either on polymeric or inorganic supports, with the possibilities of easy separation and reuse being major advantages. The nature of the catalysis by palladium nanoparticles still is an unsolved matter in many cases. In this regard, we must emphasize the importance of performing the corresponding tests and analyses that unequivocally establish the character of the process.

Although the catalysis by metals other than palladium is almost symbolic, the interesting results attained with metals such as nickel, iron, copper, and cobalt, can pave the way to develop cheaper and more sustainable catalysts. We must also underline the appearance of alternative substrates to the traditional organic halides, such as carboxylic acids and derivatives, hydrazines, sulfones, nitrocompounds or phosphonium salts, that can improve the coupling and/or give rise to products, otherwise, rather inaccessible.

The applications of continuous-flow chemistry and asymmetric catalysis to the Suzuki-Miyaura reaction are still in their infancy. Certainly, both approaches are of paramount importance in order to extend processes to the industrial scale and facilitate drug discovery. In the meantime, we hope the conclusions of this report suggest a number of new avenues for research in this fascinating reaction.

\section{Acknowledgements}

Francisco Alonso gratefully acknowledges the Spanish Ministerio de Economía y Competitividad (MINECO; grant no. CTQ2017-88171-P) and the Generalitat Valenciana (GV; grant no. AICO/2017/007) for financial support.

\section{References}

[1] (a) A. Suzuki, Angew. Chem. Int. Ed. 50 (2011) 6722-6737; (b) N. Miyaura, in: A. de Meijere, F. Diederich (Eds.), Metal-Catalyzed Cross-Coupling Reactions, Wiley-VCH, Weinheim, 2008, pp. 41-123; (c) X.-F. Wu, P. Anbarasan, H. Neumann, M. Beller, Angew. Chem. Int. Ed. 49 (2010) 9047-9050; (d) S. Kotha, K. Lahiri, D. Kashinath, Tetrahedron 58 (2002) 9633-9695; (e) C.C.C. Johansson Seechurn, M.O. Kitching, T.J. Colacot, V. Snieckus, Angew. Chem. Int. Ed. 51 (2012) 5062-5085; (f) A. Biffis, P. Centomo, A. Del Zotto, M. Zecca, Chem. Rev. 118 (2018) 2249-2245.

[2] (a) J. Magano, J.R. Dunetz, Chem. Rev. 111 (2011) 2177-2250; (b) J. Boström, D.G. Brown, R.J. Young, G.M. Keserü, Nat. Rev. Drug. Discov. 17 (2018) 709-727.

[3] A. Taheri Kal Koshvandi, M.M. Heravi, T. Momeni, Appl. Organomet. Chem., 32 (2018) e4210.

[4] D. Roy, Y. Uozumi, Adv. Synth. Catal. 360 (2018) 602-625.

[5] J. Qiu, L. Wang, M. Liu, Q. Shen, J. Tang, Tetrahedron Lett. 52 (2011) 6489-6491.

[6] (a) B.H. Lipshutz, S. Ghorai, Green Chem. 16 (2014) 3660-3679; (b) P. Klumphu, B.H. Lipshutz, J. Org. Chem. 79 (2014) 888-900; (c) C. Röhlich, A.S. Wirth, K. Köhler, Chem. Eur. J. 18 (2012) 15485-1549; (d) T. Kitanosono, K. Masuda, P. Xu, and S. Kobayashi, Chem. Rev. 118 (2018) 679-746.

[7] (a) I.P. Beletskaya, A.V. Cheprakov, J. Organomet. Chem. 689 (2004) 4055-4082; (b) A.S. Sigeev, A.S. Peregudov, A.V. Cheprakov, I.P. Beletskaya, Adv. Synth. Catal. 357 (2015) 417-429.

[8] M.S. Szulmanowicz, A. Gniewek, W. Gil, A.M. Trzeciak, ChemCatChem 5 (2013) 11521160.

[9] For a recent example, see: Mitrofanov, A. Y.; Murashkina, A. V.; Martín-García, I.; Alonso, F.; Beletskaya, I. P. Catal. Sci. Technol. 7 (2017) 4401-4412.

[10] F. Alonso, I.P. Beletskaya, M. Yus, Tetrahedron 64 (2008) 3047-3101. 
[11] (a) L. Monnereau, D. Sémeril, D. Matt, L. Toupet, Chem. Eur. J. 16 (2010) 9237-9247; (b) C.C.C. Johansson Seechurn, S.L. Parisel, T.J. Colacot, J. Org. Chem. 76 (2011) 7918-7932; (c) E. Zaborova, J. Deschamp, S. Guieu, Y. Bleriot, G. Poli, M. Menand, D. Madec, G. Prestat, M. Sollogoub, Chem. Commun. 47 (2011) 9206-9208; (d) B.P. Carrow, L. Chen, Synlett 13 (2017) 280-288.

[12] A.F. Littke, G.C. Fu, Angew. Chem. Int. Ed. 37 (1998) 3387-3388.

[13] J.P. Wolfe, R.A. Singer, B.H. Yang, S.L. Buchwald, J. Am. Chem. Soc. 121 (1999) 95509561.

[14] G.C. Fu, Acc. Chem. Res. 41 (2008) 1555-1564.

[15] P.W.N.M. van Leeuwen, P.C.J. Kamer, Catal. Sci. Technol. 8 (2018) 26-113.

[16] S. Handa, M.P. Andersson, F. Gallou, J. Reilly, B.H. Lipshutz, Angew. Chem. Int. Ed. 55 (2016) 4914-4918.

[17] (a) C. Li, T., B. Li, G. Xiao, W. Tang, Angew. Chem. Int. Ed. 54 (2015) 3792-3796; (b) T. Si, B. Li, W. Xiong, B. Xu, W. Tang, Org. Biomol. Chem. 15 (2017) 9903-9909.

[18] C. Li, G. Xiao, Q. Zhao, H. Liu, T. Wang, W. Tang, Org. Chem. Front. 1 (2014) 225-229.

[19] (a) I.P. Beletskaya, A.V. Cheprakov, Chem. Rev. 100 (2000) 3009-3066; (b) C. Deraedt, D. Astruc, Acc. Chem. Res. 47 (2014) 494-503.

[20] F.Y. Fu, J. Xiang, H. Cheng, L.J. Cheng, H.B. Chong, S.X. Wang, P. Li, S.Q. Wei, M.Z. Zhu, Y.D. Li, ACS Catal. 7 (2017) 1860-1867.

[21] W.A. Herrmann, M. Elison, J. Fischer, C. Köcher, G.R.J. Artus, Angew. Chem. Int. Ed. Eng. 34 (1995) 2371-2374.

[22] S. Díez-González, S.P. Nolan, in: F. Glorius (Ed.), N-Heterocyclic Carbenes in Transition Metal Catalysis, Springer, Berlin, 2007, pp. 47-82.

[23] (a) G.A. Grasa, M.S. Viciu, J. Huang, C. Zhang, M.L. Trudell, S.P. Nolan, Organometallics 21 (2002) 2866-2873; (b) C. Zhang, J. Huang, M.L. Trudell, S.P. Nolan, J. Org. Chem. 64 (1999) 3804-3805.

[24] C.J. O’Brien, E.A.B. Kantchev, C. Valente, H. Niloufar, N. Hadei, G.A. Chass, A. Lough, A.C. Hopkinson, M.G. Organ, Chem. Eur. J. 12 (2006) 4743-4748.

[25] E.A.B. Kantchev, C.J. O'Brien, M.G. Organ, Angew. Chem. Int. Ed. 46 (2007) 2768-2813; J. Nasielski, N. Hadei, G. Achonduh, E.A.B. Kantchev, C.J. O'Brien, A. Lough, M.G. Organ, Chem. Eur. J. 16 (2010) 10844-10853.

[26] D.-D. Lu, X.-X. He, F.-S. Liu, J. Org. Chem. 82 (2017) 10898-10911.

[27] J.S. Ouyang, Y.F. Li, F.D. Huang, D.D. Lu, F.S. Liu, ChemCatChem 10 (2018) 371-375.

[28] G.-R. Peh, E.A.B. Kantchev, J.-C. Er, J.-Y. Ying, Chem. Eur. J. 16 (2010) 4010-4017.

[29] M.-T. Chen, Z.-L. Kao, Dalton Trans. 46 (2017) 16394-16398.

[30] A. Donner, K. Hagedorn, L. Mattes, M. Drechsler, S. Polarz, Chem. Eur. J. 23 (2017) 1812918133.

[31] (a) V.P. Boyarskiy, K.V. Luzyanin, V.Y. Kukushkin, Coord. Chem. Rev. 256 (2012) 20292056; (b) M.A. Kinzhalov, K.V. Luzyanin, V.P. Boyarskiy, M. Haukka, V.Y. Kukushkin, Organometallics 32 (2013) 5212-5223.

[32] A. Bruneau, M. Roche, M. Alami, S. Messaoudi, ACS Catal. 5 (2015) 1386-1396.

[33] W.A. Herrmann, C. Brossmer, K. Öfele, C.-P. Reisinger, T. Priermeier, M. Beller, H. Fischer, Angew. Chem. Int. Ed. Engl. 34 (1995) 1844-1848.

[34] I.P. Beletskaya, A.N. Kashin, N.B. Karlstedt, A.V. Mitin, A.V. Cheprakov, G.M. Kazankov, J. Organomet. Chem. 622 (2001) 89-96.

[35] V.P. Ananikov, I.P. Beletskaya, Organometallics 31 (2012) 1595-1604.

[36] (a) T. Kinzel, Y. Zhang, S.L. Buchwald, J. Am. Chem. Soc. 132 (2010) 14073-14075; (b) N.C. Bruno, M.T. Tudge, S.L. Buchwald, Chem. Sci. 4 (2013) 916-920; (c) N.C. Bruno, N. Niljianskul, S.L. Buchwald, J. Org. Chem. 79 (2014) 4161-4166.

[37] C. Nájera, ChemCatChem 8 (2016) 1865-1881.

[38] F. Saleem, G.K. Rao, P. Singh, A.K. Singh, Organometallics 32 (2013) 387-395. 
[39] Y.-s. Liu, N.-n. Gu, P. Liu, X.-w. Ma, Y. Liu, J.-w. Xie, B. Dai, Tetrahedron 71 (2015) 79857989.

[40] W. Liu, D. Xiong, P. Huo, X. He, G. Mei, Chem. Lett. 45 (2016) 1232-1234.

[41] W. Liu, D. Xiong, P. Huo, G. Mei, Chem. Lett. 46 (2017) 1550-1552.

[42] A. Walczak, A.R. Stefankiewicz, Inorg. Chem. 57 (2018) 471-477.

[43] A. Senguel, M.E. Hanhan, Appl. Organomet. Chem. 32 (2018) e4288.

[44] T. Begum, M. Mondal, M.P. Borpuzari, R. Kar, G. Kalita, P.K. Gogoi, U. Bora, Dalton Trans. 46 (2017) 539-546.

[45] C.U. Pittman, S.K. Wuu, S.E. Jacobson, J. Catal. 44 (1976) 87-100.

[46] S.-B. Jang, Tetrahedron Lett. 38 (1997) 1793-1796.

[47] S.L. Wegener, T.J. Marks, P.C. Stair, Acc. Chem. Res. 45 (2012) 206-214.

[48] S. Muratsugu, N. Maity, H. Baba, M. Tasaki, M. Tada, Dalton Trans. 46 (2017) 3125-3134.

[49] (a) T. Borkowski, W. Zawartka, P. Pospiech, U. Mizerska, A.M. Trzeciak, M. Cypryk, W. Tylus, J. Catal. 282 (2011) 270-277; (b) E. Mieczyńska, T. Borkowski, M. Cypryk, P. Pospiech, A.M. Trzeciak, Appl. Catal. A: Gen. 470 (2014) 24-30.

[50] B. Karimi, P. F. Akhavan, Inorg. Chem. 50 (2011) 6063-6072.

[51] S.-Y. Ding, J. Gao, Q. Wang, Y. Zhang, W.-G. Song, C.-Y. Su, W. Wang, J. Am. Chem. Soc. 133 (2011) 19816-19822.

[52] R.S.B. Gonçalves, A.B.V. de Oliveira, H.C. Sindra, B.S. Archanjo, M.E. Mendoza, L.S.A. Carneiro, C.D. Buarque, P.M. Esteves, ChemCatChem 8 (2016) 743-750.

[53] J. Huang, W. Wang, H. Li, ACS Catal. 3 (2013) 1526-1536.

[54] L. Chen, S. Rangan, J. Li, H. Jiang, Y. Li, Green Chem. 16 (2014) 3978-3985.

[55] D. Nagai, H. Goto, Bull. Chem. Soc. Jpn. 91 (2018) 147-152.

[56] (a) M. Kidwai, in: P.T. Anastas and R.H. Crabtree (Eds.), Handbook of Green Chemistry, Wiley-VCH, Weinheim, 2009, vol 2, pp. 81-92; (b) V. Polshettiwar, R.S. Varma, Green Chem. 12 (2010) 743-754; (c) D. Astruc, F. Lu, J. Ruiz Aranzaes, Angew. Chem. Int. Ed. 44 (2005) 7852-7872.

[57] (a) K. Köhler, R.G. Heidenreich, S.S. Soomro, S.S. Pröckl, Adv. Synth. Catal., 350 (2008) 2930-2936; (b) A.N. Kashin, O.G. Ganina, A.V. Cheprakov, I.P. Beletskaya, ChemCatChem, 7 (2015) 2113-2121; (c) Z. Niu, Q. Peng, Z. Zhuang, W. He, Y. Li, Chem. Eur. J., 18 (2012) 9813-9817. (d) M. Pagliaro, V. Pandarus, R. Ciriminna, F. Béland, P.D. Carà, ChemCatChem, 4 (2012) 432-445.

[58] R. Narayanan, C. Tabor, M.A. El-Sayed, Top. Catal. 48 (2008) 60-74.

[59] (a) N.A. Bumagin, V.V. Bykov, I.P. Beletskaya, Bull. Acad. Sci. USSR, Div. Chem. Sci., 38 (1989) 2206-2206; (b) N.A. Bumagin, P.G. More, I.P. Beletskaya, J. Organomet. Chem. 371 (1989) 397-401; (c) N.A. Bumagin, I.G. Bumagina, I.P. Beletskaya, Dokl. Akad. Nauk SSSR 274 (1984) 1103-1106; (d) N.A. Bumagin, Y.V. Gulevich, I.P. Beletskaya, J. Organomet. Chem., 285 (1985) 415-418; (e) I.P. Beletskaya, J. Organomet. Chem. 250 (1983) 551-564.

[60] (a) A.V. Cheprakov, N.V. Ponomareva, I.P. Beletskaya, J. Organomet. Chem. 486 (1995) 297-300; (b) I.P. Beletskaya, A.V. Cheprakov, in: E Negishi (Ed.), Handbook of Organopalladium Chemistry for Organic Synthesis, John Wiley \& Sons, Chichester, 2003, pp. 2955-3006.

[61] N.A. Bumagin, V.V. Bykov, Tetrahedron 53 (1997) 14437-14450.

[62] A.V. Selivanova, V.S. Tyurin, I.P. Beletskaya, ChemPlusChem 79 (2014) 1278-1283.

[63] (a) M.T. Reetz, W. Helbig, J. Am. Chem. Soc. 116 (1994) 7401-7402; (b) M.T. Reetz, R. Breinbauer, K. Wanninger, Tetrahedron Lett. 37 (1996) 4499-4502.

[64] P. Munnik, P.E. de Jongh, K.P. de Jong, Chem. Rev. 115 (2015) 6687-6718.

[65] (a) R. Akiyama, S. Kobayashi, Chem. Rev. 109 (2009) 594-642; (b) D.E. Bergbreiter, J. Tian, C. Hongfa, Chem. Rev. 109 (2009) 530-582; (c) D.E. Bergbreiter, ACS Macro Lett. 3 (2014) 260-265.

[66] R.M. Crooks, M. Zhao, L. Sun, V. Chechik, L.K. Yeung, Acc. Chem. Res. 34 (2001) 181190; (b) R. van Heerbeek, P.C.J. Kamer, P.W.N.M. van Leeuwen, J.N.H. Reek, Chem. Rev. 
102 (2002) 3717-3756; (c) A.K. Diallo, C. Ornelas, L. Salmon, J. Ruiz-Aranzaes, D. Astruc, Angew. Chem. Int. Ed. 46 (2007) 8644-8648; (d) S. Toshiaki, N. Tsukasa, F. Hisashi, Chem. Lett. 41 (2012) 1700-1702.

[67] See, for instance: A. S. Camacho, I. Martín-García, C. Contreras-Celedón, L. Chacón-García, F. Alonso, Catal. Sci. Technol. 7 (2017), 2262-2273.

[68] (a) A. Gniewek, J.J. Ziółkowski, A.M. Trzeciak, M. Zawadzki, H. Grabowska, J. Wrzyszcz, J. Catal. 254 (2008) 121-130; (b) A.J. Amali, R.K. Rana, Green Chem. 11 (2009) 1781-1786; (c) A. Monopoli, A. Nacci, V. Calò, F. Ciminale, P. Cotugno, A. Mangone, L.C. Giannossa, P. Azzone, P. Cioffi, Molecules 15 (2010) 4511-4525.

[69] (a) Y. Li, X. Fan, J. Qi, J. Ji, S. Wang, G. Zhang, F. Zhang, Nano Res. 3 (2010) 429-437; (b) B. Cornelio, G.A. Rance, M. Laronze-Cochard, A. Fontana, J. Sapi, A.N. Khlobystov, J. Mol. Catal. A: Chem. 1 (2013) 8737-8744.

[70] (a) W. Dong, C. Feng, L. Zhang, N. Shang, S. Gao, C. Wang, Z. Wang, Catal. Lett. 146 (2016) 117-125; (b) V. Pascanu, Q. Yao, A. Bermejo Gómez, M. Gustafsson, Y. Yun, W. Wan, L. Samain, X. Zou, B. Martín-Matute, Chem. Eur. J. 19 (2013) 17483-17493; (c) B. Yuan, Y. Pan, Y. Li, B. Yin, H. Jiang, Angew. Chem. Int. Ed. 49 (2010) 4054-4058.

[71] B. Karimi, P. Fadavi Akhavan, Chem. Commun. 47 (2011) 7686-7688.

[72] (a) V. Pandarus, D. Desplantier-Giscard, G. Gingras, R. Ciriminna, P. Demma Carà, F. Béland, M. Pagliaro, Tetrahedron Lett. 54 (2013) 4712-4716; (b) A. Kaur, V. Singh, Chem. Lett. 45 (2016) 83-85; (c) T. Begum, M. Mondal, M.P. Borpuzari, R. Kar, G. Kalita, P.K. Gogoi, U. Bora, Dalton Trans. 46 (2017) 539-546.

[73] D. Ganapathy, G. Sekar, Catal. Commun. 39 (2013) 50-54.

[74] (a) B. Saikia, P.R. Boruah, A.A. Ali, D. Sarma, RSC Adv. 5 (2015) 50655-50659; (b) B. Saikia, P.R. Boruah, A.A. Ali, D. Sarma, Tetrahedron Lett. 56 (2015) 633-635.

[75] X. Huang, Y. Li, Y. Chen, E. Zhou, Y. Xu, H. Zhou, X. Duan, Y. Huang, Angew. Chem. Int. Ed. 52 (2013) 2520-2524.

[76] G. Kumar Rao, A. Kumar, B. Kumar, A.K. Singh, Dalton Trans. 41 (2012) 4306-4309.

[77] C. Liu, Q. Ni, P. Hu, J. Qiu, Org. Biomol. Chem. 9 (2011) 1054-1060.

[78] A.N. Kashin, D.A. Panchuk, L.M. Yarysheva, A.L. Volynskii, I.P. Beletskaya, Russian J. Org. Chem. 47 (2011) 48-53.

[79] (a) A. Balanta, C. Godard, C. Claver, Chem. Soc. Rev. 40 (2011) 4973-4985; (b) M. PérezLorenzo, J. Phys. Chem. Lett. 3 (2012) 167-174; (c) A. Fihri, M. Bouhrara, B. Nekoueishahraki, J.-M. Basset, V. Polshettiwar, Chem. Soc. Rev. 40 (2011) 5181-5203; (d) A.N. Kashin, I.P. Beletskaya, Russ. J. Org. Chem. 47 (2011) 475-479.

[80] (a) N.T.S. Phan, M. Van-Der-Sluys, C.W. Jones, Adv. Synth. Catal. 348 (2006) 609-679; (b) R. Narayanan, C. Tabor, M.A. El-Sayed, Top. Catal. 48 (2008) 60-74; (c) S. Cheong, J.D. Watt, R.D. Tilley, Nanoscale 2 (2010) 2045-2053; (d) D. Astruc, Inorg. Chem. 46 (2007) 1884-1894; (e) A Molnár, Chem. Rev. 111 (2011) 2251-2320.

[81] (a) S.S. Soomro, F.L. Ansari, K. Chatziapostolou, K. Köhler, J. Catal. 273 (2010) 138-146; (b) J.M. Richardson, C.W. Jones, J. Catal. 251 (2007) 80-93; (c) J.D. Jason, H. Yuki, Nanotechnology 21 (2010) 265302; (d) A.N. Kashin, O.G. Ganina, A.V. Cheprakov, I.P. Beletskaya, ChemCatChem 7 (2015) 2113-2121; (e) I.P. Beletskaya, A.N. Kashin, I.A. Khotina, A.R. Khokhlov, Synlett 2008 (2008) 1547-1552.

[82] P.-P. Fang, A. Jutand, Z.-Q. Tian, C. Amatore, Angew. Chem. Int. Ed. 50 (2011) 1218412188.

[83] A. Leyva-Pérez, J. Oliver-Meseguer, P. Rubio-Marqués, A. Corma, Angew. Chem. Int. Ed. 52 (2013) 11554-11559.

[84] A. Ohtaka, T. Teratani, R. Fujii, K. Ikeshita, O. Shimomura, R. Nomura, Chem. Commun. (2009) 7188-7190.

[85] Z. Dong, Z. Ye, Adv. Synth. Catal. 356 (2014) 3401-3414.

[86] B.J. Gallon, R.W. Kojima, R.B. Kaner, P.L. Diaconescu, Angew. Chem. Int. Ed. 46 (2007) 7251-7254. 
[87] T.V. Magdesieva, O.M. Nikitin, O.A. Levitsky, V.A. Zinovyeva, I. Bezverkhyy, E.V. Zolotukhina, M.A. Vorotyntsev, J. Mol. Catal. A: Chem. 353-354 (2012) 50-57.

[88] (a) V.I. Lozinsky, I.A. Simenel, V.K. Kulakova, E.A. Kurskaya, T.A. Babushkina, T.P. Klimova, T.V. Burova, A.S. Dubovik, I.Y. Galaev, B. Mattiasson, A.R. Khokhlov, Macromolecules 36 (2003) 7308-7323; (b) I.M. Okhapkin, L.M. Bronstein, E.E. Makhaeva, V.G. Matveeva, E.M. Sulman, M.G. Sulman, A.R. Khokhlov, Macromolecules 37 (2004) 7879-7883.

[89] A.V. Selivanova, V.S. Tyurin, I.P. Beletskaya, ChemPlusChem 79 (2014) 1278-1283.

[90] (a) Y.M.A. Yamada, S.M. Sarkar, Y. Uozumi, J. Am. Chem. Soc. 134 (2012) 3190-3198; (b) For a closely related work using PdNPs on PINIPAM-co-VP (VP = 4-vinylpiridine), see: M.C. Hong, M.C. Choi, Y.W. Chang, Y. Lee, J. Kim, H. Rhee, Adv. Synth. Catal. 354 (2012) 1257-1263.

[91] E. Hariprasad, T.P. Radhakrishnan, ACS Catal. 2 (2012) 1179-1186.

[92] Y. Monguchi, T. Ichikawa, M. Netsu, T. Hattori, T. Mizusaki, Y. Sawama, H. Sajiki, Synlett 26 (2015) 2014-2018.

[93] B. Van-Vaerenbergh, J. Lauwaert, W. Bert, J.W. Thybaut, J. De Clercq, P. Vermeir, ChemCatChem 9 (2017) 451-457.

[94] J.A. Molina de la Torre, A.C. Albéniz, ChemCatChem 8 (2016) 2241-2248.

[95] H. Min, H. Miyamura, S. Kobayashi, Chem. Lett. 45 (2016) 837-839.

[96] C. Deraedt, L. Salmon, D. Astruc, Adv. Synth. Catal. 356 (2014) 2525-2538.

[97] Minireview: M. Meilikhov, K. Yusenko, D. Esken, S. Turner, G.V. Tendeloo, R.A. Fischer, Eur. J. Inorg. Chem. (2010) 3701-3714.

[98] Y. Huang, Z. Zheng, T. Liu, J. Lü, Z. Lin, H. Li, R. Cao, Catal. Commun. 14 (2011) 27-31.

[99] X. Liu, D. Astruc, Adv. Synth. Catal. 360 (2018) 3426-3459.

[100] (a) T. Maegawa, Y. Kitamura, S. Sako, T. Udzu, A. Sakurai, A. Tanaka, Y. Kobayashi, K. Endo, U. Bora, T. Kurita, A. Kozaki, Y. Monguchi, H. Sajiki, Chem. Eur. J. 13 (2007) 59375943; (b) S.S. Soomro, C. Röhlich, K. Köhler, Adv. Synth. Catal. 353 (2011) 767-775; (c) C.R. LeBlond, A.T. Andrews, Y. Sun, J.R. Sowa, Org. Lett. 3 (2001) 1555-1557.

[101] H.R. Choi, H. Woo, S. Jang, J.Y. Cheon, C. Kim, J. Park, K.H. Park, S.H. Joo, ChemCatChem 4 (2012) 1587-1594.

[102] W. Dong, L. Zhang, C. Wang, C. Feng, N. Shang, S. Gao, C. Wang, RSC Adv. 6 (2016) 37118-37123.

[103] A. Ohtaka, J.M. Sansano, C. Nájera, I. Miguel-García, Á. Berenguer-Murcia, D. CazorlaAmorós, ChemCatChem 7 (2015) 1841-1847.

[104] S.-i. Yamamoto, H. Kinoshita, H. Hashimoto, Y. Nishina, Nanoscale 6 (2014) 6501-6505.

[105] C.B. Putta, S. Ghosh, Adv. Synth. Catal. 353 (2011) 1889-1896.

[106] D. Dey, T. Bhattacharya, B. Majumdar, S. Mandani, B. Sharma, T.K. Sarma, Dalton Trans. 42 (2013) 13821-13825.

[107] S.S. Shendage, U.B. Patil, J.M. Nagarkar, Tetrahedron Lett. 54 (2013) 3457-3461.

[108] L. Duan, R. Fu, Z. Xiao, Q. Zhao, J.-Q. Wang, S. Chen, Y. Wan, ACS Catal. 5 (2015) 575586.

[109] K. Okumura, T. Tomiyama, S. Okuda, H. Yoshida, M. Niwa, J. Catal. 273 (2010) 156-166.

[110] F. Durap, M. Rakap, M. Aydemir, S. Özkar, Appl. Catal. A: Gen. 382 (2010) 339-344.

[111] S. Singha, M. Sahoo, K.M. Parida, Dalton Trans. 40 (2011) 7130-7132.

[112] H. Veisi, A. Amini Manesh, N. Eivazi, A.R. Faraji, RSC Adv. 5 (2015) 20098-20107.

[113] (a) V. Polshettiwar, R. Luque, A, Fihri, H. Zhu, M. Bouhrara, J.M. Basset, Chem. Rev. 111 (2011) 3036-3075; (b) D. Wang, D. Astruc, Chem. Rev. 114 (2014) 6949-6985; (c) R.B.N. Baig, S. Verma, M. N. Nadagouda, R.S. Varma, Aldrichimica Acta 49 (2016) 35-41.

[114] Q. Du, W. Zhang, H. Ma, J. Zheng, B. Zhou, Y. Li, Tetrahedron 68 (2012) 3577-3584.

[115] (a) Y. Zhao, R. Tang, R. Huang, Catal. Lett. 145 (2015) 1961-1971; (b) Y. Yang, R. Tang, Chem. Lett. 47 (2018) 544-547. 
[116] (a) N.A. Bumagin, V.V. Bykov, I.P. Beletskaya, Bull. Acad. Sci. USSR, Div. Chem. Sci. 38 (1989) 2206-2206; (b) N.A. Bumagin, P.G. More, I.P. Beletskaya, J. Organomet. Chem. 371 (1989) 397-401.

[117] A.J.J. Lennox, G.C. Lloyd-Jones, Chem. Soc. Rev. 43 (2014) 412-443.

[118] (a) K. Tamao, K. Sumitani, M. Kumada, J. Am. Chem. Soc. 94 (1972) 4374-4376; (b) R.J.P. Corriu, J.P. Masse, J. Chem. Soc., Chem. Commun. (1972) 144a.

[119] F.-S. Han, Chem. Soc. Rev. 42 (2013) 5270-5298.

[120] V. Ritleng, A.M. Oertel, M.J. Chetcuti, Dalton Trans. 39 (2010) 8153-8160.

[121] R.S. Sawatzky, M. Stradiotto, Synlett 29 (2018) 799-804.

[122] J. Zhou, J.H.J. Berthel, M.W. Kuntze-Fechner, A. Friedrich, T.B. Marder, U. Radius, J. Org. Chem. 81 (2016) 5789-5794.

[123] L. Martín, E. Molins, A. Vallribera, Tetrahedron 68 (2012) 6517-6520.

[124] T. Hatakeyama, T. Hashimoto, Y. Kondo, Y. Fujiwara, H. Seike, H. Takaya, Y. Tamada, T. Ono, M. Nakamura, J. Am. Chem. Soc. 132 (2010) 10674-10676.

[125] T. Hatakeyama, T. Hashimoto, K.K.A.D.S. Kathriarachchi, T. Zenmyo, H. Seike, M. Nakamura, Angew. Chem. Int. Ed. 51 (2012) 8834-8837.

[126] R.B. Bedford, P.B. Brenner, E. Carter, T.W. Carvell, P.M. Cogswell, T. Gallagher, J.N. Harvey, D.M. Murphy, E.C. Neeve, J. Nunn, D.R. Pye, Chem. Eur. J. 20 (2014) 7935-7938.

[127] M.B. Thathagar, J. Beckers, G. Rothenberg, J. Am. Chem. Soc. 124 (2002) 11858-11859.

[128] S.K. Gurung, S. Thapa, A. Kafle, D.A. Dickie, R. Giri, Org. Lett. 16 (2014) 1264-1267.

[129] S. Asghar, S.B. Tailor, D. Elorriaga, R.B. Bedford, Angew. Chem. Int. Ed. 56 (2017) 1636716370.

[130] J. Han, Y. Liu, R. Guo, J. Am. Chem. Soc. 131 (2009) 2060-2061.

[131] N. Zhang, H. Qiu, Y. Liu, W. Wang, Y. Li, X. Wang, J. Gao, J. Mater. Chem. 21 (2011) 11080-11083.

[132] B. Zeynizadeh, F. Sepehraddin, J. Organomet. Chem. 856 (2018) 70-77.

[133] J.T. Joseph, A.M. Sajith, R.C. Ningegowda, A. Nagaraj, K.S. Rangappa, S. Shashikanth, Tetrahedron Lett. 56 (2015) 5106-5111.

[134] J.F. Cívicos, D.A. Alonso, C. Nájera, Adv. Synth. Catal. 354 (2012) 2771-2776.

[135] O. El Bakouri, M. Fernández, S. Brun, A. Pla-Quintana, A. Roglans, Tetrahedron 69 (2013) 9761-9765.

[136] N. Oger, F.-X. Felpin, ChemCatChem 8 (2016) 1998-2009.

[137] M.E. Trusova, M. Rodriguez-Zubiri, K.V. Kutonova, N. Jung, S. Brase, F.-X. Felpin, P.S. Postnikov, Org. Chem. Front. 5 (2018) 41-45.

[138] S. Si, C. Wang, N. Zhang, G. Zou, J. Org. Chem. 81 (2016) 4364-4370.

[139] T. Ben Halima, W. Zhang, I. Yalaoui, X. Hong, Y.-F. Yang, K.N. Houk, S.G. Newman, J. Am. Chem. Soc. 139 (2017) 1311-1318.

[140] (a) N. Marion, O. Navarro, J. Mei, E.D. Stevens, N.M. Scott, S.P. Nolan, J. Am. Chem. Soc. 128 (2006) 4101-4111; (b) F. Izquierdo, C. Zinser, Y. Minenkov, D.B. Cordes, A.M.Z. Slawin, L. Cavallo, F. Nahra, C.S.J. Cazin, S.P. Nolan, ChemCatchem 10 (2018) 601-611.

[141] A.H. Dardir, P.R. Melvin, R.M. Davis, N. Hazari, M.M. Beromi, J. Org. Chem. 83 (2018) 469-477.

[142] (a) C.W. Liu, Y.M. Liu, R.Z. Liu, R. Lalancette, R. Szostak, M. Szostak, Org. Lett. 19 (2017) 1434-1437; (b) P. Lei, G. Meng, Y. Ling, J. An, S.P. Nolan, M. Szostak, Org. Lett. 19 (2017) 6510-6513; (c) P. Lei, G.R. Meng, Y. Ling, J. An, M. Szostak, J. Org. Chem. 82 (2017) 6638-6646.

[143] (a) Perspective: J.E. Dander, N.K. Garg, ACS Catal. ACSCatal. 7 (2017) 1413-1423; (b) N.A. Weires, E.L. Baker, N.K. Garg, Nat. Chem. 8 (2015) 75-79; (c) T.B. Boit, N.A. Weires, J. Kim, N.K. Garg, ACS Catal. 8 (2018) 1003-1008.

[144] L. Liu, P. Chen, Y. Sun, Y. Wu, S. Chen, J. Zhu, Y. Zhao, J. Org. Chem. 81 (2016) 1168611696. 
[145] M. Nambo, E.C. Keske, J.P.G. Rygus, J.C.H. Yim, C.M. Crudden, ACS Catal. 7 (2017) $1108-1112$.

[146] G. Wang, M. Meng, L. Deng, K. Cheng, C. Qi, Appl. Organomet. Chem. 32 (2018) e4203.

[147] M.R. Yadav, M. Nagaoka, M. Kashihara, R.-L. Zhong, T. Miyazaki, S. Sakaki, Y. Nakao, J. Am. Chem. Soc. 139 (2017) 9423-9426.

[148] X. Zhang, A. McNally, Angew. Chem. Int. Ed. 56 (2017) 9833-9836.

[149] L. Vaccaro (Ed.), Sustainable Flow Chemistry. Methods and Applications, Wiley-VCH, Weinheim, 2017.

[150] C. Len, in: R. Luque, F.L.-Y. Lam (Eds.), Sustainable Catalysis. Energy-Efficient Reactions and Applications, Wiley-VCH, Weinheim, 2018, Chapter 7.

[151] W. Su, L. Pellegatti, M.A. Oberli, S.L. Buchwald, Angew. Chem. Int. Ed. 50 (2011) 1066510669.

[152] J. de M. Muñoz, M. Alcázar, A. de la Hoz, A. Díaz-Ortiz, Adv. Synth. Catal. 354 (2012) 3456-3460.

[153] Y. Suzuki, P. Laurino, D.T. McQuade, P.H. Seeberger, Helv. Chim. Acta 95 (2012) 25782588.

[154] A.K. Shil, N.R. Guha, D. Sharma, P. Das, RSC Adv. 3 (2013) 13671-13676.

[155] R. Ricciardi, J. Huskens, M. Holtkamp, U. Karst, W. Verboom, ChemCatChem 7 (2015) 936942.

[156] V. Pascanu, P.R. Hansen, A. Bermejo Gómez, C. Ayats, A.E. Platero-Prats, M.J. Johansson, M.À. Pericàs, B. Martín-Matute, ChemSusChem 8 (2015) 123-130.

[157] G.-W. Wang, Chem. Soc. Rev. 42 (2013) 7668-7700.

[158] Z.-J. Jiang, Z.-H. Li, J.-B. Yu, W.-K. Su, J. Org. Chem. 81 (2016) 10049-10055.

[159] D. Imao, B.W. Glasspoole, V.S. Laberge, C.M. Crudden, J. Am. Chem. Soc. 131 (2009) 5024-5025.

[160] L. Chausset-Boissarie, K. Ghozati, E. LaBine, J.L.Y. Chen, V.K. Aggarwal, C.M. Crudden, Chem. Eur. J., 19 (2013) 17698-17701.

[161] T. Awano, T. Ohmura, M. Suginome, J. Am. Chem. Soc. 133 (2011) 20738-20741.

[162] D.L. Sandrock, L. Jean-Gérard, C.-y. Chen, S.D. Dreher, G.A. Molander, J. Am. Chem. Soc. 132 (2010) 17108-17110.

[163] A. He, J.R. Falck, J. Am. Chem. Soc. 132 (2010) 2524-2525.

[164] M.R. Harris, L.E. Hanna, M.A. Greene, C.E. Moore, E.R. Jarvo, J. Am. Chem. Soc. 135 (2013) 3303-3306.

[165] H. Xie, Y. Li, L. Wang, J. Kuang, Q. Lei, W. Fang, Dalton Trans. 46 (2017) 13010-13019.

[166] N. Debono, A. Labande, E. Manoury, J.-C. Daran, R. Poli, Organometallics 29 (2010) 18791882.

[167] P. Schäfer, T. Palacin, M. Sidera, S.P. Fletcher, Nat. Commun. 8 (2017)15762.

[168] A.P. Taylor, R.P. Robinson, Y.M. Fobian, D.C. Blakemore, L.H. Jones, O. Fadeyi, Org. Biomol. Chem. 14 (2016) 6611-6637.

[169] C. Thomas, O. Kataeva, A.W. Schmidt, H.J. Knölker, Org. Biomol. Chem. 12 (2014) 872875.

[170] L.W.K. Moodie, S. Chammaa, T. Kindahl, C. Hedberg, Org. Lett. 19 (2017) 2797-2800.

[171] L. Chen L, P. Ren, B.P. Carrow, J. Am. Chem. Soc. 138 (2016) 6392-6395.

[172] M.S.A. Elsayed, S. Chang, M. Cushman, Org. Biomol. Chem. 16 (2018) 108-118.

[173] (a) The acceleration of the reaction by the presence of anions that coordinate to the metal center ("ate" effect) was first reported by Tchoubar et al.: A. Loupy, B, Tchoubar, Salt Effects in Organic and Organometallic Chemistry, VCH, Weinheim, Germany, 1992, pp. 267-272; (b) N. Miyaura, A. Suzuki, Chem. Rev. 95 (1995) 2457-2483; (c) G.B. Smith, G.C. Dezeny, D.L. Hughes, A.O. King, T.R. Verhoeven, J. Org. Chem. 59 (1994) 8151-8156; (d) C.M. Nunes, A.L. Monteiro, J. Braz. Chem. Soc. 18 (2007) 1443-1447; (e) N. Miyaura, J. Organomet. Chem. 653 (2002) 54-57; (f) A.A.C. Braga, N.H. Morgon, G. Ujaque, F. Maseras, J. Am. Chem. Soc. 127 (2005) 9298-9307; (g) A.A.C. Braga, N.H. Morgon, G. 
Ujaque, A. Lledós, F. Maseras, J. Organomet. Chem. 691 (2006) 4459-4466; (h) A.A.C. Braga, G. Ujaque, F. Maseras, Organometallics 25 (2006) 3647-3658; (i) C. Sköld, J. Kleimark, A. Trejos, L.R. Odell, S.O. Nilsson Lill, P.-O. Norrby, M. Larhed, Chem. Eur. J. 18 (2012) 4714-4722.

[174] B. Basu, K. Biswas, S. Kundu, S. Ghosh, Green Chem. 12 (2010) 1734-1738.

[175] B.P. Carrow, J.F. Hartwig, J. Am. Chem. Soc. 133 (2011) 2116-2119.

[176] C.F.R.A.C. Lima, A.S.M.C. Rodrigues, V.L.M. Silva, A.M.S. Silva, L.M.N.B.F. Santos, ChemCatChem 6 (2014) 1291-1302.

[177] M.A. Ortuño, A. Lledós, F. Maseras, G. Ujaque, ChemCatChem 6 (2014) 3132-3138.

[178] (a) A.F. Schmidt, A.A. Kurokhtina, E.V. Larina, Russ. J. Gen. Chem. 81 (2011) 1573-1574;

(b) A.F. Shmidt, A.A. Kurokhtina, Russ. J. Appl. Chem. 83 (2010) 1248-1253.

[179] (a) C. Amatore, A. Jutand, G. Le Duc, Chem. Eur. J. 17 (2011) 2492-2503; (b) C. Amatore, A. Jutand, G. Le Duc, Chem. Eur. J. 18 (2012) 6616-6625; (c) C. Amatore, A. Jutand, G. Le Duc, Angew. Chem. Int. Ed. 51 (2012) 1379-1382.

[180] L. Chen, D.R. Sanchez, B. Zhang, B.P. Carrow, J. Am. Chem. Soc. 139 (2017) 12418-12421. [181] A.J.J. Lennox, G.C. Lloyd-Jones, Angew. Chem. Int. Ed. 52 (2013) 7362-7370.

[182] (a) A.A. Thomas, S.E. Denmark, Science 352 (2016) 329-332; (b) A.A. Thomas, H. Wang, A.F. Zahrt, S.E. Denmark, J. Am. Chem. Soc. 139 (2017) 3805-3821; (c) A.A. Thomas, A.F. Zahrt, C.P. Delaney, S.E. Denmark, J. Am. Chem. Soc. 140 (2018) 4401-4416.

[183] O.A. Reutov, I.P. Beletskaya, Reaction Mechanism of Organometallic Compounds, NorthHolland Publishing Company, Amsterdam, 1968, p. 469.

[184] K. Matos, J.A. Soderquist, J. Org. Chem. 63 (1998) 461-470.

[185] S. Ostrowska, J. Lorkowski, M. Kubicki, C. Pietraszuk, ChemCatChem 8 (2016) 3580-3583.

[186] P.J. Ellis, I.J.S. Fairlamb, S.F.J. Hackett, K. Wilson, A.F. Lee, Angew. Chem. Int. Ed. 49 (2010), 1820-1824. 